February 2001 • NREL/TP-500-28607

\title{
The History and State of the Art of Variable-Speed Wind Turbine Technology
}

P.W. Carlin

A.S. Laxson

E.B. Muljadi

\section{National Renewable Energy Laboratory}

1617 Cole Boulevard

Golden, Colorado 80401-3393

NREL is a U.S. Department of Energy Laboratory

Operated by Midwest Research Institute $\bullet$ Battelle $\bullet$ Bechtel

Contract No. DE-AC36-99-G010337 
February 2001 - NREL/TP-500-28607

\section{The History and State of the Art of Variable-Speed Wind Turbine Technology}

P.W. Carlin

A.S. Laxson

E.B. Muljadi

Prepared under Task No. WER13010

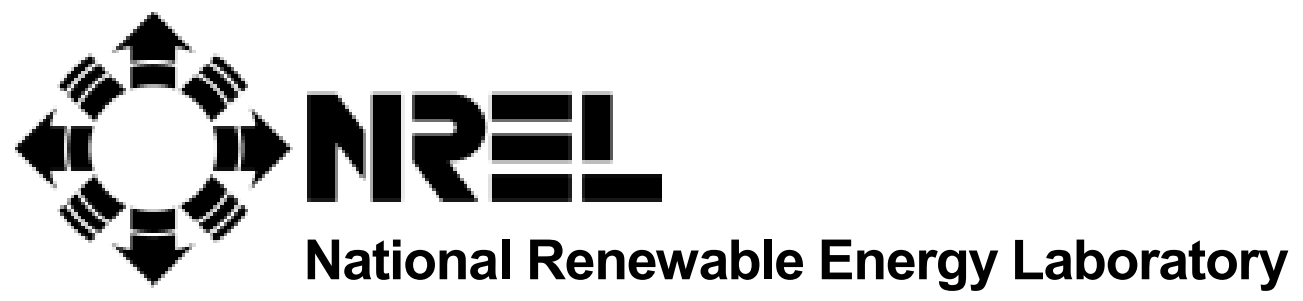

1617 Cole Boulevard

Golden, Colorado 80401-3393

NREL is a U.S. Department of Energy Laboratory

Operated by Midwest Research Institute • Battelle • Bechtel

Contract No. DE-AC36-99-G010337 


\section{NOTICE}

This report was prepared as an account of work sponsored by an agency of the United States government. Neither the United States government nor any agency thereof, nor any of their employees, makes any warranty, express or implied, or assumes any legal liability or responsibility for the accuracy, completeness, or usefulness of any information, apparatus, product, or process disclosed, or represents that its use would not infringe privately owned rights. Reference herein to any specific commercial product, process, or service by trade name, trademark, manufacturer, or otherwise does not necessarily constitute or imply its endorsement, recommendation, or favoring by the United States government or any agency thereof. The views and opinions of authors expressed herein do not necessarily state or reflect those of the United States government or any agency thereof.

Available electronically at http://www.doe.gov/bridge

Available for a processing fee to U.S. Department of Energy and its contractors, in paper, from:

U.S. Department of Energy

Office of Scientific and Technical Information

P.O. Box 62

Oak Ridge, TN 37831-0062

phone: 865.576 .8401

fax: 865.576.5728

email: reports@adonis.osti.gov

Available for sale to the public, in paper, from:

U.S. Department of Commerce

National Technical Information Service

5285 Port Royal Road

Springfield, VA 22161

phone: 800.553.6847

fax: 703.605.6900

email: orders@ntis.fedworld.gov

online ordering: http://www.ntis.gov/ordering.htm

Printed on paper containing at least $50 \%$ wastepaper, including $20 \%$ postconsumer waste 


\section{Table of Contents}

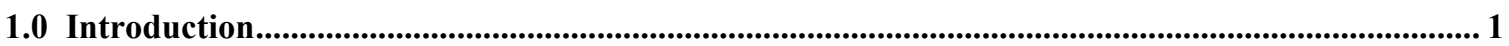

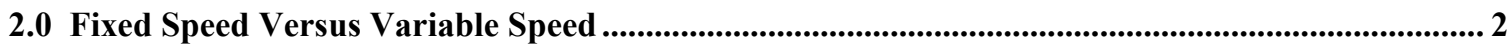

3.0 Methods of Implementing Variable Speed.......................................................................................... 8

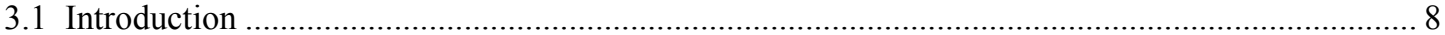

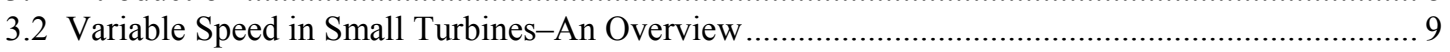

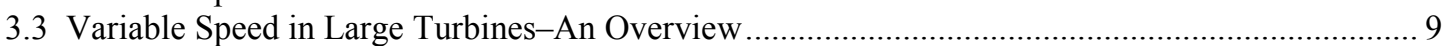

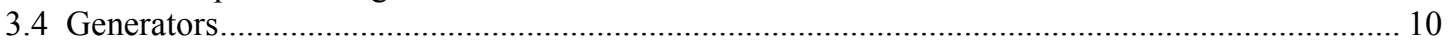

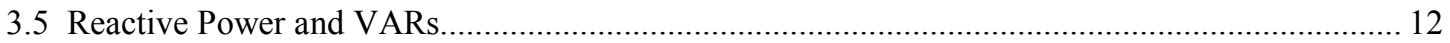

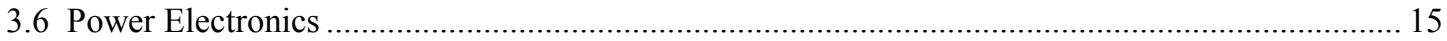

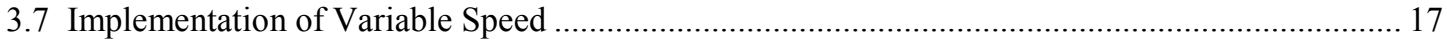

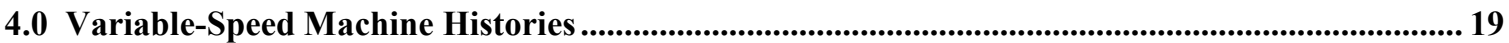

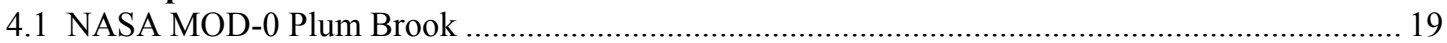

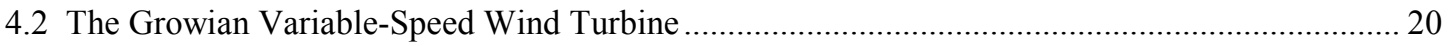

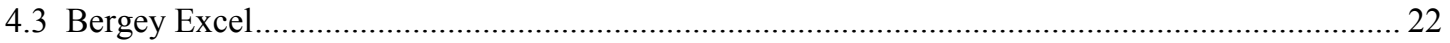

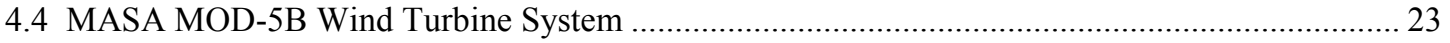

4.5 DOE/Sandia National Laboratories/U.S. Department of Agriculture

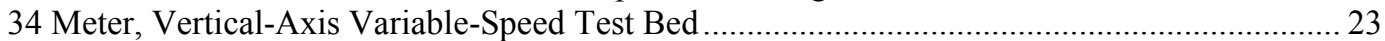

4.6 The Enercon E-40 Variable-Speed Wind Turbine .................................................................... 24

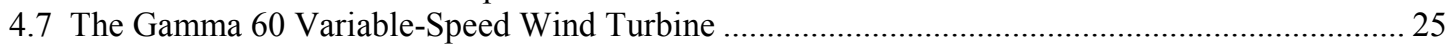

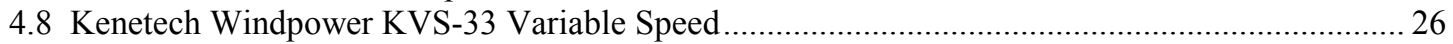

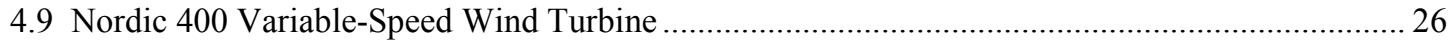

4.10 Advanced Wind Turbines AWT-26 Variable Speed with Doubly Fed Generator......................... 27

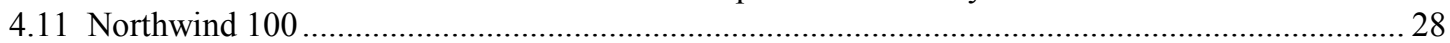

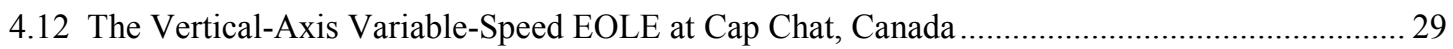

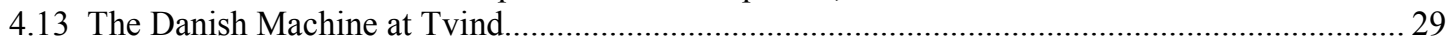

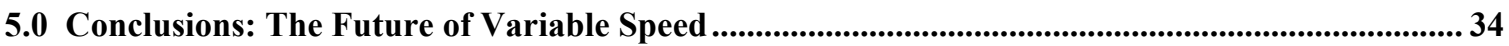

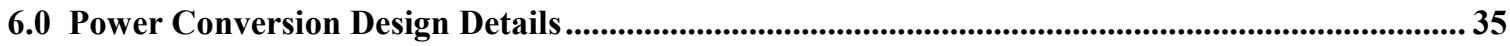

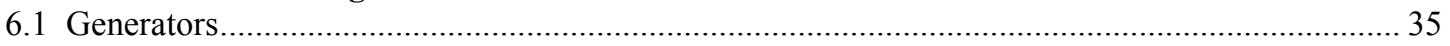

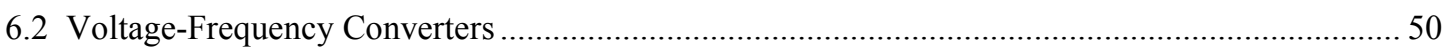

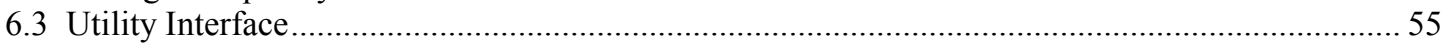

7.0 A Look at Future Development .........................................................................................................56

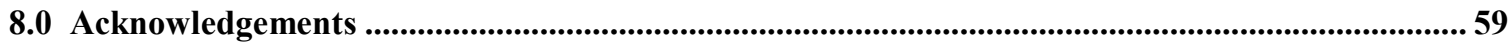

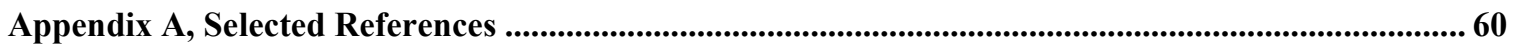




\subsection{INTRODUCTION}

One of the earliest non-animal sources of power used by man was the wind turbine. Wind turbines have been in documented use for more than 1,000 years. The earliest wind turbine designs were extremely simple; turbines were allowed to rotate at a rate proportional to the velocity of the wind. They were used to pump water, grind grain, cut lumber, and perform a myriad of other tasks. For these purposes, varying speed seldom impacted the effectiveness of the windmill enough to justify the complications of closely controlling rotational speed. Allowing the machines to run at variable speed was in fact highly advantageous as it greatly increased the total energy that could be extracted from the wind.

The earliest horizontal-axis windmill to use the principles of aerodynamic lift instead of drag may have been introduced in the twelfth century. These horizontal-axis sail turbines were allowed to run at varying speeds, limited only by braking or furling to control their speed during storms. These designs operated throughout Europe and in the Americas into the present century. In the 700 or so years since the first sail- wing turbine, designers discovered many of the key principles of aerodynamics without understanding the physics behind them. It was not until the nineteenth century that these principles began to be clearly understood.

In the early nineteenth century the classic American water pumper was introduced. The need for this machine was driven by the phenomenal growth of agriculture in the American Midwest, beginning with the opening of the Northwestern prairie states in the early 1800s. More than a million of these machines dotted the Midwest and West starting in the early 1850s. Even now these multibladed farm windmills can be seen throughout the western United States and Canada, where the energy and storage requirements for providing drinking water for cattle are well matched to the wind water pumper's power, the storage capacity of the associated stock tank, and the wind statistics of the Great Plains. These machines use the most rudimentary airfoils (often flat plates or slats of wood) and are allowed to rotate proportionally to wind velocity. For the purposes of direct mechanical water pumping, this variable-speed operation works effectively. Even though the American water-pumping design gives up something by its dependence on a flat-plate airfoil, its simplicity, ease of construction, and reliability still make it ideal for its intended purpose.

The early twentieth century saw the start of the electric era. The rapid advances in motor, generator, lighting, and appliance designs by Edison, Steinmetz, Tesla and others offered the promise of an electric- powered utopia. The homes and farms of America were not immune to this desire, and for remote locations wind turbines offered great promise. As early as 1888 the Brush wind turbine in Cleveland, Ohio, had produced 12 kilowatts of direct current (DC) power for battery charging at variable speed. DC and variable-speed wind turbines seemed only natural. Many early electric motors required direct current and the varying voltage due to turbulent winds was held relatively constant by the associated battery bank. At remote farms, where power lines might never reach, a DC wind turbine could charge batteries, and operate equipment that could never cope with varying alternating current $(\mathrm{AC})$ frequencies caused by constantly changing wind speeds.

In 1925 Marcelleus and Joseph Jacobs began work on the first truly high-speed, small-size, affordable batterycharging turbine. Thousands of their 32 volt and 110 volt DC machines were manufactured starting in the late 1920 's and running into the 1950's. This machine was followed by others such as the Windcharger. They could be set up easily and required little if any maintenance. All of these machines were allowed to run at variable speed. Even after AC utility power had begun to spread through cities and towns, Sears Roebuck and others manufactured and distributed a wide range of products designed to run on DC to satisfy the needs of remote farms and ranches using batteries and variable-speed DC turbines.

In 1937 the creation of the Rural Electric Associations started the demise of these stand-alone variable-speed DC machines. As AC power lines spread throughout rural America, the need for such machines began to fade. America was becoming connected, and in the future would depend upon large central power plants to produce electricity for all. Long transmission lines required much higher voltage for efficient distribution. Electric transformers and their required alternating current were the obvious technology to employ. It was then necessary to standardize on constant voltage levels and a constant frequency. In North America, this fixed frequency became 60 hertz ( $\mathrm{Hz}$ or cycles per second). The simple variable-speed wind turbines had no 
economical way of either interconnecting to these grids or supplying power for the many new appliances that began to fill farm households. The prudent farmer or rancher might keep his old machines running for emergencies; however, his wife began depending on cheap, dependable alternating current to wash the clothes and run the phonograph. The return to power independence for the American farmer and rancher would have to wait for a new generation of technologies.

Despite the apparent difficulties of connecting a wind turbine to the AC electrical grid, as early as 1939 in the United States, such a step had been explored. Even earlier examples of large turbines used to produce electricity tied to an established AC electrical grid may be cited; however, for depth of engineering and breadth of vision, few early pioneers have surpassed Palmer Putnam's Grandpa's knob machine. This machine was incredibly advanced for its day, with full-span pitch control, active-yaw drive, two-bladed flapping rotor, and 1.25-megawatt (MW) rating. However, the Smith-Putnam turbine rotor avoided the problem of variable speed and ran at a fixed rpm locked to a synchronous generator directly tied to the electrical grid. However, by fixing the rotational rate of the turbine to that of the electric grid, the turbine lost a great deal of wind potential. Allowing the machine to rotate at a varying rate would optimize the aerodynamics of the rotor by allowing its speed to be proportional to wind speed. In this operating mode, as we will see later, the machine can capture the maximum fraction of available wind energy. Not only would it gain more aerodynamic efficiency in high winds, but it would also be able to run at lower speeds and gather more energy than a fixed-speed machine.

The dream of a variable-speed wind turbine tied to the AC electrical grid began to become a viable reality in the early to mid-1970's. Machines went on-line in the United States and Europe, using several different methods for transforming variable-voltage, variable-frequency outputs to reliable constant-voltage, constantfrequency outputs. In addition to large grid-connected machines, small stand-alone machines were developed that incorporated these new technologies and would allow the farmer or homeowner to produce his own power, and to someday allow him to sell his excess power back to the utility grid. For example, the 8-kw Windworks machine of the early 1970's used a diode bridge to rectify the variable- frequency output of the permanent magnet generator. Silicon controlled rectifiers (SCRs) were used in an inverter module to convert the resulting rectified DC output to produce AC synchronized to the grid. Technologies like these are still in use, as described below, and are being further developed. New technologies are under constant development.

Significant issues must be addressed, however, in order for variable-speed technology to become a dominant feature of future turbine designs. Designs must be optimized to lower cost of energy, which is a primary factor in the acceptance of wind technology into a utility's generation mix. This cost of energy will be greatly affected by the cost of potentially expensive power electronics, control systems, or unique generator designs. Although variable-speed operation can reduce the impact of transient wind gusts and subsequent component fatigue, this is still an unknown factor that must be more fully explored. Generating clean power to meet standards such as Institute of Electrical and Electronics Engineers (IEEE) 519 and International Electrotechnical Commission (IEC) 1000-3-2 will be a continuing challenge.

For many technology developers, however, variable-speed operations must become a key component of the wind generator of the future given the prospects of increased performance and decreasing costs.

The National Renewable Energy Laboratory's (NREL's) National Wind Technology Center (NWTC), directed by the Department of Energy (DOE) is pursuing several research projects in variable speed. In the near future the laboratory will be reevaluating its ongoing experiments and plans. The starting point for this reevaluation will be a sound understanding of the current state of the art in design and application of variable-speed technology. This report, which outlines current technologies and historical applications of variable-speed, will provide a baseline in deciding the course of research in the upcoming years.

\subsection{FIXED SPEED VERSUS VARIABLE SPEED}

The aerodynamic efficiency of a wind turbine depends on many elements of rotor design. Airfoil shape, chord length, blade length, blade twist, revolutions per minute (rpm), and angle of attack, are all elements that must be optimized for the expected wind conditions. The design of the airfoil and its angle of attack are critical to the power-producing capacity of the rotor. Each airfoil has an optimum angle of attack to produce an optimum liftto-drag ratio (the point at which the airfoil will have its optimum performance). 
For a better understanding of how all these factors affect turbine operating modes, we will next provide a brief wind energy tutorial.

Figure 2.0a shows the power (rate of flow of energy) in kilowatts $(\mathrm{kW})$ through an imaginary 26-meter $(\mathrm{m})$ diameter area normal to the flow of a smooth wind having the speed shown on the abscissa. Note for comparison with the following graph that the power increases without limit as the cube of the wind speed. Figure 2.0b shows the mechanical power (rate of flow of energy) in kilowatts flowing from the hub of a real wind turbine, whose rotor turning at constant speed sweeps the same area as that in Figure 2.0a. In comparing the two curves, note that harvested power at each wind speed is less than the total wind power available at that speed. The numerical value of the fraction of available power extracted is defined by wind engineers as the "power coefficient", or $\mathrm{C}_{\mathrm{p}}$, of that machine at that wind speed and rpm.

Although the output power in Figure 2.0b rises with increasing wind speed for a while, it starts to fall rapidly in spite of much more available wind power. This is because the rotor speed being held constant causes the angle of attack on the blades to increase as the wind increases. This means the airfoil will stall with increasing wind and consequently loose much of its lift. A component of that lift is the source of wind machine generator torque.

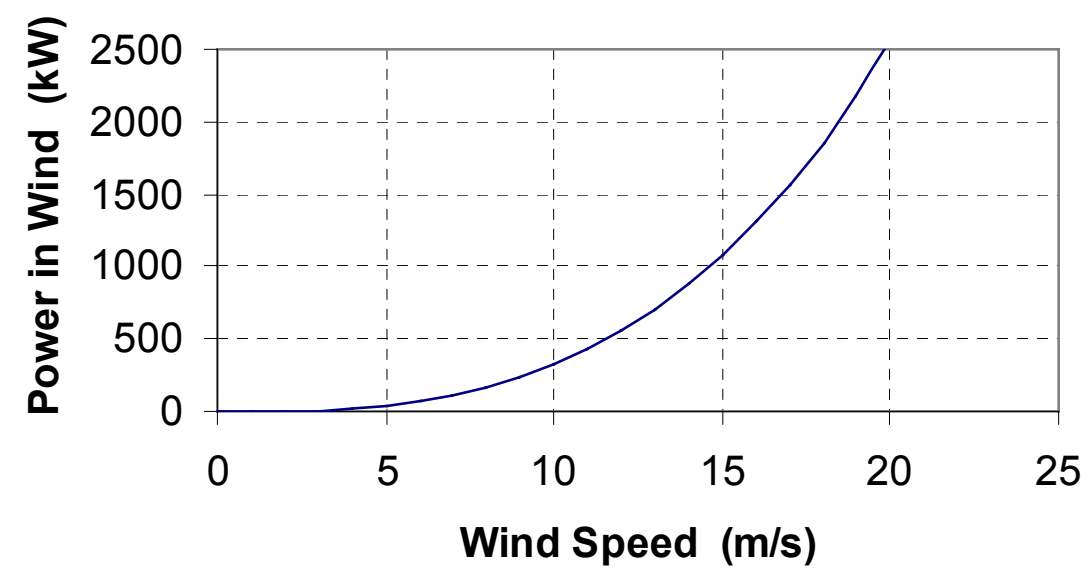

Figure 2.0a. Total power in the wind passing through a 26-meter diameter area

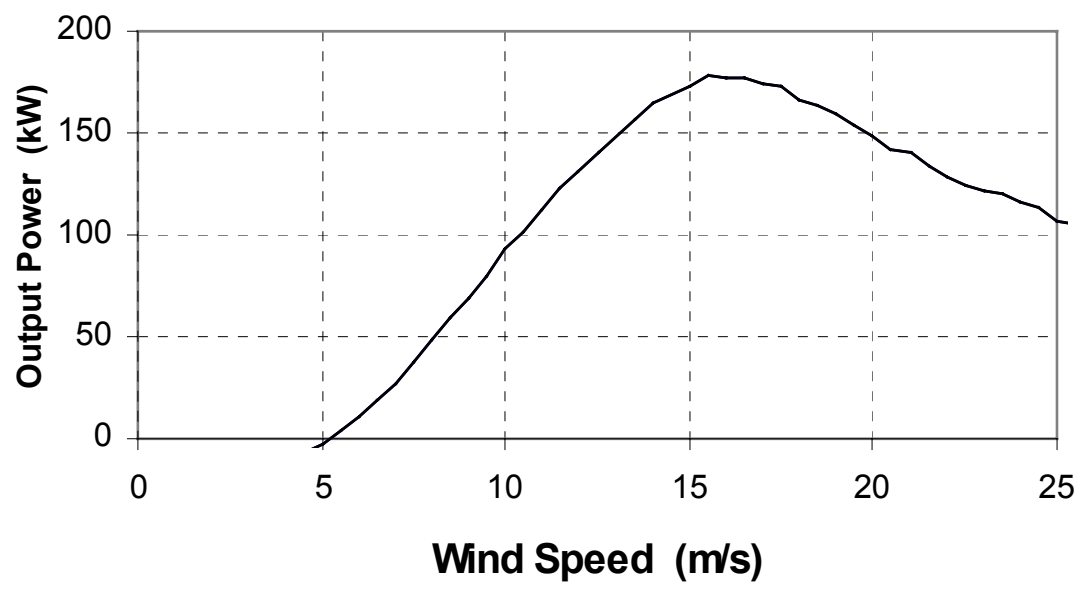

Figure 2.0b. Measured power curve for a 26-meter rotor at a constant $50 \mathrm{rpm}$ 
Because wind turbine power depends on both rotor speed and wind speed, harvested power can be represented on a three-dimensional surface. Figure 2.0c shows a characteristic surface of a smaller turbine, for which the increasing power at higher wind and rotor speeds has been truncated to $20 \mathrm{~kW}$ by a control system. At very high rotor speeds and low wind speeds, the power has turned negative. This means the turbine has turned into a very large electric fan, and must be supplied with power to remain in that region.

Although the isometric view of Figure 2.0c helps us to visualize the surface, a vertical projection or contour map of this surface can better illustrate certain features. A view directly down on the surface is shown in Figure $2.0 \mathrm{~d}$ for the lower wind speeds. Two important lines representing possible loci of wind turbine operation have been drawn on the surface. These lines are actually edge views of vertical planes intersecting the power surface of Figure 2.0c. The most important line is labeled $\lambda=7$. From analytic geometry we know that the ratio of $y$ to $\mathrm{x}$ coordinate for each point on this line is a constant. Then by knowing the turbine radius we can map the rotor speed into the linear speed of the tips of the rotor blades. For the case shown this linear speed is seven times faster than the wind speed for that point. We define the slope of this line as "tip-speed-ratio", or $\lambda$ (lambda.) This line passes into each next higher power contour at a rotor speed corresponding to the least wind that will support that level of power output-that is to say, at the point on the contour that bulges farthest to the left. Thus, it is obvious that to collect maximum instantaneous power at an existing wind speed, one should attempt to force the wind turbine to follow this operating locus. By imagining tip-speed ratio lines drawn with other slopes on either side of "7," one can see that, even if a turbine operates at variable speed along those lines, a given wind will produce less power from this machine than for the optimal ratio of 7 .

The other line, $\lambda=13$, divides the positive or power-producing region from the negative or power-consuming (fan) region. Thus, this line defines the "runaway speed" of a wind turbine, because it gives the unloaded rotor speed for each wind speed. The rotor tips will be traveling thirteen times faster than the wind speed.

Finally, this projection shows one way to compare performance of variable- and constant-speed operation. Suppose this wind turbine is operating at a constant speed of $40 \mathrm{rpm}$ and the wind speed is 3 meters per second $(\mathrm{m} / \mathrm{s})$. The contours indicate that the machine will be producing less than one kilowatt of power. If the wind suddenly increases to $6 \mathrm{~m} / \mathrm{s}$ but the machine is constrained to remain at $40 \mathrm{rpm}$, the operating point has only moved up one level of power. If, on the other hand, the machine had been allowed to increase speed and follow the $\lambda=7$ locus, the operating point will have moved upward three power contour levels for the same $6 \mathrm{~m} / \mathrm{s}$ wind. Although these graphics are for a particular machine, curves for other machines will show little difference in shape.

The traditional way to present the preceding information is with the "power coefficient versus tip-speed-Ratio," (Cp vs $\lambda$ ) curve, as seen in Figure 2.1. Ratios for best power coefficient for most wind turbines usually lie between 5 and 10 .

For fixed-rpm machines, there is only one wind velocity on the turbine's power curve (power versus wind speed) at which the tip-speed ratio is optimum because there is only one wind speed exactly one seventh (in this example) of the blade tip speed. Clearly, unless the wind regime at a particular site is highly peaked at exactly that wind velocity, the wind turbine will often be operating off of its optimum performance, and not extracting the maximum power from the wind. 


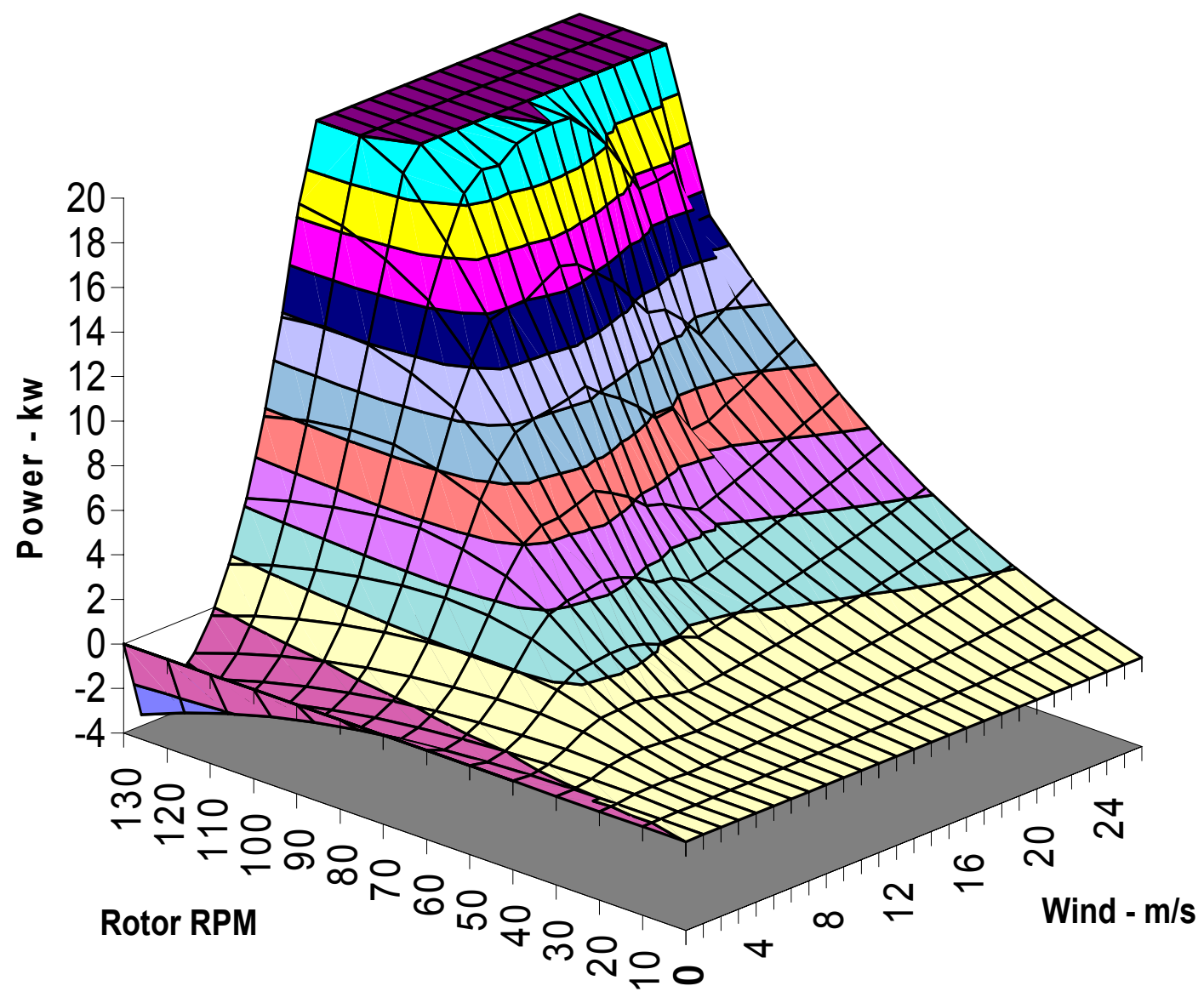

Figure 2.0c. Generic turbine power surface truncated to 20 kilowatts

A variable-speed design can remedy this situation. With a wind turbine that can produce power over a continuous range of rotor speeds, a machine can be made to operate constantly at or near its optimum tip-speed ratio. By doing this, the turbine, depending on turbine aerodynamics and wind regime, will on average collect up to $10 \%$ more annual energy, as illustrated previously. This can yield a significant revenue increase over a 20- or 30-year life of operation. However, there are a number of issues associated with variable-speed operation that must be dealt with before such a design attains its most desired form.

Although torque excursions due to wind gusts are usually more severe in fixed-speed turbines, forcing the rotor rpm of a variable-speed turbine to closely track the changes in wind velocity due to gusts and turbulence can also introduce rapid changes in rotor torque. These changes in load can ripple through the turbine drivetrain components and produce unwanted load spikes, which can cause immediate or long-term fatigue damage unless the turbine is properly designed to mitigate them. There is, however, a trade-off. By allowing variable speed operation, there may also be a moderation of turbine rotor fatigue loads, which are a major cause of machine failures. 


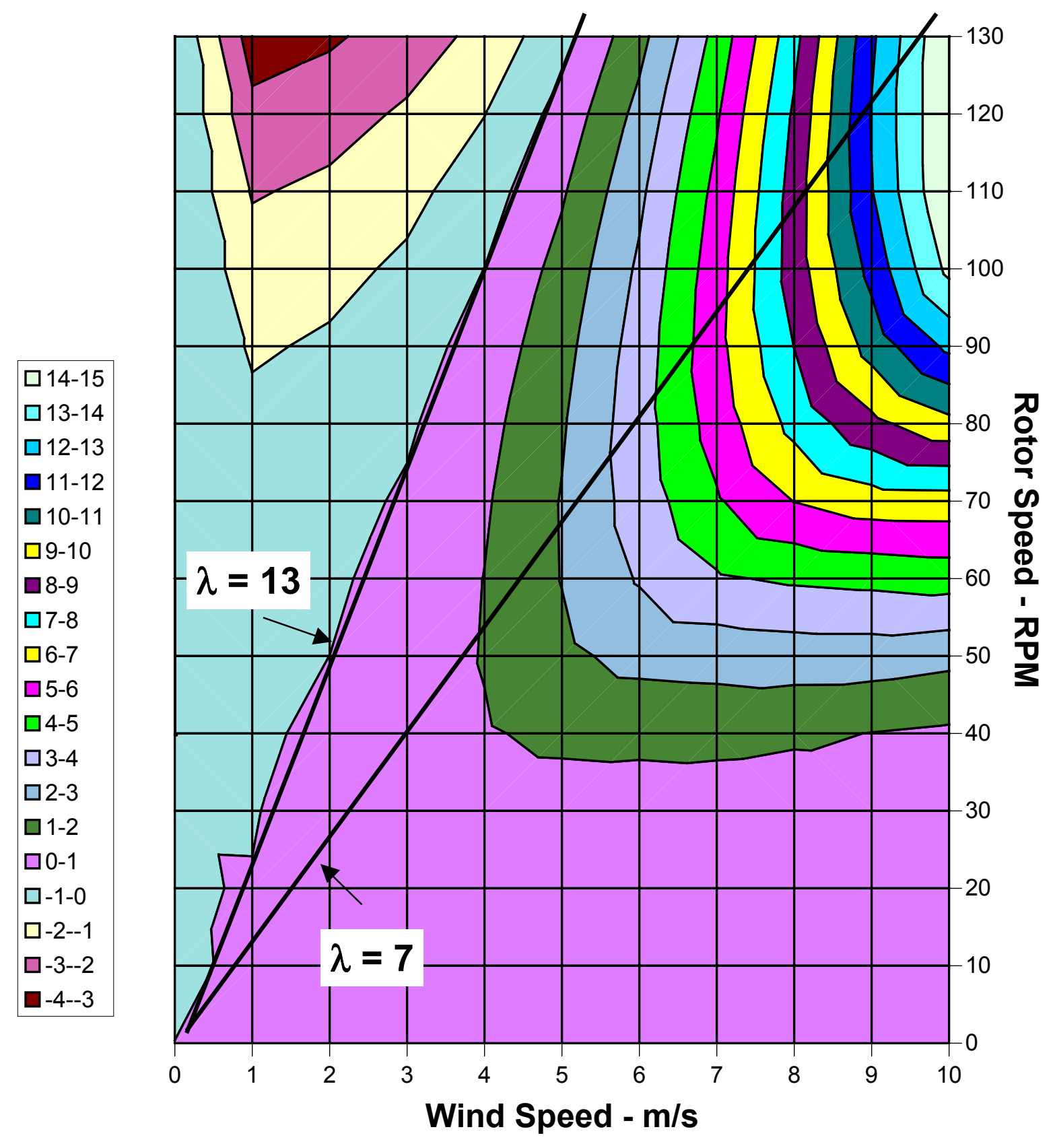

Figure 2.0d. Section of Power Surface Domain Vertical view 


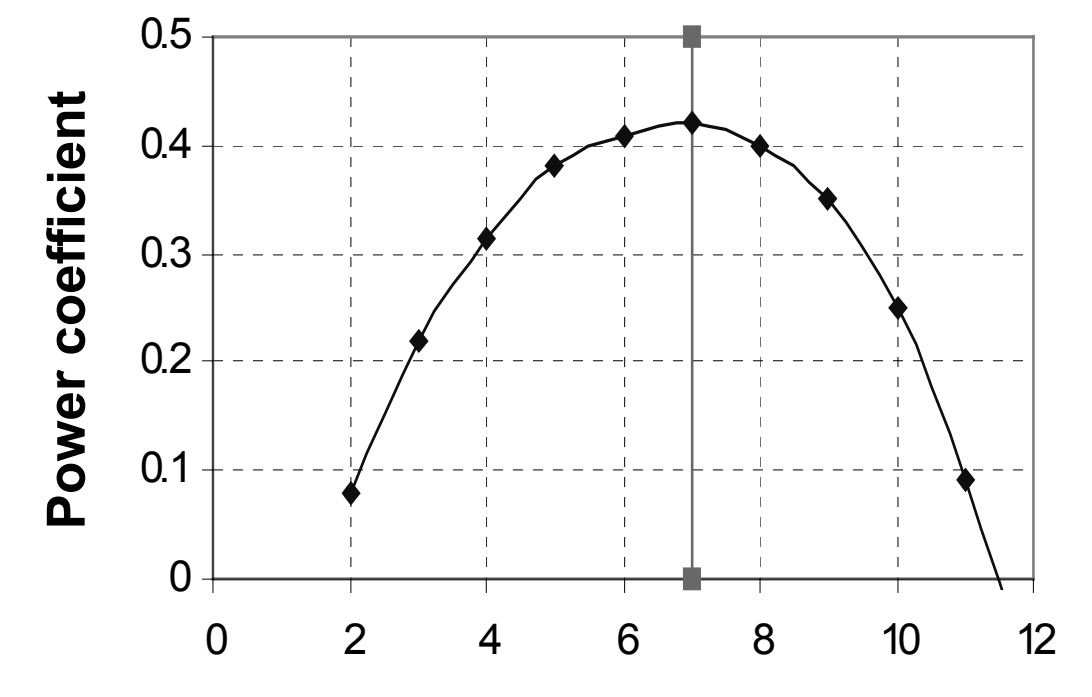

\section{Tip-speed ratio}

\section{Figure 2.1 A generic Cp vs $\lambda$ characteristic curve}

A variable-speed design normally incorporates advanced power electronics components that increase overall turbine cost. These components are required to change varying AC power to constant voltage and frequency (see sections 3.0 and 6.0 for more details). Electrical distribution grids, to which many wind turbines are connected, must maintain steady frequency and voltage levels to avoid damaging demand-side equipment of other users on the same utility, such as motors and sensitive electronics. Electrical harmonics are also a critical issue for any variable-speed design. Harmonics distort the normally smooth sinusoidal variation of utility voltage. Among many other drawbacks, harmonics increase losses and heating in motors, do not contribute to motor torque, cause unbalanced currents in power systems, as well as being harmful to many modern computer and communications components.

In addition to these well-known electrical harmonic problems, there is the special case of sudden jumps in voltage. Such voltage surges can usually be analyzed as a combination of many high-frequency harmonics. The past few years have shown a remarkable rise in insulation failures of motors and generators driven by adjustable-speed drives that employ power electronics. This phenomenon appears to be related to the sudden drive voltage changes that some power electronic circuits are capable of supplying to their associated motor or generator. Reports of transient voltage spikes between windings over one hundred times their expected value have been reported. The problem appears to grow worse as the distance between generator and power electronics increases. This problem is especially significant for wind energy because wind turbine generators (being in a nacelle) are usually remote from their driving electronics on the ground.

A key factor in dealing with the above two issues is the control methodology for the variable-speed turbine. A properly designed control scheme can smooth out the time-varying loads that are transmitted through the machine components by the use of full-span pitch control or the ability of advanced power electronics to smooth rotor loads by limiting torque excursions within the drive train. Optimum power electronic designs are still under study, as are new control methodologies.

But despite the issues and unknowns, the increased gain in energy capture by the application of variable-speed design, together with torque spike reduction, has made the pursuit of this technology a high priority for wind turbine designers for many years and continues to hold high promise for the future. 


\subsection{METHODS OF IMPLEMENTING VARIABLE SPEED}

The previous two sections gave a general introduction to the subject of variable-speed wind turbines. This section continues in the same vein but with concentration on the electrical aspect of the wind turbine system. The approach will be qualitative. The same material is presented again in section 6.0 from a detailed and more technical approach for those readers needing a quantitative point of view.

\subsection{Introduction}

There are many variable-speed architectures. The different combinations of generators, gearboxes, direct drives, and power electronics allow for a wide range of combinations, particularly when combined with the many available control scenarios. The use of variable speed in wind turbines is now centuries old. Only the methods of implementing variable speed in an electric generating environment are new. These changes are a function of new materials, new electrical components and manufacturing processes, new computer control tools, and improved understanding of the interaction of these many variables.

To understand the many elements of these technologies we must start with some basics. First, let's embed a coil of wire in the slots of a stator. The stator is the outer shell of the motor or generator that remains stationary during operation. We will assume three-phase operation, so there will actually be three independent sets of stator coils; one for each of the three phases of grid current. Then we attach another coil of wire with its ends connected together - or else a simple loop of some conducting material - to the spinning rotor. The rotor is the central spinning core of the motor or generator. When the electrical grid is connected to the stator coils, we will find an oscillating electric current surging back and forth through each stator coil at a rate of 60 times a second (in the United States.) The sequence of successive peaks of the three-phase stator currents causes a magnetic field to appear to travel around the stator air gap (the gap between the stator and the rotor). This rotating magnetic field in the stator induces a current in the rotor conductors, which creates a changing magnetic field in the rotor. The magnetic field in the rotor struggles to align itself with the rotating stator field. If there were no external forces acting on the rotor, the device would act as a motor and the moving magnetic field would accelerate the rotor to a speed nearly synchronized to that of the changing fields. In short, we have created a three-phase induction-type motor.

In a wind turbine, however, the generator rotor is attached to a set of blades. As the wind blows, an aerodynamic force produces a torque that is transmitted through the drivetrain to the generator. If the aerodynamic forces are negligible then the rotor will turn at below synchronous speed and will act as a motor, drawing power from the electrical grid to continue to turn. If the aerodynamic forces are great enough, they cause the drivetrain and generator to turn at an rpm above synchronous speed, and therefore produce a current flow and power from the turbine stator to the grid. This small departure of rotor speed from magnetic field speed in both motoring and generation is referred to as positive and negative "slip", respectively.

Slip $=\left(\mathrm{f}_{0}-\mathrm{f}_{\mathrm{r}}\right) / \mathrm{f}_{0}$

where:

$$
\begin{aligned}
& \mathrm{f}_{0}=\text { frequency of the electrical grid } \\
& \mathrm{f}_{\mathrm{r}}=\text { frequency of the rotor } \\
& (\text { at start-up slip }=1 \text {, at synchronous-speed slip }=0 \text { ) }
\end{aligned}
$$

If the aerodynamic forces are exactly balanced so that no torque is produced, then the generator will run at synchronous speed, neither drawing nor producing power. This is the condition of zero slip. Although in this case the stator currents, though circulating, are on average neither exporting nor importing energy (watts), and the generator is said to be consuming only "reactive volt amperes" or VARs (see section 3.5).

Suppose a wind turbine rotor turns at $60 \mathrm{rpm}$. Generators connected via gearbox are designed to run at high speed, normally in the range of 1200 to $3600 \mathrm{rpm}$. In the latter case, the gearbox would act as a speed increaser (60 to 1), converting the $60 \mathrm{rpm}$ of the turbine rotor to $3600 \mathrm{rpm}$. A two-pole generator (a north-south magnetic pole pair) will produce one alternating current cycle per revolution. A generator turning at $3600 \mathrm{rpm}$ will rotate 60 times in one second, thus generating 60 alternating current cycles per second or $60 \mathrm{~Hz}$ current, the frequency of U.S. electrical grids. It follows that machines rotating at $1800 \mathrm{rpm}$ require four poles to accomplish the same effect. 
If we let the machine run freely and not connected to other generators, its speed will vary according to the wind speed, the rotor will not turn at $60 \mathrm{rpm}$ as designed, and the electrical frequency will not be maintained at $60 \mathrm{~Hz}$. We will also have rapid surges and sags in voltage as the rotor speeds up and slows down. If connected to the electrical grid, these rapid changes in electrical characteristics will either cause the generator to be damaged or cause problems on the electrical grid. We must therefore either closely control the rotor power output or find a way to transform the varying voltage and frequency to make the generated power compatible with the electrical grid.

There is a range of methods for controlling aerodynamic forces on the turbine rotor and therefore limiting the peak power output of a turbine. The simplest is passive stall control in which the design of rotor aerodynamics causes the rotor to stall (loose power) when the wind velocities exceed a certain value. Other methods include yawing, in which the rotor is turned out of alignment with the wind, by some mechanical device, when a given wind speed is exceeded. The most sophisticated method is active aerodynamic control, such as flaps or fullspan pitch control. The latter can be implemented as an emergency control method that only feathers the blades in an overspeed condition. Alternatively, it can be a highly active method for starting the rotor and controlling power output over a wide range of wind speeds. Although certain of these methods are valuable adjuncts to the control methods for variable-speed operation, they do not, by themselves, allow effective variable speed operation in a grid-connected environment. To accomplish this we must introduce additional equipment to match the variable-speed generator to the grid connection.

The variable-speed methods described below are based on allowing the speed of the generator to vary. But there are other methods for operating at variable speed such as mechanical variable-speed devices, which are based on the use of continuously variable-speed mechanical or hydraulic drives. These units allow the rotor rpm to vary while maintaining the generator speed as constant. These methods will not be discussed here because, to date, the technologies have not advanced to a point that makes them competitive with other methods in the size ranges of $100 \mathrm{~kW}$ to over 5 megawatts, the target sizes of large-scale utility machines of the future.

\subsection{Variable Speed in Small Turbines - An Overview}

Small-scale, variable-speed wind turbines have been used in stand-alone and grid-connected applications. Such turbines are normally considered to be those in the size range of $50 \mathrm{~kW}$ and lower. In stand-alone applications they can produce electricity or they can apply mechanical power directly to do work such as pumping water. In their electric generating mode they can be used to charge batteries, pump water, run ice- making equipment, power communications, heat buildings, and any of the other myriad purposes for which electricity can be put to use.

A variable-speed turbine with a direct current (DC) generator can be used to charge batteries or, as was done through much of the 1920s and 1930s on farms throughout America before the Rural Electrification Administration to directly power DC equipment. These DC machines primarily depended upon commutated alternators. A small turbine rotor, however, can turn an alternating current (AC) generator that produces varying $\mathrm{AC}$ voltages and frequencies (wild $\mathrm{AC}$ ), and, by using modern power electronics and controllers, convert that $\mathrm{AC}$ to $\mathrm{DC}$ and back to $\mathrm{AC}$ at a reliable and steady frequency. In this mode they can be directly connected to electrical grids to supply power to an individual modern home or ranch and return excess power to the electrical grid. Alternatively, they can be located directly on the electrical grid at the end of remote distribution lines to decrease the need for upgrading old or undersized distribution systems. An example of a small-scale AC-DC-AC machine is the Bergey Excel (see section 4.3 for more details).

\subsection{Variable Speed in Large Turbines - An Overview}

Variable speed in large turbines has normally been implemented in one of two ways: direct AC to AC frequency converters, such as the cycloconverters described with the MOD-5B in section 4.4 and in more detail in section 6.2.4; or using DC current link converters (AC-DC-AC), which convert the varying voltage and frequencies from the variable-speed generator to a $\mathrm{DC}$ voltage, and then using some form of power electronics to convert the $\mathrm{DC}$ voltage back to $\mathrm{AC}$ at a fixed frequency appropriate for the required application (normally, grid connection). Several different types of AC-DC-AC power electronic converters are described below and in more detail in section 6.0. 
The generator used can be connected to the turbine rotor either directly or via a gearbox. Gearboxes have been used on a majority of large turbines to act as speed increasers. Large wind turbine rotors normally operate at speeds between 10 and $60 \mathrm{rpm}$, depending upon size. Off-the-shelf generators are normally designed to run in the range of 1200 to $1800 \mathrm{rpm}$. Speed increasers are necessary to convert the low rotor speeds to the higher speeds necessary to drive the generators.

Direct mechanical connection can be accomplished with a generator that is designed to run at very low rpm. Such generators normally consist of many poles and are very large (large diameter to accommodate the large number of poles) in comparison to generators attached to gearboxes. The Enercon E-40, which is a direct-drive variable-speed machine, has a turbine rotor diameter of $40 \mathrm{~m}$. $(131 \mathrm{ft})$ and is designed to run at speeds ranging from 15 to $37 \mathrm{rpm}$. The direct-drive generator of this design is over 4 meters $(13 \mathrm{ft})$ in diameter and has 84 wound poles. The output frequency is linear with speed to over $26 \mathrm{~Hz}$ in a $16.7-\mathrm{m} / \mathrm{s}$ (37-mph) wind. This variable voltage and frequency is rectified to direct current and passed on to a conventional electronic inverter to produce $50-\mathrm{Hz}$ power for the European grid.

\subsection{Generators}

With the important exception of electrostatic generators such as the Van de Graf machine, all commercially important schemes for converting the energy of mechanical motion into electrical energy depend on Faraday's Law of induction from beginning physics. This Law states that the strength of the instantaneous total electromotive force (EMF) in volts around any closed path, whether in a conductor or otherwise, is proportional to the time rate of change (not the absolute value) of the magnetic flux passing through or linking that closed path. Because we know that magnetic fields close on themselves, we can think of an EMF path and its parent magnetic field as relating to each other like successive links in an ordinary chain.

Technologists have found several ways to create this required changing magnetic field. Three examples are:

1) A constant-magnitude magnetic field pattern is moved repeatedly in space past a stationary path, as in the synchronous generator whose magnetized rotor poles move repeatedly past its stator windings.

2) A path for an EMF in space (a coil of wire) is moved repeatedly past a constant magnetic field fixed in space, as in a DC generator with a commutated armature. (The source of the magnetic field for these two examples can be either one or more permanent magnets or externally supplied currents in coils of wire. Permanent magnet generators are highly popular because of their simplicity and ease of construction. They require no field windings, no field circuitry, nor external power sources.)

3) A magnetic field that both varies in time and moves in space sweeps past a stationary path, as in the squirrel cage induction generator. Here, low-frequency currents are induced in the rotor and create a changing magnetic field that sweeps repeatedly past the stationary stator windings.

To complete examples of Faraday's Law, one should mention the case of a power transformer. Although both the magnetic flux and the EMF path are fixed in space, the alternating current in the transformer primary creates the required changing magnetic field that links a path for an EMF in the transformer secondary, thereby creating an external voltage.

\subsubsection{Generators}

The classical DC generator consists of a spinning armature and a surrounding stationary field winding, which induces an output or load current in the armature winding. (This is the reverse of AC generators used today and described earlier in which the load current is induced in the stator. However, the same physics applies.) As mentioned earlier, depending on the number of poles, one or more cycles of alternating voltage are induced per revolution. The output of this turning armature must be continuously mechanically switched so that the output current will always be flowing in the same direction. The switch used is of course the well-known commutator with its copper segments insulated from each other and carbon brushes pressing against them. When these rotating machines are used as generators, they may provide their own field current. These types of generators were used in factories, machine shops and vehicles from the early part of the twentieth century on. The stationary field winding may also be replaced by permanent magnets, thus saving the current required to create the constant magnetic field. 
The addition of commutators and brushes makes DC designs more expensive and less reliable than comparable AC generators. A classical example of an early variable-speed DC turbine is the Jacobs machine discussed in section 1.0.

\subsubsection{Synchronous Generators}

Essentially, all primary generators employed by electric utilities belong to the synchronous class. The fundamental characteristic of synchronous motors and generators is that their rotor speed is always locked in with and exactly proportional to the frequency of the interconnected power grid. If a synchronous machine is the only generator on the grid, the grid frequency is determined by its speed. If the grid includes other generators, that grid will probably be much more powerful (stiff), and will therefore force any added synchronous generator to turn at exactly the grid synchronous speed. If the torques or currents necessary to accomplish this exceed the added machine's rating, either circuit breakers will open or the generator and its prime mover will be damaged. Changes in load will cause the synchronous machine rotor to advance or drop back a few degrees from the spinning magnetic field of the stator supplied by the utility. Thus we see that if a wind turbine using a synchronous generator is directly connected to a stiff grid, this turbine will necessarily become a constant speed machine. On the other hand if this turbine stands alone its voltage and frequency will be determined by the wind, assuming there is no control system.

However, if a wind turbine is connected to a power grid through appropriate electronic power processing modules, not only will the grid be supplied with power at constant voltage and frequency, but also the power (and therefore speed) demanded of the turbine can be determined from an algorithm programmed into the turbine control system.

The source of the magnetic field in such a generator determines which of several sub-classes a synchronous machine belongs to. Nearly all of the largest machines belong to the conventional class in which slip rings or other means on the rotor feed direct current (DC) into wire wound magnetic pole pieces. Not only do these magnets provide the essential magnetic field for generator action, but the amount of reactive power (kilovars or kVAs) supplied by the machine to a stiff grid is controlled by the magnitude of this field current. As this field current is increased the generator passes from consuming to producing Volt-Ampere, Reactive, (VARs) (see section 3.5).

In a similar but rapidly developing subclass, the electromagnets of the conventional synchronous machine are replaced by permanent magnets (PMs). Advantages of the PM subclass of machines are simplicity and no need to waste DC power to create the magnetic field. The disadvantages are expense of permanent magnets, and no means to control the strength of the magnetic field and therefore reactive power. With the introduction of power electronics between a synchronous machine stator and the electrical grid, a synchronous machine can run at variable speed. An example of a PM synchronous machine running at variable speed is the Bergey Excel. It is described in more detail in section 4.3. An example of a wound- field synchronous machine running at variable speed but on a much larger scale is the Enercon E Series (e.g., the E-40, described in Section 4.6).

\subsubsection{Induction Generators}

The simplest form of AC generator (after the PM type) and the type that has most often been used in wind turbines is the induction generator. The induction generator depends on an external voltage source (e.g., the electric utility) to produce a magnetic field in the stator, which is to say that this device consumes VARS in order to produce watts. The current in the rotor is induced by the differential speed of the rotor coils with respect to the spinning stator field. The simplest form of induction generator is the squirrel cage, in which the rotor is formed from welded copper bars, rods, or copper castings embedded in a soft iron cylindrical rotor. Induction generators are also constructed using wound rotors, in which rotor currents are induced in windings of copper or aluminum wire. When wound rotors are accessible through slip rings, a variable resistance can be inserted. This can control the electrical torque and will control the percentage of slip. Alternatively, a power electronics module can be substituted for the external resistance, thus allowing the injection of currents of appropriate frequency into the rotor windings. 


\subsection{Reactive Power and VARs}

The term "reactive power," sometimes referred to as "wattless power," was coined by early power transmission engineers. The concept is usually limited to linear circuits containing steady-state sinusoidal currents and voltages. However, management of this phenomenon directly affects power transmission efficiency and voltage support on distribution lines.

To establish a basis for a qualitative understanding of the concept, let us compare and contrast energy flow in a few primitive electric circuits. Assume initially that we have three separate circuits each consisting of a single-phase, sinusoidal voltage source driving in the first a resistor, the second a pure inductance (a coil), and in the third a pure capacitor. If we examine the movement of energy in these three cases after any starting transient has passed we find the following:

Case 1) During one cycle of the alternating voltage in this circuit, the resistor receives two pulses of energy from the generator, one on the positive half voltage cycle, and one during the negative half cycle. Both packets of energy come from the generator and raise the temperature of the resistor slightly.

Case 2) Consider the behavior of circuit \#2. Starting at a time just after the sinusoidal current has just gone through zero, then during the next one-quarter of a cycle of the alternating current, the inductor receives a pulse of energy from the generator that goes into the magnetic field of the inductor. During the next following quarter of a cycle of the alternating current, energy flows back to the generator as the magnetic field goes to zero. As the third-quarter cycle starts in the opposite direction, a packet of energy again comes from the generator and flows into the reversed and growing magnetic field of the coil. Finally, during the last quarter cycle, the same amount of energy again flows from the magnetic field back to the generator. The cycle then repeats.

Case 3) If we examine a pure capacitance connected to a sinusoidal generator, we find almost exactly the same behavior. During one-quarter of the alternating voltage, the capacitor receives a pulse of energy that is stored in the electrostatic field of the capacitor dielectric. During the succeeding quarter cycle, that energy returns to the generator as the capacitor discharges. As with the inductor during the negative half of the cycle, a packet of energy again flows with reverse polarity into the capacitor, then back to the generator.

Note that for the inductor and capacitor (the so-called reactive-circuit elements), although appreciable amounts of energy are moving about, after an integral number of cycles there is no net transfer of energy from generator to circuit element and no energy is lost nor degraded to heat (as in the resistor case). This is plainly not useful. Closer examination of the two reactive elements reveals that though the energy transfer behavior is similar, the times of export and import are complementary or out of phase. That is, with respect to the voltage across the element, one element exports energy when the other is importing and vice versa.

In electric-circuit analysis classes, Kirchhoff's general differential equations yield analytic solutions for the preceding circuits. The solutions show that in all cases the sinusoidal voltage of the generators causes a sinusoidal current to flow. The cases differ in the phase relation between the voltage and resulting current sinusoids. In the resistive case the two are exactly in phase so that they are either both positive or both negative at the same time. Thus, the power flow, being the product of voltage and current, is always positive. For the two pure reactive cases, however, the two sinusoids are exactly 90 degrees out of phase. Current leads in the case of the capacitor and lags for the inductor. This means voltage and current alternate between having the same sign and having opposite signs every quarter of a cycle. It follows that power flow alternates between positive and negative every quarter cycle.

Let us continue these imaginary electric-circuit experiments by selecting one of the previous two reactive circuits (say, the perfect inductor). Now, let us gradually add resistance to this circuit and reduce the inductance at the same time. It seems plausible that little by little some of the characteristics of the pure resistor circuit should begin to appear. Remember that "resistance" is the resistance to the flow of current. Addition of the resistance will retard the current flow and tend to reduce the phase difference in the circuit towards the pure resistive case in which the voltage and current are exactly in phase. In fact, measurement by an oscilloscope will show that the same four sending and receiving phases of energy still exist. However, the importing or receiving periods are becoming longer than a quarter cycle each and the exporting or sending periods are becoming shorter than a quarter of the AC fundamental cycle. This means that there is some net energy transfer 
to the resistors in spite of a lot of additional energy moving back and forth between the inductor and the generator or energy source. Finally, as the inductance disappears, the two exporting periods collapse to zero, and the two unidirectional resistive energy surges remain.

If the circuit just described has an applied sinusoidal voltage of RMS value, $\mathrm{V}$, and the current is another sinusoid with phase angle, $\phi$, and RMS value, I, then the complete analytic solution for instantaneous power flow in the circuit is:

$$
\begin{gathered}
\mathrm{p}(\mathrm{t})=\mathrm{VI} \cos (\phi)-\mathrm{VI} \cos (2 \omega \mathrm{t}-\phi) \\
\phi=\operatorname{Atan}(\omega \mathrm{L} / \mathrm{R})
\end{gathered}
$$

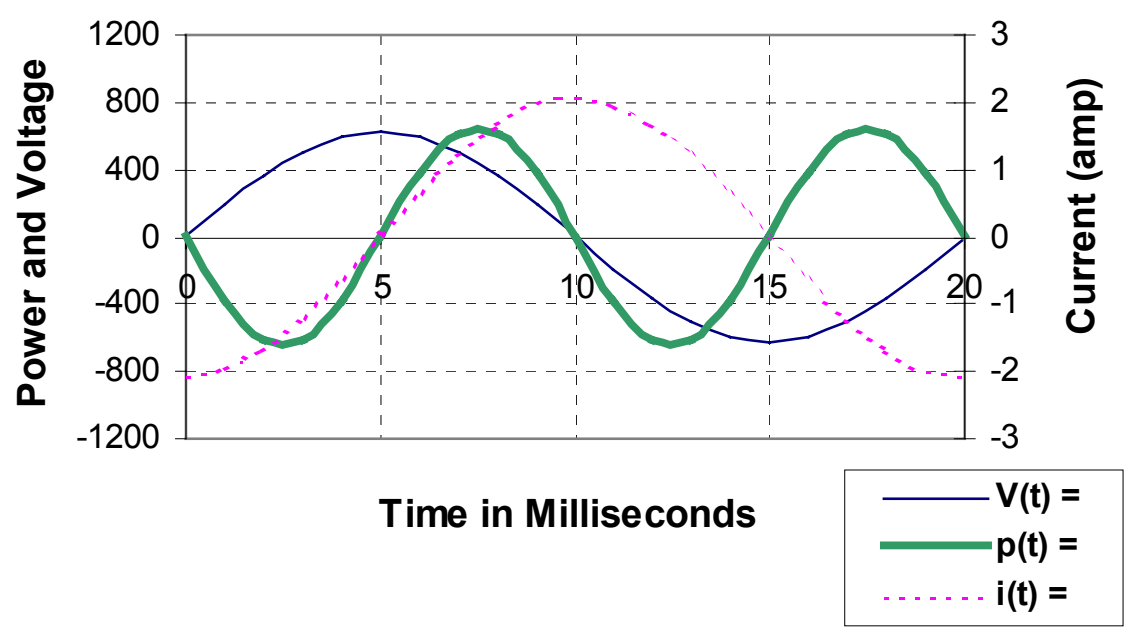

Figure 3.5a. - Power flow in an RL circuit (impedance predominately inductive [L] )

Omega is the angular frequency of the voltage and current, $\mathrm{L}$ is the coil inductance in henries, and $\mathrm{R}$ is the resistance in ohms. Note that the average power is given by the first term alone. Figures $3.5 \mathrm{a}, \mathrm{b}$, and c illustrate three stages in the above imaginary experiment.

Although the energy behaviors of the two reactive circuit elements (circuits \#2 and \#3 in paragraph 3.5) is nearly the same, early power transmission engineers needed to devise a terminology to distinguish the two cases. Because power systems considered as electric circuits have more inductive elements in the form of motors, transformers, and long lengths of transmission lines than they have of capacitive elements in the form of capacitance between conductors, these engineers arbitrarily decided to say that these inductive elements were drawing reactive power or consuming VARs. Circuits that were more capacitive than inductive were said to produce or export reactive power or VARs. It is important to emphasize that the definition of direction of flow of reactive power is a naming accident of history, and ignores the reality that the flow of energy changes direction four times per cycle.

It is much less confusing to examine how the sinusoidal current into a complicated network is related to the voltage across that network. If the positive peak of current occurs after the positive peak of voltage, the current is said to be lagging. This means the circuit is more inductive than capacitive, any return of energy to the source occurs just after the instantaneous voltage changes sign, and the circuit is said to consume reactive power or VARs. If the positive peak of current occurs before the positive peak of voltage, the current is said to be leading, the network is more capacitive than inductive, any return of energy to the source occurs just before the instantaneous voltage changes sign, and the network is said to be producing VARs. 


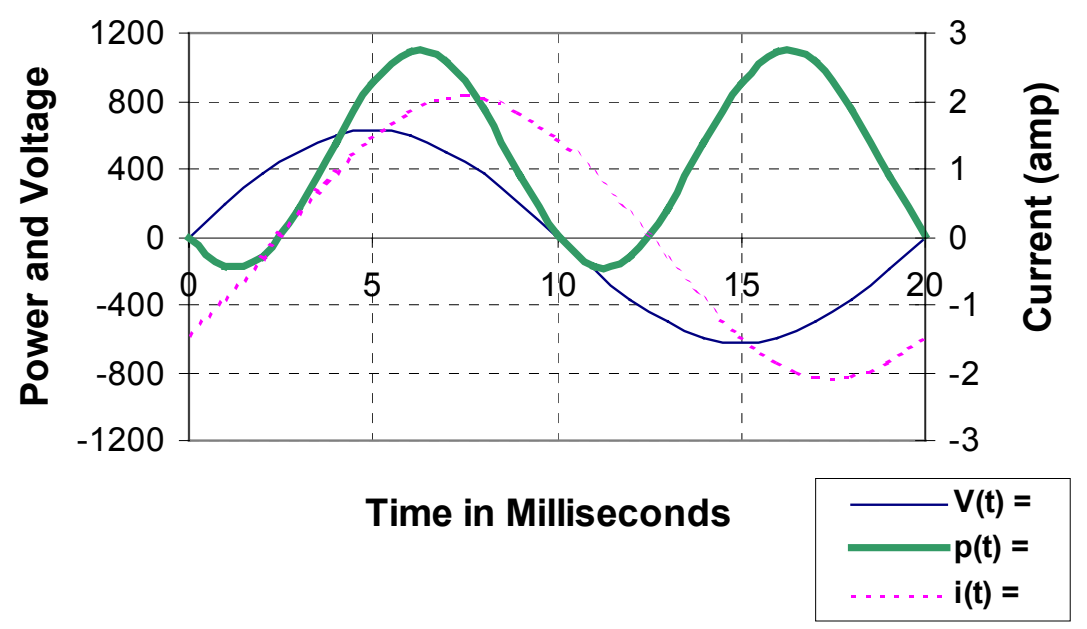

Figure 3.5b. - Power flow in an RL circuit ( $R$ and $L$ impedances approximately equal.)

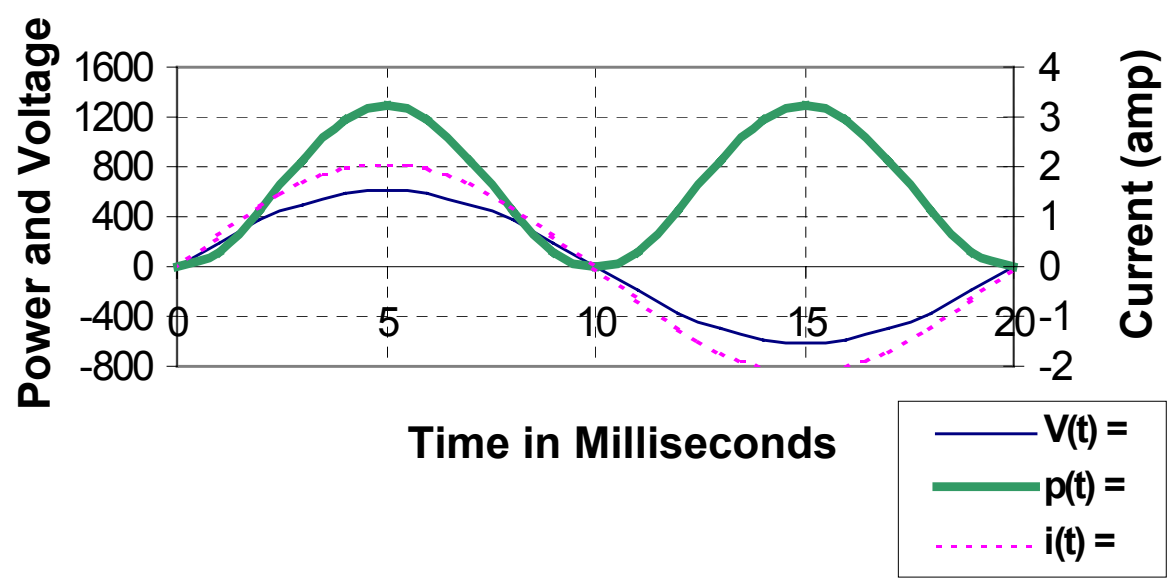

Figure 3.5c. - Power flow in an RL circuit (impedance predominately resistive [R] )

Thus, if the purpose of an electric network is to efficiently transfer large amounts of energy from one point to another, it is not useful to send some of it back to the energy source two times per AC cycle. Early power engineers noted the natural complementarity of capacitors and inductors in that one imports energy when the other is exporting energy. They then correctly placed capacitors near inductors (e.g., rotating machines) and by properly sizing the capacitors, these two reactive elements continuously exchange the same packet of energy. The generator that supplies this combination is unaware that this is happening and does not need to be built large enough to handle the extra out-of-phase component of current. It needs to supply the network only the in phase current component, which transfers energy unilaterally to the useful load and supplies unavoidable network losses.

A utility distribution line, because it connects to a network of utility transformers and generators, will have internal inductance. It is therefore not surprising that any customer-added compensating capacitors will also exchange energy with these inductors. By using phasor diagrams similar to those in section 6.1.2, one can show that increasing capacitance and therefore VAR injection at the load will increase the utility voltage at that point. We can think of it as the circuit starting to show series resonance. 
To complete this discussion, we should mention some practical details. We have assumed all of the above example circuits had previously been energized and are in the mathematical steady state. For those that contain reactive elements, there would have been a transient starting phase lasting for only a few dozen cycles in which the sinusoidal energy source or generator supplied the initial packets of energy which, in the subsequent steady state, are cycled in and out of the respective elements. When a real system is finally turned off, this circulating energy is usually lost.

The single-phase circuits of the above examples transferred energy in periodic positive or negative bursts. These fluctuations would be transmitted through a single-phase generator to its drive shaft as positive and negative torque increments. One of the many advantages of three-phase systems is that the staggered timing of the three single phases that make up these systems mutually cancel these torque increments and apply a smooth constant torque to the prime mover.

\subsection{Power Electronics}

The introduction just after World War I of the vacuum tube with its remarkable speed stimulated the explosive development of the modern communications industry. Long-distance telephony, radio broadcasting, and later television and radar transformed civilization as well as warfare. That development was then dwarfed by the discovery and development of solid-state electronic devices that ignited the computer revolution and replaced the vacuum tube. It was the speed and sensitivity of both of these devices and not their power ratings nor energy efficiency that was fundamental to this development. However, the pressure to fill the demand for components for this communication and information world inevitably led to fabrication techniques whose byproducts were larger and more efficient devices. These new trends soon caught the attention of power engineers.

Perhaps due to the first energy crisis, the manufacturing industry discovered that variable-speed drives could transform otherwise constant-speed AC motors into variable-speed motors and save energy at the same time. Eventually, electric power engineers began to realize that solid-state devices were attaining efficiencies and power-handling capacities that made them candidates for use in these adjustable speed drives (ASDs). This emerging market for efficient devices handling appreciable power helped to create the level of power electronics development we see today.

Almost all of the previously described grid-connected variable-speed techniques have one factor in common. They must all use power electronic devices of some type coupled to the rotor, stator, or both. These devices contain electronic switches of some form.

Since the 1960s, the advances in solid-state electronics have been phenomenal, both in efficiency, in component size, and in power-handling capability. But the last 15 years has witnessed an even more accelerated advance in high-power (voltage and current) devices. Some of the earliest sophisticated devices, such as thyristors, (silicon-controlled rectifiers-SCRs; gate turn-off thyristors-GTOs) were applied to variable-speed wind turbine designs before 1975. Since then, designs using bipolar junction transistors (BJTs), metal-oxide-semiconductor field-effect transistors (MOSFETs), insulated-gate bipolar transistors (IGBTs) have all been applied to wind turbine designs. These devices as well as other circuit elements, can be combined in a range of ways to control switching, current flow, resistance, and voltages. In the 1990s the costs for many of these devices have come down sharply while power-handling capabilities have increased, making their application on a large scale more economic. Manufacturing processes continue to improve and new devices are under development that may make the existing devices obsolete within the next 10 years. 
The devices each have different characteristics that make them more or less useful for the different applications. Table 3.0 (courtesy of R.W. Erickson, University of Colorado, Boulder) outlines the different important characteristics of several of the devices.

Table 3.0 Summary Of Commercial Semiconductor Power Handling Devices

\begin{tabular}{|c|c|c|c|c|c|}
\hline \multirow[b]{2}{*}{ DEVICE } & \multicolumn{2}{|c|}{ Recommended Range } & \multirow{2}{*}{$\begin{array}{l}\text { Easy to } \\
\text { Parallel? }\end{array}$} & \multirow{2}{*}{$\begin{array}{c}\text { Typical } \\
\text { Switching } \\
\text { Speed } \\
\end{array}$} & \multirow{2}{*}{$\begin{array}{l}\text { Other } \\
\text { Notes }\end{array}$} \\
\hline & Voltage & Current & & & \\
\hline BJT & $0-1200 \mathrm{~V}$ & $0-600 \mathrm{~A}$ & no & $1 \mu \mathrm{s}$ & difficult to drive \\
\hline MOSFET & $0-1000 \mathrm{~V}$ & $0-600 \mathrm{~A}$ & yes & $0.1 \mu \mathrm{s}$ & easy to drive \\
\hline IG B T & $600-3300 \mathrm{~V}$ & $0-1500 \mathrm{~A}$ & yes & $1 \mu \mathrm{s}$ & easy to drive \\
\hline $\begin{array}{l}\text { Thyristor: standard } \\
\text { grade SCR }\end{array}$ & $600-8000 \mathrm{~V}$ & $0-3500 \mathrm{~A}$ & no & $100 \mu \mathrm{s}$ & $\begin{array}{l}\text { controlled turn-off } \\
\text { impossible }\end{array}$ \\
\hline $\begin{array}{l}\text { Thyristor: inverter } \\
\text { grade SCR }\end{array}$ & $600-3000 \mathrm{~V}$ & $0-2000 \mathrm{~A}$ & no & $10 \mu \mathrm{s}$ & $\begin{array}{l}\text { controlled turn-off } \\
\text { impossible }\end{array}$ \\
\hline Thyristor: GTO & $600-3300 \mathrm{~V}$ & $0-2000 \mathrm{~A}$ & no & $10 \mu \mathrm{s}$ & $\begin{array}{l}\text { very difficult to } \\
\text { drive }\end{array}$ \\
\hline
\end{tabular}

In addition to the devices themselves, a major element in their successful application is the multiplicity of circuits in which they can be employed. These devices are, in essence, very fast switches. It is the sequence in which they are turned on and the rate at which they ramp up to full capacity and turn off that gives them the ability to modulate currents and voltages to generate usable wave forms for injection into the electrical grid. Small computers and logic controllers or other simple circuit elements to perform a wide range of functions can control this switching.

The earliest and still most widely used type of these power semiconductor circuits uses the AC/DC/AC topology, in which the variable frequency, variable voltage from a variable or "wild" source is first rectified to DC. This steady direct current is then inverted to utility-grade alternating current of constant voltage and frequency.

For each of these successive transformations there is a wide choice of circuits that could be selected, thus leading to an even larger number of complete $\mathrm{AC} / \mathrm{DC} / \mathrm{AC}$ systems. For example, a simple three-phase diode bridge or a phase-controlled rectifier using SCRs could be used to convert the wild AC to DC. The latter could control the current drawn and therefore the torque required to drive the generator. Similarly, the DC bus could have a capacitor connected across it, which would tend to hold its voltage constant, or, it could have an inductor in series with it, which would tend to hold the DC bus current constant.

Even more choices are available for the conversion of the DC bus energy to utility frequency and voltage. The first inverters were 6- or 12-pulse bridges of SCRs that connected the DC bus in various ways to the AC line 6 or 12 times per cycle. Switching losses were low but harmonics such as the fifth and seventh were strong and filtering was necessary. Later, with the widening choice of devices mentioned above, pulse width modulation (PWM) inverter techniques became common. In these circuits the DC bus is connected to the output for various durations several hundred times per cycle. This, of course, allows fabrication of a much-improved approximation to a sinusoid, which results in weaker and much higher frequency harmonics that are much easier to filter out.

Instead of using a DC link as in the family just described, one can substitute a high-frequency resonant circuit. Recall that if an electric pulse is injected into a coil and capacitor circuit, it tends to "ring." That is, a damped sinusoid of voltage and current will briefly exist. This can be used to advantage by a control circuit if it actuates the semiconductor switches when a link voltage or current to be switched is crossing through zero. The switching losses become minimal if a semiconductor does not have to interrupt a finite current or voltage, thereby improving conversion efficiency. 
Still another approach is to omit the center DC link altogether. With the addition of a few more semiconductor switches, we have a cycloconverter. This topology is described in section 6.2.4 and examples of its use are found in paragraphs 4.1.2, 4.2.2, and 4.4.2.

\subsection{Implementation of Variable Speed}

Taking all the pieces we've discussed, we can now start tying them together to create different variable- speed topologies. We'll look at them in two general categories: partial power handling and full power handling.

In a "full power-handling" system, the entire variable power output of a conventional generator is fed to the associated power-conditioning electronics module to be transformed to constant frequency at constant voltage for injection into the local utility. Although no special requirements are placed on the generator, the power electronics must be sized large enough to handle the full system output continuously.

On the other hand, it is possible to install a wound rotor induction generator with slip rings or other means of access to the rotor, and connect the rotor winding to the same type of power converter as the previous case. In this case, however, by appropriate gating of the switches in the electronic input circuits, the generator rotor can in principle be caused to run at any positive or negative slip rate. For small values of slip, the amount of rotor real power involved is small so that the electronic converter hardware needs to be rated for only a small fraction of the total generator power. This means important cost savings.

It is not surprising, however, to learn that the amount of wound rotor power that must be handled is strongly dependent on the range of variable speed over which the system is designed to operate. For example, in the limit of zero rotor speed, the generator becomes a transformer and power in or out at the stator is equal to power out or in at the rotor.

\subsubsection{Partial Power Handling}

The variable-speed approaches discussed in this section all have one aspect in common: the rotor is connected to external devices via slip rings or other means and only the current in the rotor is controlled to allow variablespeed operation. For example, at rotor speeds above synchronous speed for a wound rotor induction machine, electrical energy will flow into any electrical load connected to the rotor slip ring terminals. Increasing power flows with increasing speed difference above synchronous. Conversely, as the turbine rotor speed falls below synchronous speed and the rotor is connected only to a passive circuit, the synchronous machine will become a motor and will drive the turbine as a large fan.

One of the simplest methods for the implementation of variable speed using an induction generator is by using a diode rectifier to change varying $\mathrm{AC}$ from the rotor to $\mathrm{DC}$ and then some form of inverter to convert the DC back to utility AC. (Power produced through the stator will be grid synchronous.) This so- called "slip recovery" procedure was often used in elevators in the early twentieth century to recover some energy when an elevator car was descending. During the early 1980's, an application of this technology was tested on the MOD-0 at Plum Brook, Ohio. The rectifier in this application was a three-phase diode bridge feeding a DC bus. This DC energy was fed to the utility through a twelve-pulse inverter employing SCRs.

A more limited form of variable speed can be classified as variable slip. As we have seen, the current in the rotor is induced by the rotation of the rotor in the magnetic field of the stator. This current always acts to oppose the torque of the generator. If one increases the electrical resistance in the rotor it becomes harder to induce rotor current to flow. To maintain a constant torque, the speed of rotation of the rotor must increase to increase the current flow and maintain the generator at the same point on its torque-rpm curve. (See section 6.1.3 for more details.) Varying the rotor resistances through several different methods can thus allow for variable speed by constantly changing the slope of this torque-rpm curve. Devices with low rotor resistance are low in slip or stiff, and thus highly efficient. Devices that introduce high resistance have high slip and expend power through resistive heating. Unless this heat can be used, these devices are electrically inefficient. One example of variable speed using these principles is the early Russian Balaclava machine (circa 1930s) which used a rheostat to adjust the resistance in the rotor. With the proper design, this resistance heating can be recovered for useful purposes such as hot-water heating or space heating. 
Another more recent and sophisticated example of variable slip is the Vestas Opti Slip. In this design, the resistors and switching electronics are located on the rotor. These electronics are used to switch the resistors in and out of the circuit to change the rotor resistance. The unique feature of this design is the use of an optical coupling to the rotor to control the resistor switching. This optical coupling eliminates the need for costly and unreliable slip rings and brushes.

Variable-slip designs have somewhat limited variable-speed ranges. And, though these designs may be inefficient, they are normally only active when generator power is at a maximum and the control algorithm is trying to shed power. At this point efficiency is not a critical issue of operation.

A more efficient method of taking advantage of this varying slip is to find a way of converting the slip to power and returning it to the electrical grid. An early form of this method was the cycloconverter. These devices do not use an intermediate DC rectifier or inverter. Instead, they allow variations in rotor rpm by providing variable rotor excitation using a network of thyristor switches referenced to the grid frequency through control circuits. For small slip ranges (speed ranges) the cycloconverter does not have to handle large amounts of power and can be small. As speed ranges increase, to say 2:1, the cycloconverter must be large enough to handle more of the total power output of the generator. At this point other methods become more efficient. This technique was applied on the Growian turbine described in section 4.2 as well as one version of the MOD0 (see section 4.1) and the MOD-5B (see section 4.4). The output from these devices required heavy filtering, due to the poor quality of the output $\mathrm{AC}$ wave form. See section 6.2.4 for more details on the operation of a cycloconverter.

As mentioned above, one can replace the passive resistor of a slip recovery system with an active power electronics module. It is then possible to inject a controlled current of appropriate frequency and phase into the rotor windings. This allows control of the generator torque and thus the turbine speed both above and below synchronous, as well as control of the reactive power exported to the grid. An example is the AWT-26 (Advanced Wind Turbines Inc.) which uses an Electronic Power Conditioning, Inc. converter employing silicon controlled rectifiers in a unipolar series resonant converter. (See section 4.10 for more details).

These are only a few of the better-known examples of partial-power-handling techniques.

\subsubsection{Full Power Handling}

The induction generator techniques we have discussed so far used a connection to the rotor to, in some manner, control or regulate the rotor currents. If all the external devices connected to the rotor slip rings mentioned in the above paragraph were removed together with the slip rings, and the rotor winding leads shorted together, we would have a conventional induction machine. If placed in operation, fluctuating winds could drive the generator rotor fast and slow. However, the strong magnetic field of the stator, which is provided by the utility, will resist this changing speed and will allow only a few percent variation in speed in the form of positive or negative slip. By using appropriate power electronics to supply stator current, rather than rotor current, it is possible to control generator torque as in the above case of partial power handling. The rotor of the generator can be a wound rotor with no external connections or a simple squirrel-cage induction generator.

The power electronics design is the key to this approach. One power electronics approach is to use an AC-DCAC current link. This design uses semiconductor switches to convert the turbine (wild) AC to DC and DC back to utility $\mathrm{AC}$ at the grid. For instance, the wind turbine rotor is commanded to spin at the optimum rpm in relation to the wind. A computer controller senses the wind and determines what frequency the stator voltage should be for optimum operation of the turbine. The power switches can be switched on and off in rapid sequences to allow current to flow in such a way as to appear as a waveform of the necessary frequency. One method for controlling this switching is pulse width modulation, in which current flow is controlled by the length of time the switch is closed. In order for this to work efficiently, the switches must be capable of very rapid actuation. With a DC current link, two sets of switching modules are set up, one either side of the DC link (one to control the frequency to the stator and the other to control the frequency of the lines output to the grid). One set of switches may be controlled based on wind speed input, and another set may be controlled based on the grid frequency. 
In the late 1980s, Kenetech Windpower (now Green Ridge Services Company) chose the AC-DC-AC current link converter and PWM control for the design of the KVS-33 wind turbine. This machine used two squirrelcage generators connected to a single dual-output gearbox. The power electronics links were capable of 600 amps at 1400 volts. Switching was accomplished using IGBTs and a PWM switching technique. The control algorithm was designed to control the torque of the generator and limit changes in the torque load. This arrangement provided for bi-directional power flow and would allow motoring the turbine as well as power production. This machine is discussed in more detail in section 4.8.

Even though we described a number of different approaches to implementing variable speed in wind turbines we have only touched the surface. We described several electronic switches. However, the number of circuit designs that can be developed using these devices is limited only by the imagination and understanding of the designer. Besides circuit designs there are other topologies (combinations of generator designs, power electronics circuits, and control strategies) for variable-speed operation that have been examined and tested in wind turbine designs. The potential number of combinations is almost infinite. In a report of this size, it is impossible to provide a detailed explanation of all the possible methods or even describe all of the methods that have been tested. But the number of different approaches that have been reduced to practice in one form or another stretches into the hundreds. Please refer to section 6.0 for additional information on other designs or concepts.

\subsection{VARIABLE-SPEED MACHINE HISTORIES}

Many manufacturers have developed variable-speed machines over the last few decades. There have been many production machines and an even greater number of prototypes or proofs of concept. Table 4.1 identifies a number of these machines and the combinations of generators and power conversion methods that allowed them to run in a variable-speed mode. The list is, however, far from complete. We focused here on machines for which well-documented public data exist. But it represents a general cross section of the different methods for allowing variable-speed operation. This database may expand as additional information becomes available.

\subsection{NASA MOD-0 Plum Brook}

\subsubsection{History}

The experimental wind turbine erected at the Plum Brook Station of the NASA Lewis Research Center near Sandusky, Ohio, holds an important place in the recent history of wind energy in the United States. The sudden rise in fuel costs during the 1970s precipitated the federal wind energy program, the administration of which was assigned to the Energy Research and Development Administration. One component of the program was directed toward investigating large $(>100 \mathrm{~kW})$ wind turbines. This was the origin of the "MOD" series of wind machines that eventually culminated in the MOD-5B machine in Hawaii (described in Section 4.4).

The design and fabrication of the first of this series, the MOD-0, was assigned to the NASA Lewis Research Center (LeRC) in Cleveland, Ohio. The LeRC Plum Brook field-testing facility 60 miles west of Cleveland and just outside Sandusky, Ohio, had space and moderate annual wind and so was chosen for the test site. The first iteration of this family was analyzed, designed, fabricated, and erected in 18 months. The nacelle was placed atop its 30-meter tower on September 3, 1975. The machine achieved an 80-KW output at $30 \mathrm{rpm}$ on October 23,1975 . Not surprisingly for a prototype machine, over the next 11 years many transformations of the original design were conceived and tested. For example, the tower shadow created by the original lattice tower and its open stairway precipitated the substitution of a tubular steel tower. To add experimental flexibility, this tower was mounted on elastic footings with adjustable spring constants in order to study resonances. Many different rotors were tested including a single blade with a counterbalance. 


\subsubsection{Configuration}

The original $100-\mathrm{kW}$ synchronous generator was driven by a $45: 1$ gear ratio transmission and a 30 -meter (125-ft), two-bladed, downwind, rigid-hub, full-span pitch-controlled rotor. Rated power of 100-kW was achieved at the constant $40 \mathrm{rpm}$ with a wind of about 8 meters per second (17.7 miles per hours). Eleven years later in 1985 after many data sets from many interesting modifications had been analyzed, the configuration for the final test appeared.

The equipment for this variable-speed test had evolved to a 200 kilovolt-ampere (kVA) wound-rotor induction motor fabricated by the Bogue Electric Manufacturing Company. It was driven through the original transmission with an added V-belt coupling of step-up ratio 1.28:1. This drivetrain was driven by two 14.3-meter (47-ft) teetered, wooden blades, each with 2 meters of pitchable tips. The three-phase generator stator was connected directly to the utility. The generator rotor winding was connected to the utility through a cycloconverter custom designed by the Westinghouse Electric Corporation. Because the cycloconverter could supply variable low-frequency, three-phase voltage to the generator rotor with either phase rotation, the system could operate either above, below, or at synchronous speed. Theoretically, this 0 - to $45-\mathrm{Hz}$ voltage range supplied by the cycloconverter could allow the system theoretically to turn at speeds from 450 to $3150 \mathrm{rpm}$. However, due to transformer voltage and generator mechanical load limitations, operation was limited to between 1440 and $2160 \mathrm{rpm}$. For less-than-rated winds, the control system regulated system speed by controlling generator torque and attempted to match electrical power to the utility to the power available in the wind at that instant. When the wind power exceeded rated value for the machine, the controller shifted to a constant power output algorithm and controlled speed by pitching the blade tips.

To facilitate comparison of this variable-speed operation with an equivalent constant-speed system, the generator rotor could be switched from the cycloconverter to a set of resistors. This caused the generator to become, in effect, a squirrel-cage induction machine with slip of about $5 \%$.

As a by-product of the analysis performed by the control system, it was possible to supply reactive power to the interconnected utility. This feature could help support voltage on power distribution lines if requested by the utility.

\subsubsection{References}

1. Herrera, J.I. and Reddoch, T.W.; "Testing Requirements for Variable Speed Generating Technology for Wind Turbine Applications.” Electric Power Research Institute (EPRI) AP-4590, Project 1996-22, final report, May 1986.

2. McDade, J., Ziemke, R., and Schmidt, W.; "Variable Speed System Testing on the MOD-0 Wind Turbine," Sverdrup Data report (Internal Solar Energy Research Institute (SERI) Report, ." January 1986-June 1986.

3. Herrera, J.I,. Reddoch, T.W., and, Lawler, J.S.; "Experimental Investigation of a Variable-Speed, Constant-Frequency Electric Generating System from a Utility Perspective.” DOE/NASA/4105-1, NASA CR-174950, May 1985.

4. Herrera, J.I. and Reddoch, T.W.; "Analysis of The Electrical Characteristics of a Westinghouse Variable Speed Generating System for Wind Turbine Applications." SERI/STR-217-3133, DE88001139, February 1988.

\subsection{The Growian Variable-Speed Wind Turbine}

\subsubsection{History}

One of the first very-large prototype wind turbines was initiated by funding provided by the Federal Republic of Germany in 1977/1978. At the end of the 1970s, three German utilities formed Growian GmbH, a company whose purpose was to specify, design, build, and test a large-scale wind energy conversion system (LS WECS). The name was derived from Grosse Windenergie-Anlage or Large Wind Energy Plant. The resulting 3,000-kW turbine was advanced for its time in that it featured a variable-speed drivetrain with power electronics and a 100-meter (328-ft) teetered rotor with full-span pitch. In 1979 the designers set up a trade-off between a synchronous generator with a frequency converter in the stator circuit versus a doubly fed asynchronous (induction) machine with a frequency converter in the rotor circuit. The doubly fed system was chosen. 
The wind machine test station at the Kaiser-Wilhelm-Koog in northern Germany was chosen for the installation location. During October 1982 the nacelle with its two bladed rotor attached was raised to the top of its 100 -meter (328-ft) tower. Regular testing began during the summer of 1983, which yielded confirmation of the predicted power curve and power coefficient. The machine responded well to the control system and no vibrations or resonances were observed. Testing continued through the Spring of 1987.

Early in the testing, cracks developed in the material of the highly stressed parts of the hub. Repairing these problems caused extended periods of downtime. After a total of 500 hours of intermittent operation, it was decided to end the tests in August 1987. It was dismantled during summer, 1988.

The data archived during the testing year has been thoroughly analyzed under the management of Industrieanlagen-Betriebsgesellschaft $\mathrm{mbH}$, which tested a full Growian rotor blade in the early 1980s. This information has been valuable for the design of subsequent machines, such as the WKA 60 .

\subsubsection{Configuration}

To summarize, the Growian was a 3-megawatt (MW), variable speed, downwind machine on a 100-m (328-ft) concrete tower. The 100-m (328-ft), teetered, two-bladed, rotor was fabricated from glass fiber around a steel spar. From the cut-in wind speed of $6.3 \mathrm{~m} / \mathrm{s}(14 \mathrm{mph})$ up to the rated wind of $11.8 \mathrm{~m} / \mathrm{s}(26 \mathrm{mph})$, the control system attempted to hold optimum tip-speed ratio. Full-span pitch allowed power limitation to $3 \mathrm{mw}$ for winds up to the cut-out speed of $24 \mathrm{~m} / \mathrm{s}(53 \mathrm{mph})$. Nacelle mass was 240 metric tons $(529,000 \mathrm{lbs})$ and its orientation (yaw) was actively controlled. The rotor speed could vary between 15.73 and $21.28 \mathrm{rpm}$.

Three modes of operation were initially considered. First was simple direct connection of a synchronous generator with DC field excitation to the utility (essentially constant-speed operation). Computer simulations of output power fluctuations in turbulent winds immediately ruled out this mode. The two other modes considered permitted variable rotor speed and therefore the possibility for maximum power tracking. One mode used the just-described synchronous generator, but fed its entire output to an $\mathrm{AC} / \mathrm{DC} / \mathrm{AC}$ chain consisting of a rectifier, a DC bus, and an inverter to the grid. However, the mode finally chosen was to use a synchronous generator with a three-phase slip ring fed rotor (essentially, a wound-rotor induction machine.) The rotor was fed using field orientation techniques from a power electronics frequency converter. Recall that field orientation uses control of phase and amplitude of the generator rotor excitation to set real and reactive power output to the utility independently of each other. In spite of the slight additional cost, this was the system that was built and installed. The system has since been used as a model for many wind turbines.

\subsubsection{References}

1. Leonard, W.; "Field Oriented Control of a Variable Speed Alternator Connected to the Constant Frequency Line in Implementing Agreement for Co-Operation in the Development of Large Scale Wind Energy Conversion Systems: Second Meeting of Experts-Control of LS-WECS and Adaptation of Wind Electricity to the Network." Scientific coordination by R. Meggle and R. Windheim; Published by Zentralbibliothek der Kernforschungsanlage Jülich GmbH, Jülich, Germany, 1979.

2. Warneke, O.; "Application of a double-fed asynchronous generator in the Growian wind power plant," 1985; Windkraft Journal (Germany, Federal Republic of) Vol. 5:4. Coden: WIJOD; pp. 164-166.

3. Warneke, O.; "Use of a double-fed induction machine in the large GROWIAN wind energy converter." 1983; Siemens Energietech (Germany, Federal Republic of) Vol. 5:6. Coden: SIEED; pp. 364-367.

4. Braun, D., Kloeppel, V., Marsch, G., Meggle, R., Mehlhose, R. Schoebe, B. Wennekers, R.; "Wind energy converter GROWIAN II; Original Title: Windenergieanlage GROWIAN II." Corporate Source: Bundesministerium für Forschung und Technologie, Bonn (Grmany, F.R.); Publication Date: April 1984, p. 148.

5. Koerber, F.; "Final plans for the construction of GROWIAN." Interim final report; Corporate Source: Bundesministerium für Forschung und Technologie, Bonn (Germany, Federal Repulic of); Publication Date: December 1980, p. 89.

6. IEA Wind Energy Annual Report for 1988, NUTEK, Swedish National Board for Industrial and Technical Development, Allmänna Förlaget, Kundtjänst, S-106 47 Stockholm, Sweden, pp. 30-31. 


\subsection{Bergey Excel}

\subsubsection{History}

The Bergey Windpower Company, headquartered in Norman, Oklahoma, marketed its first variable-speed, utility-connected wind turbine in 1980. In 1983, the larger, 10-kW EXCEL wind turbine was offered, and in about five years over 300 machines had been installed, usually on farms and ranches. The standard grid- tied installation featured the EXCEL turbine, a power electronics unit that converted the variable-voltage, variablefrequency alternating current ("wild $\mathrm{AC}$ ") to direct current and from there back to utility alternating current. This is the classical AC-DC-AC system.

\subsubsection{Configuration}

The EXCEL aerodynamic rotor with its three fixed blades is attached directly to the generator rotor. Because this rotor carries the permanent magnet excitation for the generator, the stator windings can be stationary and mounted on the wind machine frame, thereby obviating the need for slip rings. The fiber- reinforced plastic blades are flexible around their longitudinal axes. This feature, together with special pitch weights at the outboard leading edges, causes a change in pitch angle as rotor speed increases. Thus, the relatively high angle at stand-still provides higher starting torque; and, as rotor speed increases, the blades deflect toward flatter pitch, thereby allowing a higher tip-speed ratio.

The two-fold function of all wind turbine control systems is to harvest maximum wind energy in normal operation, and to protect the machine from damage in winds above rated power. For the latter requirement, the EXCEL can capitalize on its furling control. Although its rotor is $7 \mathrm{~m}(23-\mathrm{ft})$ in diameter, it is still practical to orient this machine into the wind by using a tail. By design, the horizontal axis of rotation of the turbine rotor does not intersect the vertical yaw axis of the whole machine. When the wind speed approaches dangerous values, the preceding axis offset causes the rotor generator combination to yaw out of the wind and the machine slows to moderate speeds. This yawing is possible because the tail is hinged to the main machine body. However, the hinge axis is inclined to the vertical so that as soon as the excessive wind gust has passed, a gravitational restoring moment exists that returns the machine to its operating configuration.

To match the incoming wild three-phase AC power from the 38-pole permanent magnet generator to a singlephase utility line, a half-controlled, three-phase bridge is paired with a voltage-source line-commutated inverter. The SCRs in this bridge permit the control system to control the voltage level on the linking DC bus, and thus to control the charge level of any batteries connected to it. The second purpose of this DC bus is to provide power to the voltage-source inverter power electronics, which feeds power into the utility. Once again, the switches provided in this element are SCRs.

\subsubsection{Reference}

1. "BWC Excel-R Windpower Generator Owner's Manual and Parts List," Bergey Windpower Company, Inc., 2001 Priestley Avenue, Norman, Oklahoma 73069. 1983. 


\subsection{NASA MOD-5B Wind Turbine System}

\subsubsection{History}

The MOD-5 program was originally conceived in 1980, and drew significantly on the MOD-0 and MOD-2 programs. It was funded by DOE and managed by the Wind Energy Project Office of the NASA Lewis Research Center. The machine was installed at Kahuku Village, Oahu, and was first operational in July 1987. Early in 1988, operation of the turbine was transferred to Hawaiian Electric Incorporated. Later operation of the turbine passed to Makani Uwila Power Corporation (MUPC) and the machine was kept in service intermittently until late in 1996. At that time, due to financial difficulties, the machine was shutdown along with the rest of MUPC, all property of which passed to the property owner, Campbell Estates. With no prospects for continued operation of the machine, Campbell estates decided to disassemble and scrap the machine. Prior to this decommissioning, DOE/NREL salvaged the drivetrain gearbox and generator in July 1998.

\subsubsection{Configuration}

The turbine consisted of a $97.5-\mathrm{m}$ (320-ft) diameter, two-bladed rotor, with welded-steel blades, incorporating partial span hydraulic pitch regulation, in which the outer 16.8 meters $(55 \mathrm{ft})$ of each blade could be controlled to limit rotor torque. Operation included an upwind teetered rotor, a hydraulically driven yaw system, and a 103:1 step-up planetary gearbox to drive a wound rotor generator. The nacelle set atop a welded 58.2-m $(191 \mathrm{ft})$ tubular tower, with a $61-\mathrm{m}(200-\mathrm{ft})$ hub height. Cut-in wind speed was $5.4 \mathrm{~m} / \mathrm{s}(12 \mathrm{mph})$, with cut-out at $27 \mathrm{~m} / \mathrm{s}(60 \mathrm{mph})$. Rotor rpm varied from 12.9 to 17.3 .

Power generation was accomplished with a four-pole, three-phase, $60-\mathrm{Hz}, 4160-\mathrm{V}$, wound rotor induction generator with secondary power recovery. The generator had a 3.5-MVA rating. Normal variable-speed operating ranges ran from 1330 to $1780 \mathrm{rpm}$. The generator had a dynamic speed range capability of 1250 to $1880 \mathrm{rpm}$, with a maximum survival speed of $2270 \mathrm{rpm}$.

Variable-speed and secondary power recovery was accomplished by a cycloconverter. This arrangement provided for AC-AC variable-speed operation. The rotor was allowed to vary in rpm within a limited range. The thyristor switches within the cycloconverter were programmed to provide vector control of the air gap field. The switches were provided with a reference waveform for each generator phase (the grid frequency). The result of this method was a very rough waveform for each of the rotor phases. Extensive filtering was necessary to produce an acceptable system output meeting IEEE-519 requirements. Introduction of IGBTs and other sophisticated high-power electronic switches allows for much-improved implementation of this technology.

\subsubsection{References}

1. "MOD-5B Wind Turbine System Final Report, Volume II, Detailed Report." NASA CR-180897, March 1988.

2. "MOD-5B Wind Turbine System Concept and Preliminary Design Report." NASA CR-168047, September 1982.

3. Spera, D.A., Miller, M.W.; "Performance of the 3.2 MW MOD-5B Horizontal Axis Wind Turbine During 55 Months of Commercial Operation in Hawaii." WindPower 92 Proceedings," American Wind Energy Association 1992.

\subsection{DOE/Sandia National Laboratories /U.S. Department of Agriculture 34 Meter, Vertical-Axis Variable-Speed Test Bed}

\subsubsection{History}

Design of the 34 meter vertical-axis wind turbine (VAWT) was begun in 1984 by Sandia engineering staff. Design required approximately two years. Ohio State University provided aerodynamics design support. Fabrication and assembly of components required approximately one year. The machine was installed at the USDA test site in Bushland, Texas, near Amarillo, and was dedicated in spring 1987. The machine included the 
first laminar flow, stall-regulated airfoils for wind turbines. At the time, the blades were the largest multivoid extruded-aluminum airfoils ever built. The machine remained in operation from 1987 until its final decommissioning in June 1998.

\subsubsection{Configuration}

The machine consisted of a 34-m (121-ft) diameter rotor with a height-to-diameter ratio of 1.25. The rotor top was $50 \mathrm{~m}(164-\mathrm{ft})$ above ground level. Rotor bottom was $7 \mathrm{~m}(23-\mathrm{ft})$ above ground level. The blades were $56 \mathrm{~m}(184 \mathrm{ft})$ in length, using a stepped tapered-blade design, and were stall regulated. The central aluminum support tube was $3-\mathrm{m}$ in diameter, $12.5-\mathrm{mm}$ of thick, and supported at its upper end by three pairs of $63-\mathrm{mm}$ steel bridge strand cables at an angle of 35 degrees to the ground. The rotor, which drove a $700-\mathrm{kW}$ transmission, was rated at $500 \mathrm{~kW}$ at $37.5 \mathrm{rpm}$ in a $12.5-\mathrm{m} / \mathrm{s}(28-\mathrm{mph})$ wind. The turbine ran in variable speed between 25 and $38 \mathrm{rpm}$.

Power generation was accomplished through a $625-\mathrm{kW}$-rated synchronous generator. The generator was capable of operating between $288 \mathrm{rpm}$ and $1900 \mathrm{rpm}$. Variable-speed operation was accomplished with a current source-load commutated inverter, also known as a DC current link frequency converter. This provided AC-DC-AC conversion.

\subsubsection{References}

1. Klimas, P.C., Dodd, H.M., Clark, R.N.; "An Overview of the DOE/Sandia/USDA Vertical Axis Wind Turbine Test Bed.” WindPower'87 Proceedings. American Wind Energy Association, 1987.

2. Ralph, Mark E.; "Control of the Variable Speed Generator on the Sandia 34-Metre Vertical Axis Wind Turbine.” WindPower'89 Proceedings. American Wind Energy Association, 1989.

3. Ralph, Mark E.; "A Model of the 34-M VAWT Variable Speed Generator Control System", Windpower '90 Proceedings. Wind Energy Symposium, American Society of Mechanical Engineers, 1990.

\subsection{The Enercon E-40 Variable-Speed Wind Turbine}

\subsubsection{History}

The Enercon Company of Aurich, Germany, has been fabricating and supplying industrial drive inverter systems in sizes from 0.5 to $500 \mathrm{~kW}$ since 1984. Depending on size and the time of introduction, they have incorporated MOSFETs, IGBTs, and GTOs as switches in their products. As an application of their power electronics drives, Enercon designed and began to fabricate wind turbines in 1984. The first turbine, the E-16, was a variable-speed, fixed-pitch, $16 \mathrm{~m}(52.5-\mathrm{ft}), 55 \mathrm{~kW}$ machine, of which 46 were installed. With the success of this model, in 1987 Enercon introduced the variable-speed, $18 \mathrm{~m}(59-\mathrm{ft}), 80 \mathrm{~kW} \mathrm{E-18.} \mathrm{About} 150$ of these turbines were sold before the end of production in 1993.

Research and development on the E-32/300 also began in 1987. This is a 32-m (105-ft), 300-kW machine having both variable speed and variable pitch. These units began to be installed in 1989. By 1993 over 180 machines had been installed some of which achieved capacity factors of $33 \%$ and annual energy capture of over a million kilowatt-hours $(\mathrm{kWh})$.

\subsubsection{Configuration}

While the E-32 continued the design of the previous smaller E series, Enercon initiated a parallel design effort in 1987 with a new variable-speed machine. This $36-\mathrm{m}$ (118-ft), $400 \mathrm{~kW}$ prototype (E-36) instituted a lowspeed generator, which connected directly to the three bladed wind turbine rotor. Testing of this prototype began in March 1992. Achieving reasonable power in the designed speed range of 15 to $37 \mathrm{rpm}$, required a ring generator of about $4 \mathrm{~m}(13-\mathrm{ft})$ diameter.

The E-40, which followed as an augmentation of the E-36, is a 40-m (131-ft), 500-kW variable-speed machine, using an 84-pole, salient-pole synchronous generator, which began to be marketed and installed in late 1993. 


\subsubsection{References}

1. IEA Wind Energy Annual Report for 1991. p. 55, NUTEK, Swedish National Board for Industrial and Technical Development, Allmänna Förlaget, Kundtjänst, S-106 47 Stockholm, Sweden. 1992

2. Haller, Mark; "A $500 \mathrm{~kW}$ Variable Speed Gearless Wind Turbine Generator for the American Market"; Windpower'94 Proceedings, American Wind Energy Association, 1994.

\subsection{The Gamma 60 Variable-Speed Wind Turbine}

\subsubsection{History}

In October 1986 ENEA (the Italian National Committee for Research and Development of Nuclear and Alternative Energies) signed a cooperative agreement with the Aeritalia-FIAT Aviazione for Wind Energy Consortium for the design and fabrication of a large, 60-m (197-ft), horizontal-axis wind turbine, rated at $1500 \mathrm{~kW}$. Funding was supplied from ENEA, the European Commission, and some other Italian organizations. The next March, ENEL (the Italian National Electricity Board) placed an order for the machine with Aeritalia, which acted as the prime contractor in the consortium. This prototype turbine was erected at the wind energy test site in the northwest corner of Sardinia. Prominent in the specifications was the requirement for broadrange variable speed (15 to $44 \mathrm{rpm}$ ), as well as teetering hub, fixed pitch, and power regulation through yaw control.

\subsubsection{Configuration}

The blade design was based on the WTS-4 blades made by Hamilton Standard. This allowed the same equipment to be used for the Gamma 60 machine. Some modifications, such as shortening the blades and installing an internal bulkhead-type rib (to reduce the centrifugal loads due to air pressure at high speeds), were agreed upon. The rotor was designed to withstand runaway speeds in case of loss of utility or generator.

The 1.5-m (4.9-ft) low-speed shaft disc brake was designed to be able to stop the machine from excessive speed or from some other emergency. The two-stage epicyclical gearbox has a gear ratio of 33:1.

A direct current link is used between the generator rectifier and the utility inverter because that type of frequency converter provides the required width of speed range, excellent torque control, and electric damping of structural modes.

The control algorithm chosen had the usual two operating regions. In the first, which is commonly called region two, the control system attempts to maintain rotor speed proportional to the existing wind and thereby hold a constant tip-speed ratio. The second region, commonly called region three, is where power starts to exceed the rating of the turbine, so that speed must be limited aerodynamically. In this case, this is done by yawing. Unusual, however, for the Gamma 60 , is another short region between the two already mentioned. In this region, the drivetrain torque limit has been reached; however, the generator and drivetrain power limit has not been reached. The control algorithm then allows the torque to decrease a small amount. The resulting rotor acceleration allows more power to be transferred until the generator power limit is reached. At this point, operation at the resulting higher-than-optimum tip-speed ratio is unimportant, because excess wind power is available anyway.

The power electronics is also capable of driving the generator as a motor. Accordingly, the gearbox was constructed to transmit torque in either direction.

\subsubsection{Reference}

1. IEA Wind Energy Annual Report for 1989, p. 48, NUTEK (Swedish National Board for Industrial and Technical Development). Allmänna Förlaget, Kundtjänst, S-106 47, Stockholm, Sweden, 1989.

2. IEA Wind Energy Annual Report for 1992, p. 85, NUTEK (Swedish National Board for Industrial and Technical Development). Allmänna Förlaget, Kundtjänst, S-106 47, Stockholm, Sweden, 1992. 


\subsubsection{History}

During 1987, EPRI conducted a feasibility study for an advanced variable-speed wind turbine design. In 1988, an industry consortium was formed (EPRI, Pacific Gas and Electric Company, and KENETECH) to proceed with the development of the proposed advanced turbine. In 1990, Niagara Mohawk Power Corporation joined this consortium. Between 1989 and 1993, this effort led to the introduction of the KVS-33 variable speed turbine. The first prototype turbines (then called the 33-300) were installed in 1989. Twenty-two preproduction prototype machines were installed in Altamont Pass, California, in 1991 . Between 1992 and 1996 approximately 700 turbines were produced and installed in locations as divergent as New York, Crowley Ridge, Canada, Buffalo Ridge, Minnesota, Guadalupe Pass, Texas, and Costa Rica. 1995 saw the installation of the first KVS-45 prototype turbine in west Texas. In 1996, KENETECH was forced to file for bankruptcy, placing the future development of the KVS-33 and related technologies in jeopardy.

\subsubsection{Configuration}

The KVS-33 is a three-bladed upwind system. The rotor is 33-m (108-ft) in diameter. Each blade is composed of laminated fiberglass using NASA LS-1 airfoils. The total rotor swept area is $855 \mathrm{~m}^{2}\left(9,200 \mathrm{ft}^{2}\right)$. Power regulation is via full-span pitch control, using linear hydraulic cylinders. The system is yaw driven, with a hydraulic motor, planetary gear system, and hydraulic damping. A parallel shaft, dual- output helical gearbox drives two squirrel-cage induction motors. The machine is designed to operate on truss or monotube towers in heights varying from $24-$ to $43-\mathrm{m}$ ( 80 to $140 \mathrm{ft})$. Cut-in wind speed is $4.05 \mathrm{~m} / \mathrm{s}(9 \mathrm{mph})$. Cut-out wind speed is $29.25 \mathrm{~m} / \mathrm{s}(65 \mathrm{mph})$.

The two, parallel, squirrel-cage induction generators are each rated at $150 \mathrm{~kW}$. During variable-speed operation, the generator outputs can run from 0 to $90 \mathrm{~Hz}$. Each generator feeds its own dedicated $250 \mathrm{kVA}$, three-phase $\mathrm{AC} / \mathrm{DC} / \mathrm{AC}$ electronics converter programmed for vector field control. These converters consist of solid-state switching using IGBTs to perform rectification and inversion, to produce $60 \mathrm{~Hz}$ utility output. Control of the switches is via a PWM algorithm. The equipment can be converted to $50 \mathrm{~Hz}$.

\subsubsection{References}

1. EPRI; "Power-Electronic, Variable-Speed Wind Turbine Development: 1988-1993, A Summary of the 33M-VS Wind Turbine Development Program Conducted by KENETECH. Windpower, Pacific Gas and Electric Company, Niagara Mohawk Power Corporation, and EPRI", EPRI Technical Report TR-104738, Projects 1590-16 and 3062-02, 1995.

\subsection{Nordic 400 Variable-Speed Wind Turbine}

\subsubsection{History}

In July 1990, the Swedish State Power Board decided to install two 400-kW wind turbines on Basteviksholmen, which is a small islet near the village of Lysekil on the west coast of Sweden. One turbine was to be a commercially available machine to serve as a baseline for comparison. The other was to be the prototype of a new design from a newly formed company called the Nordic Wind Power Company. The complete, twomachine project was named the Lyse Wind Power Station.

A Bonus 450-kW Mk 2 machine was chosen as the comparison machine and was installed during June 1992. Nordic Wind Power completed the design of the advanced prototype machine, the Nordic 400, in Autumn, 1991; it was installed in August 1992. Both machines were installed on a low, rocky ridge in the Bastseviksholmarna harbor. The perennial wind fetch from the open North Sea was similar for both machines, so performance comparison is fair. The turbines are operated from the utility control center 70 kilometers ( 43.5 miles) distant. 


\subsubsection{Configuration}

The Nordic 400 weighs 28 metric tons $(61,730 \mathrm{lbs})$, whereas the Bonus weighs 46 metric tons $(101,400 \mathrm{lbs})$. When parked, the Nordic teetered rotor presents less solidity to extreme winds than the three-bladed Bonus. The Bonus is a constant-speed machine, whereas the Nordic machine is a variable-speed, stall- controlled turbine with a $35-\mathrm{m}(115-\mathrm{ft})$ upwind rotor. The two teetering glass-fiber reinforced polyester blades have rotatable tips for emergency stopping. The range of variable-speed operation is from 20 to 39 revolutions per minute. Hub height is 40 meters $(131 \mathrm{ft})$.

The 400-kW induction generator is driven by a Flenders planetary 40:1 gearbox. The electric power is processed through an $\mathrm{ABB}$-designed $\mathrm{AC} / \mathrm{DC} / \mathrm{AC}$ line-commutated-type, power-processing converter for delivery to the local utility. During one 7000-hour test period, the Nordic turbine produced 805 megawatt-hours of energy.

\subsubsection{References}

1. IEA Wind Energy Annual Report for 1992. NUTEK, Swedish National Board for Industrial and Technical Development. Liljeholmsvagen 32, S-117 86, pp. 120 - 121, Stockholm, Sweden, 1992.

2. IEA Wind Energy Annual Report for 199. NUTEK, , Swedish National Board for Industrial and Technical Development, Liljeholmsvagen 32, S-117 86S-106 47 Stockholm, Sweden, p. 110, 1993.

3. IEA Wind Energy Annual Report for 1994. National Renewable Energy laboratory (NREL), 1617 Cole Boulevard, Golden, CO, 80401-3393, pp. 121, 124. USA, 1994.

4. IEA Wind Energy Annual Report for 1995. National Renewable Energy laboratory (NREL), 1617 Cole Boulevard, Golden, CO, 80401-3393, p. 130. USA, 1995.

\subsection{Advanced Wind Turbines AWT-26 Variable Speed with Doubly Fed Generator}

\subsubsection{History}

The AWT-26 variable-speed turbine is a modification of the AWT-26/27 configuration developed by Advanced Wind Turbines, Inc. The AWT-26 used the ESI-80, developed by Energy Sciences, Inc., of Boulder, Colorado, as a point of departure. Development of the AWT-26 began in 1990 under subcontract to the National Renewable Energy Laboratory. The first prototype machine was installed in Tehachapi, California, in February 1993. Additional prototypes were installed between 1993 and 1995, culminating in the modified AWT-27.

The AWT-26 variable speed turbine was originally installed at the NWTC in August 1994. In its initial configuration, this machine was a standard AWT-26 with a squirrel-cage induction generator and a $57 \mathrm{rpm}$ fixed-speed rotor. Beginning in summer 1996, this machine was converted for variable speed operation under a subcontract with Electronic Power Conditioning, Inc., with AWT as a lower-tier subcontractor. The machine conversion was accomplished by replacing the induction generator with a wound rotor generator and a power electronics package allowing variable-speed operations. At the conclusion of testing in 2000 the machine was converted back to fixed speed operation

\subsubsection{Configuration}

The NWTC AWT-26 is a two-bladed, downwind, free-yaw machine. It includes a $27-\mathrm{m}$ ( 88.5 -ft) teetered rotor. The blades are of wood composite design and incorporate SERI airfoils and passive stall control. Rotor control is provided by aerodynamic, electromechanically activated tip brakes. The machine includes a redundant mechanical brake incorporated into the drivetrain which includes a planetary gearbox manufactured by Flenders. The gearbox incorporates two stages at fixed, specified ratios between 25 and 35 to 1 . The ratio selected depends upon rotor diameter and the generator frequencies required. The machine is also provided with a small mechanical yaw drive for unwinding the droop cable. A PLC controller provides control of the machine. The nacelle sits atop a $24.4-\mathrm{m}(80-\mathrm{ft})$ tubular tower. 
Power conversion is accomplished using a $325-\mathrm{kVA}$, wound rotor generator. This unit operates at $480 \mathrm{~V}$ and a nominal $60 \mathrm{~Hz}$. This is a doubly fed unit, in which variable-speed operation is provided by connecting the rotor windings to a power electronic converter. Speed variation is accomplished by controlling the rotor winding currents. Power conversion is achieved using an electronics package incorporating both IGBTs and SCRs and a semi-resonant converter circuit that inherently soft switches.

\subsubsection{References}

1. Weigand, Claus H., Lauw, Dr. Hian K., Marckx, Dallas A.; "Utility-Scale Variable-Speed Wind Turbines Using a Doubly-Fed Generator With A Soft-Switching Power Converter.” WindPower'96 Proceedings, American Wind Energy Association, 1996.

2. Lynette, Robert; "Development of the WC-86 Advanced Wind Turbine." WindPower'92 Proceedings, American Wind Energy Association, 1996.

3. McCoy, Timothy J.; "Loads Measurements on the AWT-26 Prototype Wind Turbine." SED-Vol. 16, Wind Energy-1995, ASME, 1995.

\subsection{Northwind 100}

\subsubsection{History}

Design of the Northwind 100 began in early 1994 under a design subcontract between CERTEK and the National Renewable Energy Laboratory Next-Generation Innovative Subsystem project. The original design concept included a Permanent Magnet direct-drive generator. In 1996, due to the tragic death of the CERTEK principal (Ed Lucas), CERTEK withdrew from the project and Northern Power Systems (NPS) assumed responsibility for executing the subcontract. NPS extended their collaborative effort to include the NASA Ames Research Center and the National Science Foundation. This joint collaboration was focused on developing a high-reliability machine for remote and harsh environments. NPS was ideally suited to this effort due to their long history of providing equipment for deployment at the South Pole and other marine and coldweather environments. In 1998, the first of the NW 100 machines was deployed at a Vermont test site. Future plans include installation of a machine at the National Wind Technology Center for certification in preparation for applications in Alaska and Antarctica.

\subsubsection{Configuration}

The NW 100 is a $100-\mathrm{kW}$, three-bladed, upwind variable-speed machine. The unit is direct-drive. The generator is a wound-rotor, salient-pole synchronous alternator that was designed by the Westinghouse Electric Company. Aerodynamic power is supplied through a $16.6-\mathrm{m}(54-\mathrm{ft})$ stall-controlled rotor with blades provided by LM Glassfiber. Details of the variable-speed drive and control remain proprietary.

\subsubsection{Reference}

1. Migliore, Paul, Calvert, S.D.; "U.S. Department of Energy Wind Turbine Development Projects." NREL/CP-500-26151, April 1999. 


\subsection{The Vertical-Axis Variable-Speed EOLE at Cap Chat, Canada}

\subsubsection{History}

In the early 1980s, Hydro-Quebec and the National Resource Council of Canada began a joint venture to develop a large-scale Darrieus turbine (VAWT). In 1983 a preliminary design was completed. By the end of 1984, detailed design and fabrication subcontracts were awarded. Erection of the machine was finally complete by November 1986. Rotor fabrication was performed by Versatile Vickers shipyard in Montreal and shipped to the site by barge. The machine was sited near the village of Cap Chat, in Quebec Province, on the south shore of the St. Lawrence River. This site was chosen for its $8.5-\mathrm{m} / \mathrm{s}(18.9-\mathrm{mph})$ wind speed average at $60-\mathrm{m}$ (197-ft), which represents rotor mid-height.

First rotation and grid coupling occurred in July 1987. The machine was commissioned in August of the same year and became fully operational in March 1988. The machine operated regularly under operator supervision from 1988 until 1993, when it was shut down due to failure of the bottom bearing. During the five years of operation, the machine was run at power levels of up to $2.7 \mathrm{MW}$. During its lifetime it produced $12,740 \mathrm{MWh}$ in 18,600 hours of operation. Over this period it maintained an availability of approximately $94 \%$.

\subsubsection{Configuration}

The Eole machine was a vertical axis wind turbine 96-m (344-ft) in height. Its equatorial diameter was 64-m $(210-\mathrm{ft})$, with a swept area of $4000-\mathrm{m}^{2}\left(43,055-\mathrm{ft}^{2}\right)$. Two blades were employed in the design using NACA 0018 airfoils of $2.4-\mathrm{m}(7.9-\mathrm{ft})$ chord. The machine was designed as a direct-drive variable-speed machine. The generator was $12-\mathrm{m}(39.37-\mathrm{ft})$ in diameter and power conversion was achieved using a static- frequency converter with power factor controls. The rated speed was $14.25 \mathrm{rpm}$ with a maximum power output of 3.8 MW. Designed cut-in wind speed was $5.5 \mathrm{~m} / \mathrm{s}(12.2 \mathrm{mph})$ and cut-out wind speed was $20 \mathrm{~m} / \mathrm{s}(44.5 \mathrm{mph})$. However, these operational speeds and power output were not attained in operation due to structural resonances that were discovered during check-out. The final schedule that was selected combined variable-speed operation with constant-speed operation according to the average wind. For winds from 6.5 to $8 \mathrm{~m} / \mathrm{s}$ (14.5 to $17.8 \mathrm{mph}$ ), the machine ran in variable-speed mode from 7.9 to $9.8 \mathrm{rpm}$. For winds between 8 and $11.5 \mathrm{~m} / \mathrm{s}$ (17.8 to $25.6 \mathrm{mph})$ the power electronics governed the machine to a constant speed of $11.35 \mathrm{rpm}$. Similarly, above $11.5 \mathrm{~m} / \mathrm{s}$ $(25.6 \mathrm{mph})$ the machine was governed to a constant speed of $13.5 \mathrm{rpm}$. The machine did operate up to $13.5 \mathrm{rpm}$ with a cut-out wind speed of $17 \mathrm{~m} / \mathrm{s}(37.8 \mathrm{mph})$. Data acquisition systems were developed built upon VAWT software from Sandia National Laboratories.

\subsubsection{References}

1. IEA Wind Energy Annual Report for 1987. NUTEK, Swedish National Board for Industrial and Technical Development, p. 11, Allmänna Förlaget, Kundtjänst, S-106 47, Stockholm, Sweden, 1987.

2. IEA Wind Energy Annual Report for 199. NUTEK, Swedish National Board for Industrial and Technical Development, p. 31, Allmänna Förlaget, Kundtjänst, S-106 47, Stockholm, Sweden, 1993.

\subsection{The Danish Machine at Tvind}

\subsubsection{History}

In Spring 1975, a boarding school in the village of Tvind near Ulfborg in the Jutland region of Denmark decided to construct and install a large wind turbine. Some of the reasons for this were that the project would provide the students with practical experience to supplement their theoretical classes, the energy would be a hedge against the expected rise in heating oil prices, and the idea fit with the school's philosophy of decentralization. As this was early in the present era of wind turbine development, several ideas for the design of the machine were successively considered, found unsatisfactory, and dropped. For example, it had been intended initially to supply supplementary heat to the school buildings by circulating water heated from a windturbine-driven churn. A conventional generator with eddy current brake for heating water piped to the nacelle was also rejected. Next, a direct-coupled, 48-pole synchronous generator was being considered for electrical 
heating. However, at this point an eight-pole, 2200-kVA, synchronous generator and a 1200-kW gearbox became available at a reasonable price. Further consideration revealed that, although all the wind machine energy could be used for heating in the winter, in the summer there would be an energy surplus.

Eventually it was decided that some of this power should be sold to the electric utility. Direct synchronization of the eight-pole generator to the utility was not indicated for several reasons. For example, the 20-kilometer $(\mathrm{km})(12.3$-mile) utility distribution line was very weak. The transmission gear ratio was not optimal for the wind regime at synchronous speeds, and the turbine blades were limited to a narrow range of tip-speed ratios for dynamic reasons. Therefore, it was finally decided to connect to the electric utility through a frequency converter. This alleviated many of the above considerations, and would allow for variable-speed operation.

\subsubsection{Configuration}

As finally built, the Tvind School's machine was provided with a three-bladed, downwind rotor having a 54-m (177-ft) diameter. The blade material was glass-fiber-reinforced epoxy of 4700 kilograms $(10,364 \mathrm{lbs})$ mass per blade. The three-bladed rotor implied a rigid hub, which was at a height of 53-m (174 ft) on a concrete tower. Full-span pitch as well as the torque from the generator controlled the machine. The variable rotor speed ranged from 14 to $24 \mathrm{rpm}$.

Although the generator was capable of more, the machine was rated at 900-kW. In keeping with its original purpose of providing space heating for the school, output power could be switched either to a $1600-\mathrm{m}^{3}$ $\left(56,503-\mathrm{ft}^{3}\right)$ water reservoir or to classroom radiators. At the same time, some power was directed to a $400-\mathrm{kW}$ rectifier/inverter. For medium winds heating power was held constant, the frequency converter took up the remaining varying power.

The three-phase generator at rated power provided 3300 volts at the output, which was transformed down to 400 volts for the frequency converter. Six bridge-connected, solid-state thyristors rectified this power onto the constant current DC bus, which had inductors in both the positive and negative sides. This DC energy was inverted using six more thyristors under six-pulse phase control. This $50 \mathrm{~Hz}$ output was then transformed up to 10,000 volts for injection into the utility distribution line. Filters were installed between the inverter and the output transformer. Their two-fold purposes were to attenuate the fifth and seventh harmonics from the sixpulse inverter, and to supply some compensation for reactive power. This filter was able to provide $200 \mathrm{kVA}$ of reactive compensation. The frequency converter was designed and built by 12 students in a special course given by The Laboratory of Electric Circuits and Machines at The Technical University of Denmark.

In approximately 50,000 hours of operation, this machine supplied about 1,000 megawatt-hours of electric energy per year. By early 1993 the machine's rotor had accumulated over 53 million revolutions. In 1997 it celebrated its 20-year anniversary

\subsubsection{References}

1. Krabbe, Ulrik; The Electric Power Equipment for the Windmill in Tvind, pp. 25-33. In Implementing Agreement for Co-operation in the Development of Large Scale Wind Energy Conversion Systems: Second Meeting of Experts-Control of LS-WECS and Adaptation of Wind Electricity to the Network. Scientific coordination by R. Meggle and R. Windheim; Published by Zentralbibliothek der Kernforschungsanlage

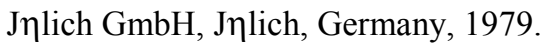

2. IEA Wind Energy Annual Report 1993, p. 36, NUTEK, Liljeholmsvgen 32, S-117 86, Stockholm, Sweden, 1993. 
Table 4.1. Summary of Features of Selected Variable-Speed Turbines

\begin{tabular}{|c|c|c|c|c|c|c|c|c|}
\hline \multicolumn{3}{|c|}{ Wind Turbine } & \multicolumn{3}{|c|}{ Generator Description } & \multicolumn{3}{|c|}{$\begin{array}{c}\text { Power Electronics } \\
\text { Modules }\end{array}$} \\
\hline Turbine Name & $\begin{array}{l}\text { Date of } \\
\text { First } \\
\text { Turning }\end{array}$ & $\begin{array}{c}\text { Variable- } \\
\text { Speed } \\
\text { Range } \\
\text { (rpm) }\end{array}$ & *Class & *Subclass & $\begin{array}{l}\text { Stator } \\
\text { Pole } \\
\text { Count }\end{array}$ & $\begin{array}{l}\text { Rectifier } \\
\mathrm{AC} \rightarrow \mathrm{DC}\end{array}$ & *Link Type & $\begin{array}{l}\text { Inverter } \\
\mathrm{DC} \rightarrow \mathrm{AC}\end{array}$ \\
\hline AWT-26 & $\begin{array}{c}\text { August } \\
1998\end{array}$ & 32 to 60 & Induc & WR & 4 & $\begin{array}{c}\text { Rotor } \\
\text { Terminal } \\
-20 \rightarrow+20 \\
\mathrm{~Hz} \\
\end{array}$ & Resonant & $\begin{array}{l}\text { Utility Output } \\
3 \phi, 480 \mathrm{v}, 60 \mathrm{~Hz} \\
\text { IGBT }\end{array}$ \\
\hline $\begin{array}{l}\text { Bergey } \\
\text { Excel }\end{array}$ & 1983 & 0 to 350 & Synch & PM & 38 & $\begin{array}{l}\text { Controlled } \\
\text { SCR } 3 \phi \\
\text { Bridge }\end{array}$ & $\begin{array}{c}\text { 300-v. DC } \\
\text { Voltage } \\
\text { Source }\end{array}$ & $\begin{array}{c}\text { Line } \\
\text { commutated } \\
1 \phi, 240 \mathrm{v} .\end{array}$ \\
\hline $\begin{array}{c}\text { Enercon } \\
\text { E-40 }\end{array}$ & 1993 & 15 to 37 & Synch & $\mathrm{DC}$ & 84 & $\begin{array}{c}\text { Not } \\
\text { Available }\end{array}$ & $\begin{array}{c}\text { Not } \\
\text { Available }\end{array}$ & $\begin{array}{c}\text { Not } \\
\text { Available }\end{array}$ \\
\hline $\begin{array}{c}\text { EOLE } \\
\text { Cap Chat }\end{array}$ & $\begin{array}{c}\text { July } \\
1987\end{array}$ & 7.9 to 13.5 & $\begin{array}{l}\text { Direct- } \\
\text { Drive } \\
\text { Synch }\end{array}$ & $\mathrm{DC}$ & (Large) & $\begin{array}{c}\text { Not } \\
\text { Available }\end{array}$ & $\begin{array}{c}\text { Not } \\
\text { Available }\end{array}$ & $\begin{array}{c}\text { Not } \\
\text { Available }\end{array}$ \\
\hline Gamma 60 & $6 / 03 / 92$ & 15 to 44 & Synch & $\mathrm{DC}$ & 12 & $\begin{array}{c}\text { Not } \\
\text { Available }\end{array}$ & $\mathrm{DC}$ & $3 \phi$ \\
\hline Growian & $\begin{array}{c}\text { Summer } \\
1983\end{array}$ & 15 to 21.3 & Induc & WR & & (na) & $\begin{array}{l}\text { Cyclo- } \\
\text { Converter }\end{array}$ & (na) \\
\hline $\begin{array}{c}\text { KENETECH } \\
\text { KVS-33 }\end{array}$ & $\begin{array}{l}\text { June } \\
1995\end{array}$ & $\begin{array}{c}\text { Not } \\
\text { Available }\end{array}$ & $\begin{array}{l}\text { Induc } \\
\text { (Two) }\end{array}$ & Cage & 4 & $\begin{array}{l}\text { PWM } \\
\text { IGBT }\end{array}$ & $\begin{array}{c}\text { DC } \\
\text { Voltage }\end{array}$ & $\begin{array}{l}\text { PWM } \\
\text { IGBT }\end{array}$ \\
\hline $\begin{array}{l}\text { Plum Brook } \\
\text { MOD-0 }\end{array}$ & $\begin{array}{c}\text { March } \\
1986\end{array}$ & 25 to 37.5 & Induc & WR20 & 4 & $\begin{array}{c}3 \phi \text { Diode } \\
\text { Bridge }\end{array}$ & $\begin{array}{c}\text { DC } \\
\text { Voltage }\end{array}$ & $\begin{array}{l}12 \text { pulse } \\
\text { Line comm. } \\
\text { SCR }\end{array}$ \\
\hline $\begin{array}{c}\text { DOE } \\
\text { Mod-5B }\end{array}$ & $\begin{array}{c}\text { July } \\
1987\end{array}$ & $\begin{array}{c}12.9 \text { to } \\
17.3\end{array}$ & Induc & WR & 4 & (na) & $\begin{array}{l}\text { Cyclo- } \\
\text { Converter }\end{array}$ & (na) \\
\hline Nordic 400 & $\begin{array}{c}\text { August } \\
1992\end{array}$ & 20 to 38 & Induc & WR & 4 & $\begin{array}{c}\text { Not } \\
\text { Available }\end{array}$ & $\mathrm{DC}$ & $\begin{array}{c}\text { Grid } \\
\text { Commutated }\end{array}$ \\
\hline $\begin{array}{c}\text { Northwind } \\
100\end{array}$ & 1998 & $\begin{array}{c}\text { Not } \\
\text { Available }\end{array}$ & Synch & WR & 4 & $\begin{array}{c}\text { Not } \\
\text { Available }\end{array}$ & $\begin{array}{c}\text { Not } \\
\text { Available }\end{array}$ & Line \\
\hline $\begin{array}{c}\text { Sandia } \\
\text { 34-m VAWT }\end{array}$ & $\begin{array}{c}\text { Spring } \\
1987\end{array}$ & 25 to 38 & Synch & WR & 4 & $\begin{array}{l}\text { 6-pulse } \\
\text { Line comm } \\
\text { SCR }\end{array}$ & $\begin{array}{c}\text { DC } \\
\text { Current }\end{array}$ & $\begin{array}{l}6 \text { pulse } \\
\text { Line comm. } \\
\text { SCR }\end{array}$ \\
\hline $\begin{array}{l}\text { Tvind } \\
54 \mathrm{M}\end{array}$ & 1977 & 14 to 24 & $\begin{array}{c}\text { Synch } \\
3 \mathrm{kV}\end{array}$ & WR & 8 & $\begin{array}{c}3 \phi \text { Diode } \\
\text { Bridge }\end{array}$ & $\begin{array}{c}\text { DC, } \\
\text { Current }\end{array}$ & $\begin{array}{l}\text { 6-pulse } \\
\text { Line comm. } \\
\text { Thyristor }\end{array}$ \\
\hline
\end{tabular}




\section{*GLOSSARY FOR TABLE 4.1}

\section{CLASS}

\section{Rotating Machine:}

Either an electric motor or an electric generator (or alternator). Usually, the same machine can function in either capacity.

Synch: A rotating machine employing a rotor carrying a source of constant magnetic field, either from permanent magnets or from a winding connected to a source of direct current. When such a machine is connected to a utility grid either as a motor or a generator, the ratio of the grid AC frequency to the machine rotational speed is at all times a constant independent of load.

Induc: An induction rotating machine. A rotating machine whose principle of operation depends on induced voltages caused by the relative motion between the spinning magnetic field in the air gap and conductors on the spinning mechanical rotor.

Comm: A rotating machine (either AC or DC) that transfers energy to or from the spinning rotor by means of a segmented commutator and brushes. This combination usually functions as a mechanical rectifier.

\section{SUBCLASS}

Cage: Cage or squirrel cage describes the construction of the rotor of the traditional induction machine. A cylinder of soft iron has bars of good conducting metals embedded in its surface and parallel to its axis of rotation. These bars are all electrically connected together by being welded to conducting rings at either end of the rotor cylinder. No external electrical connections are made to it.

WRnn: The wound rotor is an alternative to the more common cage rotor of induction rotating machines. The numerals (nn) that follow the WR designator (when present) give the maximum percent of the full load power of the induction machine, which must be handled by the associated power electronics.

DC: $\quad$ The traditional synchronous rotating machine has a rotor equipped with coils of wire wound on soft iron cores, and usually fed from slip rings. When these coils are supplied with direct current, they produce constant radial magnetic fields alternating in direction around the circumference of the rotor. The number of magnetic poles is made to be the same as the poles of the corresponding stator. The surface of the rotor may be either perfectly cylindrical (round rotor) or supporting radically projecting pole pieces called salient poles.

PM: To simplify the design of the traditional synchronous rotating machine, a system of Permanent Magnets can be substituted for the rotor field windings. The resulting generator starts to develop voltage as soon as the rotor starts to turn. Because the field strength is not adjustable, these machines cannot readily control reactive power flow.

\section{LINK TYPE}

DC, Voltage:

The voltage on the direct current bus for transferring energy from the generator rectifier to the inverter that feeds the utility is controlled to a constant value. It is characterized by the presence of a capacitor across the bus. The current in this link depends on demand.

\section{DC, Current:}

The current in the direct current bus for transferring energy from the generator rectifier to the inverter that feeds the utility is controlled to a constant value. It is characterized by the presence of an inductor in series with the bus. The voltage on the bus is not controlled. 


\section{Cycloconverter:}

See Figure PE-5 in section 6.2.4.

\section{Resonant:}

If the link between the electronics of the variable-speed source and the inverter that supplies the load is formed from appropriately connected inductors and capacitors, then current in the link is caused to consist of one or more sinusoidal oscillations. The advantage of this arrangement is that by proper timing, switching can occur at instants of zero voltage (ZVS) and/or zero current (ZCS) switching. (See section 3.6) 


\subsection{CONCLUSIONS: THE FUTURE OF VARIABLE SPEED}

After examining the long history of wind technology, it is clear that variable-speed operation is the norm, not the exception. In the new environment of grid-connected power, variable-speed operation has been implemented using a wide variety of power-conditioning technology. This report has documented many of the variable-speed approaches that have been successfully implemented. Yet even with this wide range of methods, no consensus has been reached on the best technology approach. Cost of energy remains the driving force in wind energy deployment. There is a constant trade-off between equipment capital costs and gains in efficiency. For variable speed to become universally adopted and a clear economic winner, the added cost of power electronics required by most variable-speed designs must be clearly offset by the added energy capture, reduction in loads and other systems costs, and the added benefit of providing power conditioning for utilities. As power electronics designs improve and costs of manufacture come down, the balance may tilt in the favor of variable speed; this technology could come to dominate the future of wind energy technology. 


\subsection{POWER CONVERSION DESIGN DETAILS}

\subsection{Generators}

As mentioned in section 3.0, this section repeats some of the electrical topics covered in the earlier body of the report from a quantitative and much more technical point of view. The generator diagrams show first the generator's internal connections followed by its equivalent electric circuit. The two blades of a symbolic wind turbine rotor are shown connected to the rotating part of each generator.

\subsubsection{The DC Generator}

Based on the magnetic field excitation produced by the stationary part (the stator), there are two types of DC generators used in wind turbines. One uses permanent magnets (PM) to generate the field and the other uses a field winding, as can be seen in Figure DC-1. The latter needs direct current power to generate the field flux. On the other hand, the permanent magnet does not consume power to generate field flux. Thus, for the same armature size, a PM generator is more efficient than a wound field generator. If the field winding is directly connected across the armature output terminals to obtain its power, it is called shunt excitation. If the field current is controlled separately from the armature voltage, it is called separately excited. Other types of excitation are not discussed in this report. The armature winding (rotor) carries the armature current that supplies the load. The power generated by the generator is transferred to its load from the armature winding via commutator and brushes. The power generated can be controlled by adjusting the field current of the generator.
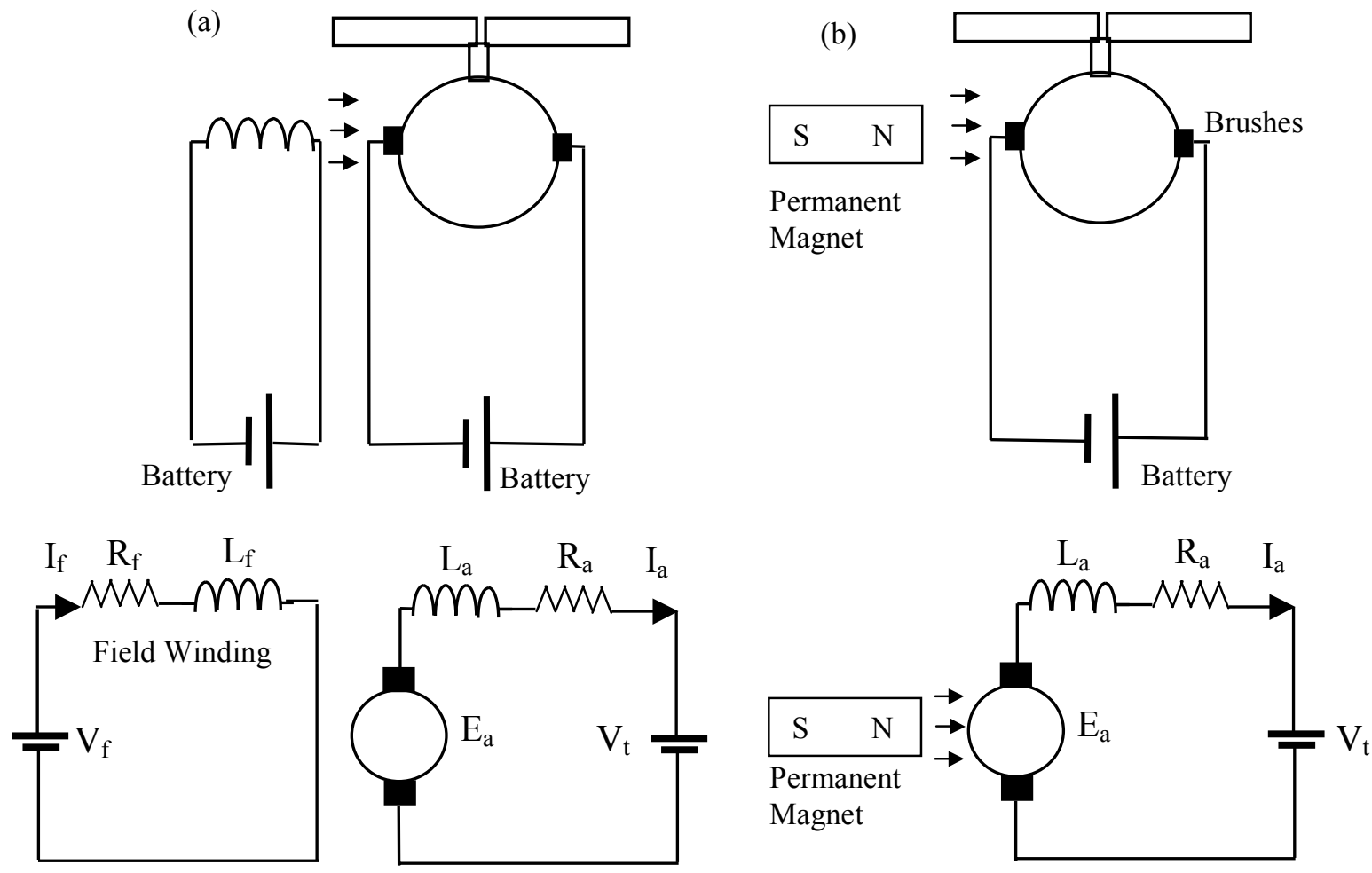

Figure DC-1. Physical diagrams and equivalent circuits of DC machines

(a) wound field excitation

(b) permanent magnet excitation 
The following are the steady-state equations that govern the DC generators in Figure DC-1. All quantities are real scalars with non time varying values. Thus, the inductive components can be ignored. Units for the three generator constants (the Ks) are determined by their equations. Their numerical values are governed by generator geometry and can be determined by measurement.

$\phi=\mathrm{K}_{\mathrm{f}} \mathrm{I}_{\mathrm{f}}$
$\mathrm{I}_{\mathrm{f}}=\mathrm{V}_{\mathrm{f}} / \mathrm{R}_{\mathrm{f}}$
$\mathrm{E}_{\mathrm{a}}=\mathrm{K}_{\mathrm{e}} \phi \omega_{\mathrm{r}}$
$\mathrm{E}_{\mathrm{a}}=\mathrm{V}_{\mathrm{t}}+\mathrm{I}_{\mathrm{a}} \mathrm{R}_{\mathrm{a}}$
$\mathrm{T}=\mathrm{K}_{\mathrm{T}} \phi \mathrm{I}_{\mathrm{a}}$
$\mathrm{P}_{\text {out }}=\mathrm{V}_{\mathrm{t}} \mathrm{I}_{\mathrm{a}}$

where

$\underline{\text { Units }}$

$\phi=$ magnetic field flux

Webers

$\mathrm{I}_{\mathrm{f}}=$ current of the field winding

A

$\mathrm{V}_{\mathrm{f}}=$ voltage across the field winding

$\mathrm{V}$

$\mathrm{R}_{\mathrm{f}}=$ field winding resistance

$\Omega$

$\mathrm{E}_{\mathrm{a}}=\mathrm{emf}$ generated in the armature

$\mathrm{V}$

$\omega_{\mathrm{r}}=$ angular speed of the armature

$\mathrm{rad} / \mathrm{sec}$

$\mathrm{V}_{\mathrm{t}}=$ terminal voltage of the armature winding

$\mathrm{V}$

$\mathrm{I}_{\mathrm{a}}=$ armature current

A

$\mathrm{R}_{\mathrm{a}}=$ armature resistance

$\Omega$

$\mathrm{T}=$ electrical torque

$\mathrm{Nm}$

$\mathrm{P}_{\text {out }}=$ output power

W

$\mathrm{K}_{\mathrm{T}}, \mathrm{K}_{\mathrm{e}}$, and $\mathrm{K}_{\mathrm{f}}=$ constants of the DC generator

For a wind turbine generator, the output power and driving torque required are desired variables. Equation (d5) shows that torque control can be accomplished via controlling flux $\phi$ (field current) or by controlling armature current $\left(\mathrm{I}_{\mathrm{a}}\right)$. With a constant voltage across the field winding, the field current is constant. Thus, a DC-DC converter or rheostat is needed to control the field current (flux). Fortunately, the power required in the field winding is generally very small for a good generator. The armature current can be controlled by setting the DC voltage across the armature winding. To control this power with a battery load, we would need to install a DCDC converter between the battery and the armature winding. A permanent-magnet generator can only be controlled by adjusting the armature current.

\subsubsection{The Synchronous Generator}

A synchronous machine usually consists of a stator holding a set of three-phase windings, which supplies the external load, and a rotor that provides a source of magnetic field. This may be supplied either from permanent magnets or from direct current flowing in a wound field. Examples of wound field synchronous generators can be found on several large wind turbines such as the MOD-0 series, and several Enercon turbines. Permanentmagnet synchronous generators are commonly found in small direct-drive wind turbines. Fixed-speed synchronous generators such as the early MOD series have very stiff characteristics, however, and may create unfavorable mechanical interaction with the wind turbine, thus affecting the gearbox, the main shaft torque, and bending moments. Variable-speed operation has remedied most of the drawbacks of the synchronous generator in fixed-frequency applications.

As stated in section 3.0, the synchronous generator rotational speed is locked to its stator frequency. The expression relating the rotational speed in revolutions per minute, the number of magnetic poles in the machine, and the electrical frequency in hertz can be expressed as:

$\mathrm{rpm}=120 \mathrm{x}$ frequency/poles 
Figure SM-1 shows two, three-phase, synchronous generators with their balanced utility loads together with the equivalent circuits for one of their phases. Note that the motor convention was used in assigning the positive direction for current. (The current arrow flows out at the utility symbol.)
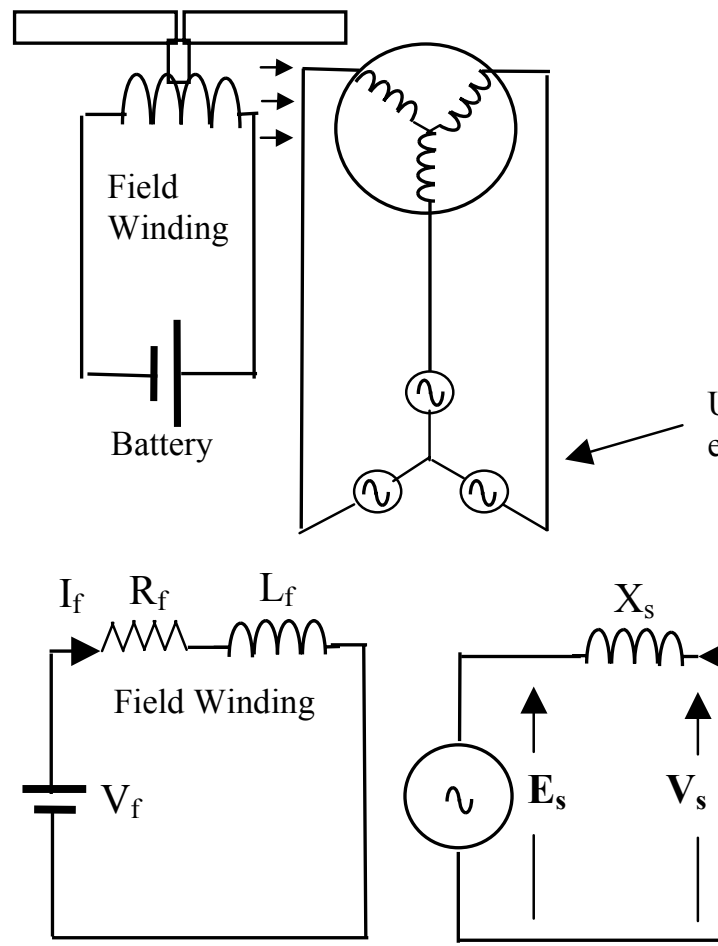

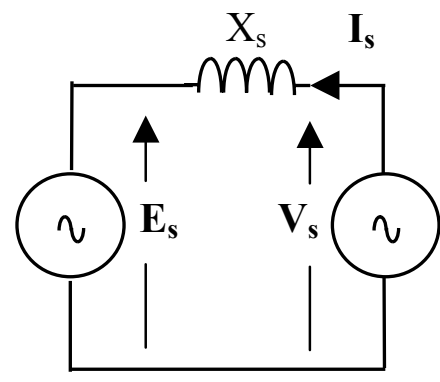

(a)
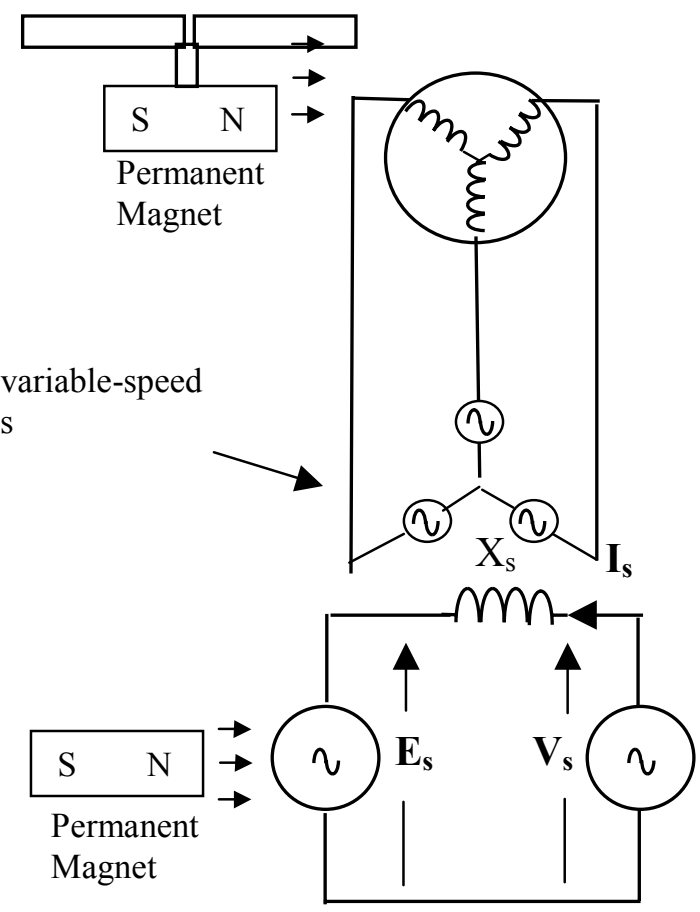

(b)

Figure SM-1. Physical diagram and equivalent circuits of a synchronous machine

(a) Wound field excitation

(b) Permanent magnet excitation

The equations presented below were derived under the assumptions that the machine was in steady state, that the machine model is linear over the range of the variables, and that the stator winding resistance is negligible compared to its reactance. Under the steady-state assumption, we will assume all non-constant electrical quantities vary sinusoidally in time. This allows us to employ phasors in the equations to represent them. Because phasors represent quantities that vary sinusoidally, they have both magnitude and phase. They can thus be conveniently represented by complex numbers and as such are depicted here by boldface symbols. The same symbol in normal font represents magnitude only. We will assume that their magnitudes are given as RMS (root-mean-square) values. The non-varying DC electrical quantities are, of course, a special case of RMS values.

[Note: Although it is nearly universal that a lower-case "i" is recognized by mathematicians as the symbol for the square root of minus one, electrical engineers use lower case "j" instead. (cf. Eq. s4)]

$$
\begin{aligned}
& \phi=\mathrm{K}_{\mathrm{f}} \mathrm{I}_{\mathrm{f}} \\
& \mathrm{I}_{\mathrm{f}}=\mathrm{V}_{\mathrm{f}} / \mathrm{R}_{\mathrm{f}} \\
& \mathrm{E}_{\mathrm{s}}=\mathrm{K}_{\mathrm{e}} \phi \omega \\
& \mathbf{E}_{\mathrm{s}}=\mathbf{V}_{\mathrm{s}}-\mathrm{j} \mathbf{I}_{\mathrm{s}} \mathrm{X}_{\mathrm{s}} \\
& \mathrm{P}_{\text {out }}=\left(3 \mathrm{E}_{\mathrm{s}} \mathrm{V}_{\mathrm{s}} / \mathrm{X}_{\mathrm{s}}\right) \sin \delta \\
& \mathrm{T}=\mathrm{P}_{\text {out }} / \omega_{\mathrm{r}}
\end{aligned}
$$


where:

$\phi=$ field flux linking the armature

$\mathrm{I}_{\mathrm{f}}=$ the current through the field winding

$\underline{\text { Units }}$

$V_{f}=$ the DC voltage across the field winding

webers

$\mathrm{R}_{\mathrm{f}}=$ the field winding resistance

A

$\mathrm{V}$

$\mathrm{E}_{\mathrm{s}}=$ internal emf generated in a phase

$\Omega$

$\omega_{\mathrm{r}}=$ rotor angular speed

$\mathrm{V}$

$\omega=(\mathrm{p} / 2) \omega_{\mathrm{r}}$, electrical angular frequency

(rotor radians $/ \mathrm{sec}$ )

(electrical radians $/ \mathrm{sec}$ )

hertz

$\mathrm{V}_{\mathrm{s}}=$ terminal voltage of the stator winding

$\mathrm{V}$

$\mathrm{I}_{\mathrm{s}}=$ stator current

A

$\mathrm{X}_{\mathrm{s}}=\omega \mathrm{L}_{\mathrm{s}}=$ inductive reactance of one phase of a stator winding

$\Omega$

$\delta=$ Phase angle of phasor $\mathbf{E}_{\mathbf{s}}$ with respect to phasor $\mathbf{V}_{\mathbf{s}}$

degree

$\mathrm{T}=$ electrical torque

$\mathrm{N}-\mathrm{m}$

$\mathrm{P}_{\text {out }}=$ output power

$\mathrm{W}$

$\mathrm{K}_{\mathrm{e}}, \mathrm{K}_{\mathrm{f}}=$ constants of the synchronous generator

Examination of two different applications of a synchronous machine will illustrate the information contained in a phasor plot of the voltage equation, $\mathbf{E}_{\mathbf{s}}=\mathbf{V}_{\mathrm{s}}-\mathrm{j} \mathbf{I}_{\mathrm{s}} \mathrm{X}_{\mathrm{s}}$ (Eq s4). The first application is that of an overexcited synchronous motor, which means that the machine converts electrical energy into mechanical energy. However, as the internal magnetic field is very strong, the machine is exporting VARs (volt amperes, reactive) back to the utility.

We will choose the motor terminal voltage, $\mathbf{V}_{\mathbf{s}}$, to be the reference and plot it along the real axis in the complex plane. Angles measured counter-clockwise are positive. The assumption that the machine is a motor implies that there must be a component of the load current in the same direction as (in phase with) the terminal voltage. The overexcited assumption means that the other component of the current, which is normal to the voltage, must lead this voltage. Note as shown in Figure SM-2a, the load is drawing a current that is leading the voltage by about $\theta=30^{\circ}$. As we are assuming the internal impedance of the motor is purely inductive, the voltage drop across it will lead the current through it by exactly $90^{\circ}$. The magnitude of this voltage drop (as a sort of Ohms Law for reactances) is equal to $X_{s} I_{s}$. Prefixing (multiplying by) $j=\operatorname{sqrt}(-1)$ rotates this voltage drop from the direction of the current, $\mathbf{I}$, to a phase angle that is $90^{\circ}$ advanced.

Our original voltage equation implies that the sum of the internal emf, $\mathbf{E}_{\mathbf{s}}$, and the voltage drop across the internal impedance, equals the terminal voltage, $\mathbf{V}_{\mathbf{s}}$. The two voltage phasors do indeed add vectorially to equal the terminal voltage, and the internal voltage drop does lead its current by a right angle. Thus, the phasor diagram conforms to the given equations.

\section{$\mathbf{I}_{\mathrm{S}}$}

Figure SM-2a. Overexcited Synchronous

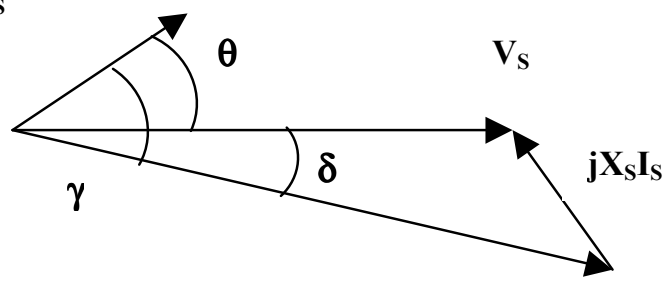

Motor Phasor Diagram 
The voltage equation just employed is most convenient for constant-frequency applications. However, if the equation is divided by omega, the system electrical angular frequency, the following equation, which is convenient for variable-speed applications, results:

$$
\mathrm{K}_{\mathrm{e}} \phi=\mathbf{V}_{\mathrm{s}} / \omega-\mathrm{j} \mathbf{I}_{\mathrm{s}} \mathrm{L}_{\mathrm{s}}
$$

Because only the magnitudes and not the phase of the terms were affected, the phasor representation of this equation shown below has the same shape as the preceding diagram. Figure SM-2b illustrates that if the $\mathbf{V}_{\mathbf{s}} / \omega$ term-the so called "volts per hertz" ratio-is held constant, the relative phases of the voltages will remain constant.

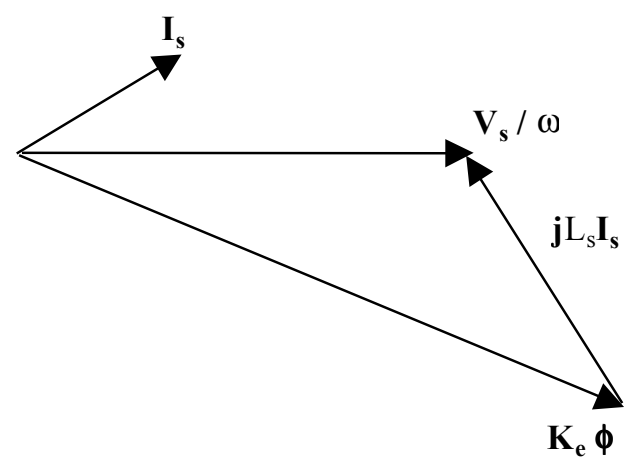

\section{Figure SM-2b. Synchronous Motor Phasor Diagram for Variable Speed}

The second example of a phasor diagram is that of an underexcited generator. Conceptually, it is possible to imagine that the field excitation of the previously described motor is gradually reduced to under-excitation, and at the same time, the retarding mechanical load on its driveshaft changed from retarding torque to a driving torque in the same direction of rotation. That is, if the motor load were changed into an energy source, we would find that the phasor diagram of Figure SM-2a (above) would smoothly transform itself into the following diagram:

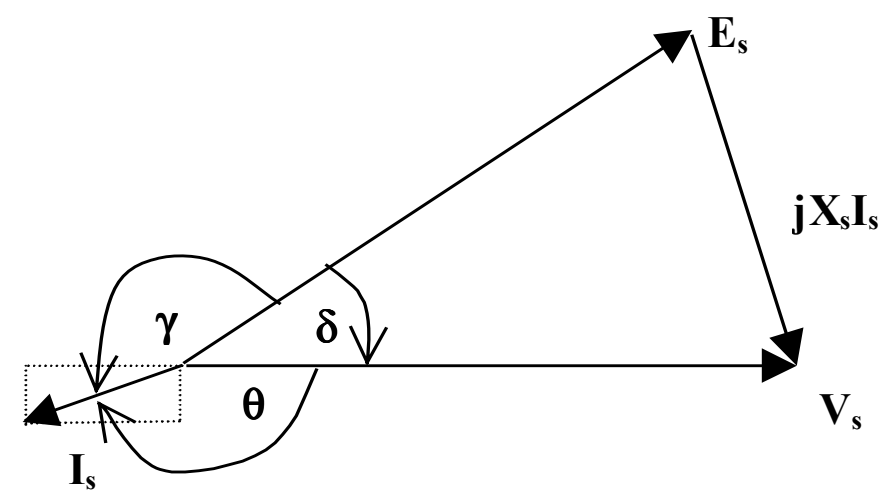

Figure SM-2c. Underexcited Generator Puasor Diagram 
As before, the internal emf, $\mathbf{E}_{\mathbf{s}}$, and the internal voltage drop across the generator impedance, $\mathbf{j} \mathbf{X}_{\mathbf{s}} \mathbf{I}_{\mathbf{s}}$, add to equal the applied voltage from the utility, $\mathbf{V}_{\mathbf{s}}$. However, now the component of the current phasor parallel to the applied voltage (dotted horizontal line) is in the opposite direction. This means that energy is now flowing in the opposite direction. Namely, mechanical energy from the generator shaft is flowing into the utility lines. The VAR component of current which is at right angles to the applied voltage (short vertical dotted line) now lags that voltage by $90^{\circ}$ thus showing that this machine is drawing lagging current or is consuming VAR's from the utility. These two components make up the current phasor, $\mathbf{I}_{\mathbf{s}}$. Note also that, because the direction of the applied torque has reversed, the torque angle, $\delta$, has crossed over the applied voltage and $\mathbf{E}_{\mathbf{s}}$ now leads it.

As in the motor example, the variable-speed phasor diagram in Figure SM-2d retains the same phase angle relations as long as the "volts per hertz" ratio is unchanged.

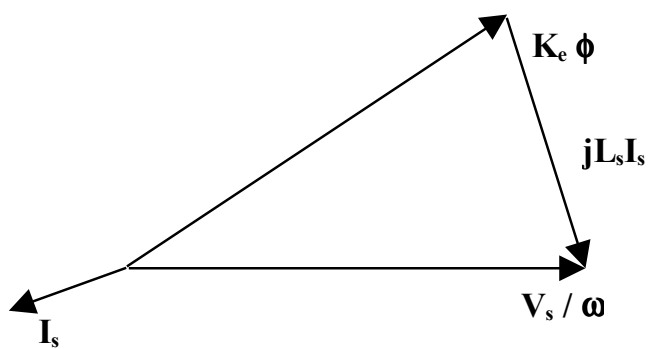

Figure SM-2d. Underexcited Generator Phasor Diagram for Variable Speed

The previous two examples can be seen to be special cases from the plot in the complex plane in Figure SM-3. If the applied voltage phasors $\left(\mathbf{V}_{\mathbf{s}}\right)$ in the previous examples were plotted along the real axis below, the current of the motor example would fall in the first quadrant, and the current from the generator example would fall in the third quadrant. We would expect that weakening the field strength of the motor would move its current phasor into the fourth quadrant, while increasing the generator field strength would move its current phasor into the second quadrant.

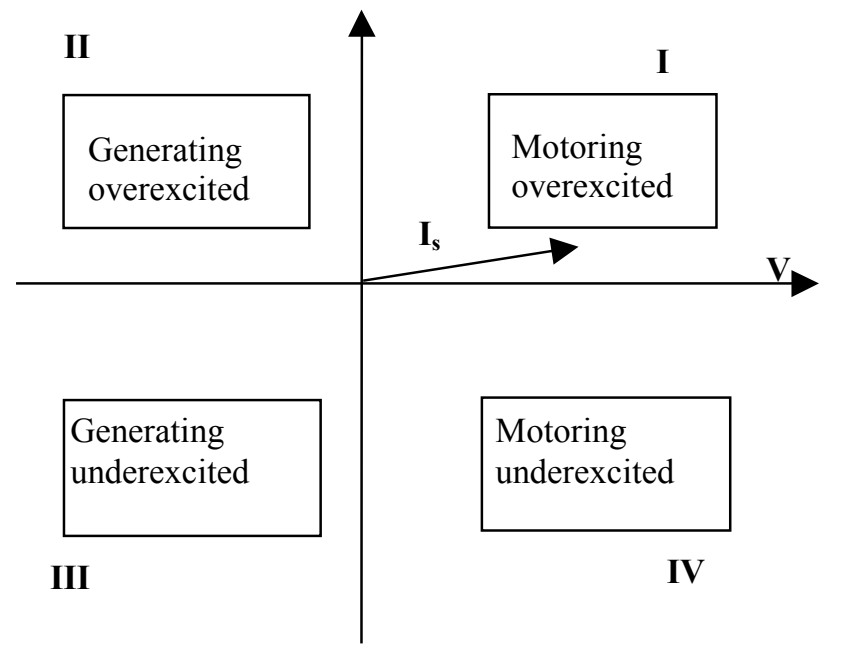

The phasor of the stator current determines the operation of the synchronous machine.

- In the first quadrant, the synchronous machine operates as an over-excited synchronous motor.

- In the second quadrant, the synchronous machine operates as an over-excited synchronous generator.

- In the third quadrant, the synchronous machine operates as an under-excited synchronous generator

- In the fourth quadrant, the synchronous machine operates as an under-excited synchronous motor

Figure SM-3. Phasor diagram of the stator current of a synchronous machine in different operational modes. 


\subsubsection{Four Quadrant Drives}

When a power electronics adjustable speed drive (ASD) is specified as being a four-quadrant drive, it can handle all of the above four cases. Thus, such a drive could drive a wind machine as a large fan or accept its energy as a wind generator while simultaneously and independently controlling reactive power flow.

By continuing the same simplifying assumptions about linearity and neglecting stator losses, we can write machine torque in terms of new variables. From (s5) and (s6):

$$
\mathrm{T}=\left(3 \mathrm{E}_{\mathrm{s}} \mathrm{V}_{\mathrm{s}} / \mathrm{X}_{\mathrm{s}}\right) / \omega_{\mathrm{r}} \sin \delta
$$

Using the expression for internal emf (s3) and the relation between electrical and mechanical angular speed, one can write:

$$
\mathrm{T}=\left[\mathrm{K}_{\mathrm{T}} \phi\left(\mathrm{V}_{\mathrm{s}} / \omega\right) / \mathrm{L}_{\mathrm{s}}\right] \sin \delta
$$

where:

$\omega_{\mathrm{r}}=$ rotor angular frequency in mechanical $\mathrm{rad} / \mathrm{sec}$

$\mathrm{K}_{\mathrm{T}}=3 \mathrm{~K}_{\mathrm{e}} \mathrm{p} / 2$

$\mathrm{p}=$ number of generator poles

This expression is useful in that generator driving torque under variable-speed conditions will be constant if its "volts per hertz" is held constant—other things being equal.

It also shows that the generator power angle, $\delta$, depends on torque applied. This is illustrated in Figure SM-4. Note that, as the torque changes continuously from driving torque through zero to retarding torque, the torque angle changes smoothly and monotonically from negative $90^{\circ}$ to positive $90^{\circ}$ In addition, outside of this range, the magnitude of the torque decreases so that if mechanical torque either increases or decreases beyond this range of torque angle, the generator or motor becomes unstable, will pull out of synchronism, and either accelerate to probable destruction or stall, respectively.

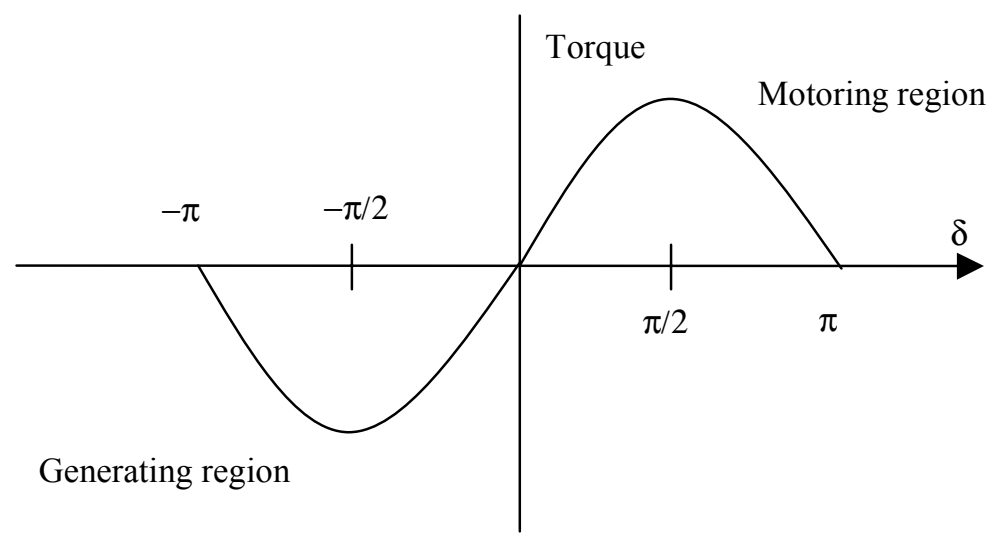

\section{Figure SM-4. Torque characteristic of a synchronous machine as a function of the power angle $\delta$}

The torque equation can be rewritten in another way:

$$
\mathrm{T}=\left(3 \mathrm{E}_{\mathrm{s}} \mathrm{I}_{\mathrm{s}} / \omega_{\mathrm{r}}\right) \cos \gamma
$$

where $\gamma$ is the phase angle of the load current with respect to the internal emf phasor.

$$
=\mathrm{K}_{\mathrm{T}} \phi \mathrm{I}_{\mathrm{s}} \cos \gamma
$$


Equation (s9) can be used to control the torque speed characteristic of the generator when it is connected to a voltage source inverter. Equation (s11) can be used to control the torque speed characteristics of the generator when it is connected to a current source inverter. In general, control of a synchronous generator requires position and speed sensors. The position sensor is required to adjust the angle between the voltage or current and the main flux.

In some applications, a synchronous generator can have unique characteristics:

- For a permanent magnet generator, $\mathrm{K}_{\mathrm{e}} \phi$ is constant, while in a wound-field, synchronous generator it is adjustable up to its rated value.

- For a utility-connected synchronous generator, $\mathbf{V}_{\mathbf{s}} / \boldsymbol{\omega}$ is constant.

- For a synchronous generator connected to a diode bridge rectifier, the load presented is a resistive load (unity power factor). $\theta=180^{\circ}$

- For a synchronous generator operated as a synchronous condenser, the terminal voltage $\mathbf{V}_{\mathbf{s}}$ and stator current $\mathbf{I}_{\mathbf{S}}$ will be in quadrature (zero power factor). $\theta=-90^{\circ}$

- For a synchronous generator connected to a phase-controlled rectifier, the load presented will have an inductive component $(\mathbf{Z}=\mathrm{R}+\mathrm{j} \omega \mathrm{L})$.

\subsubsection{Adjustable Speed Drive (ASD) Terminology}

Voltage Source: An energy source in an electric circuit is called a voltage source if it can hold its designated terminal voltage irrespective of the current being drawn from or fed to it. Approximations to perfect voltage sources are storage batteries for DC, or a utility connection for AC. For short periods of time in practical circuits, a charged capacitor approximates a voltage source.

Current Source: An energy source in an electric circuit is called a current source if it continues to supply its designated current to that circuit irrespective of the voltage across its terminals. There are no simple examples of isolatable current sources, although the high-voltage Van de Graf electrostatic generator behaves approximately as a current source. In practical circuits, the "electric current inertial effect" of an inductance approximates a current source for a short time.

Current Source Mode: Most variable-speed operation is in the current source mode. The equation (s11) is used to control the torque-speed characteristics. Both the magnitude of current $\mathrm{I}_{\mathrm{s}}$ and the angle $\gamma$ can be controlled. For a wound-field generator, the field flux can also be used as a control variable. This control variable is normally used in the flux-weakening region (high rpm). Different current source inverters (load commutated inverters $[\mathrm{LCI}]$ or current-regulated pulse-width modulation [CRPWM]) can be used to achieve the same goals.

Voltage Source Mode: Most voltage source inverters operate on a volt $/ \mathrm{Hz}\left(\mathrm{V}_{\mathrm{s}} / \omega\right)$ basis. With a voltage source inverter, the PM synchronous generator can be controlled by adjusting the angle $\delta$. If the volt/Hz ratio can be adjusted, then it can be used as an additional control variable. For a wound-field generator, the field flux can also be used as a control variable. This control variable is normally used in the flux- weakening region (high rpm). Different voltage source inverters (square-wave VSI or PWM VSI) can be used to achieve the same goals.

Battery-charging Mode: A diode bridge rectifier can be used to connect the synchronous generator to a battery. The terminal voltage is clamped to the battery voltage; thus, the volt/Hz ratio changes as the frequency changes in inverse proportion to the frequency. The battery load and the diode bridge are presented to the generator as a unity power factor load. The charging-current or the torque-speed characteristic of the synchronous generator can be controlled by adjusting the field current or the armature current. For a PM synchronous generator, the field current cannot be controlled. The characteristic can be changed if the volt $/ \mathrm{Hz}$ can be controlled. This can be accomplished by inserting the DC-DC converter between the battery and the rectifier. 


\subsubsection{Induction Generator}

Currently, the most commonly used generator in wind turbines is the induction generator. Several reasons for using induction generators are:

- $\quad$ Low cost

- Ruggedness

- Operates with slip (i.e., with some speed elasticity)

- $\quad$ Readily available in the market in many sizes

- Mature technology

There are two kinds of induction generators used in wind turbines, squirrel cage and wound rotor. Presently, about $90 \%$ of utility-grid-connected wind turbines use squirrel-cage induction generators. The rotor is made of soft iron with shorted rotor bars of copper or aluminum. They do not need slip rings like a synchronous or wound rotor induction generator.

The physical diagrams of a squirrel-cage induction machine (SCIM) and a wound rotor induction machine (WRIM) are presented in Figure IM-1. The squirrel-cage induction machine has a shorted rotor; therefore, the rotor current is not accessible. Although physically there is no electrical connection between the rotor and stator; the electrical characteristics of the rotor are affected by the stator through magnetic coupling.

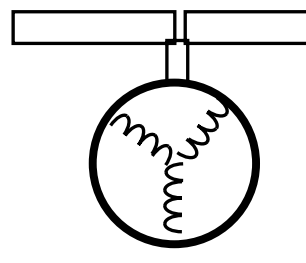

Rotor winding shorted for squirrel-cage IM

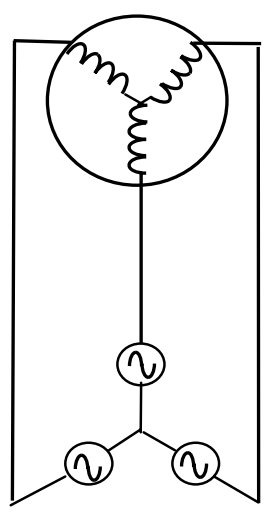

(a)

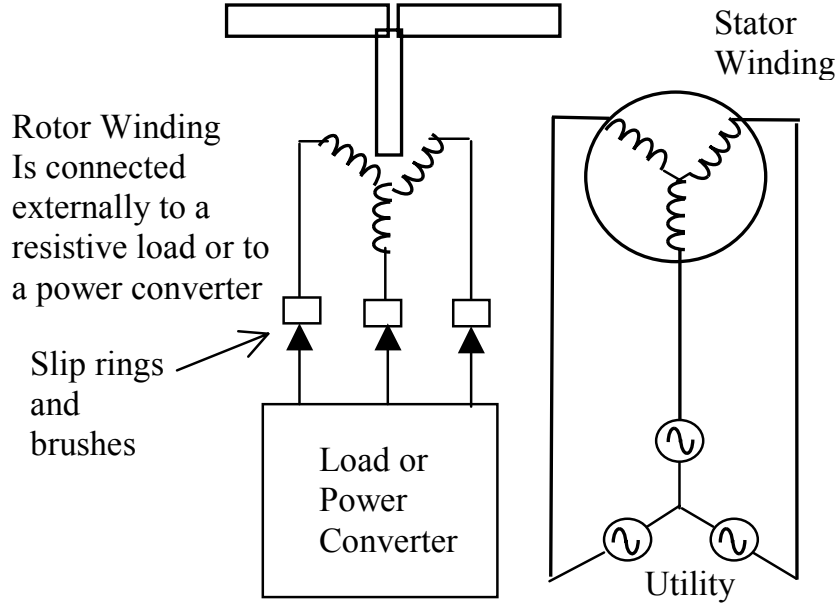

(b)

Figure IM-1. Physical diagram of induction generator in WTG applications

(a) Squirrel-cage induction machine

(b) Wound rotor induction machine

With a wound rotor induction machine, the rotor is normally constructed as a three-phase winding with the same number of poles as the stator. Three-phase slip rings (and brushes) are used to allow control of the rotor current. A resistive load or a bi-directional power converter can be connected to the rotor winding through these three-phase slip rings.

\subsubsection{Squirrel-Cage Induction Machine}

Figure IM-2 shows the torque-speed characteristic of an induction machine in the motoring and in the generating region. The National Electrical Manufacturer's Association (NEMA) has established a terminology for four classes of induction machines, Types A, B, C, and D. In most applications, type B induction machines (shown in solid line) are used because they give a good starting torque and good efficiency and power factor at rated output. Type D (shown in dashed line) is used when high starting torque is required. Type D has a higher rotor resistance. 


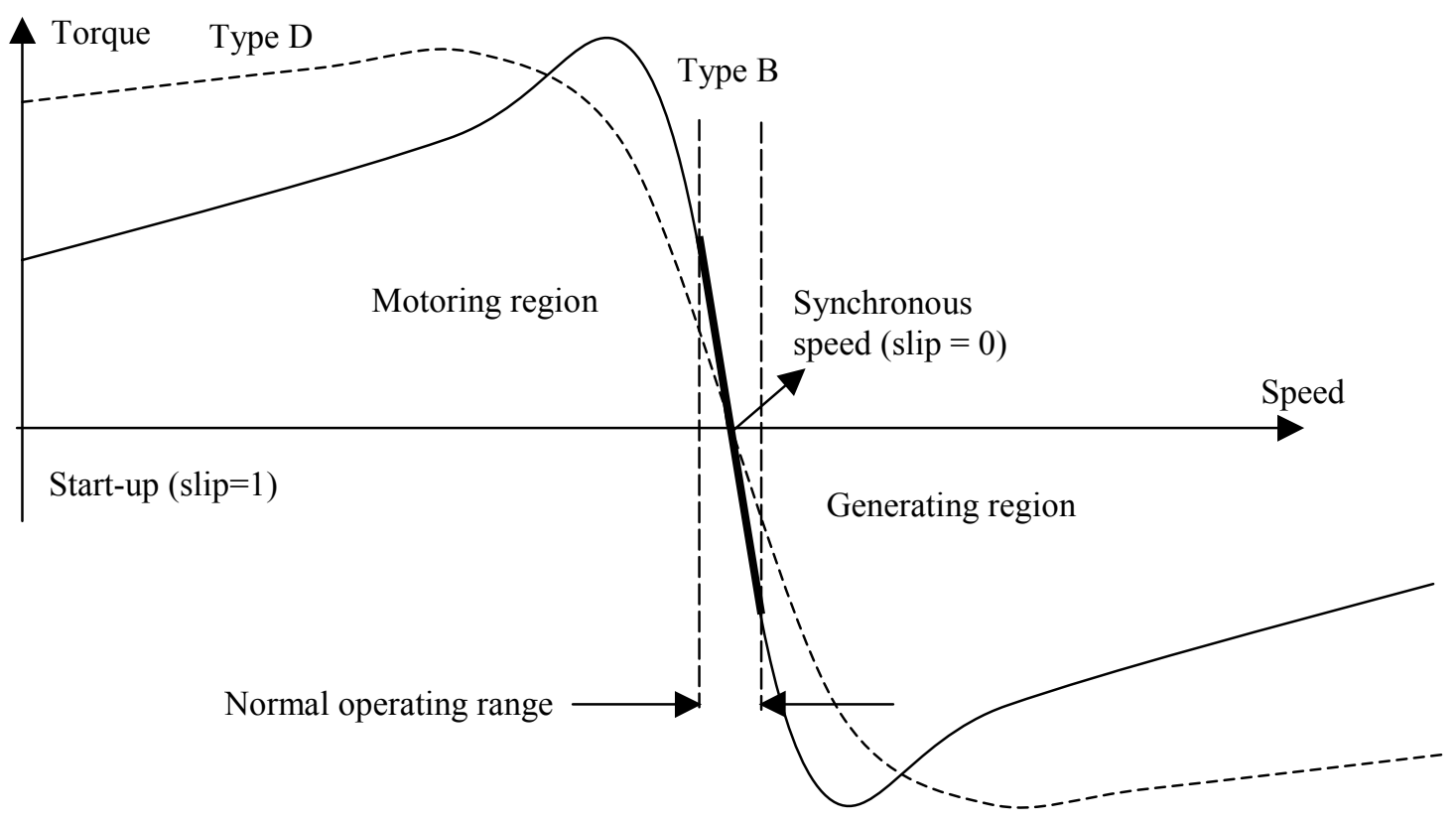

Figure IM-2. Torque-speed characteristic of an induction machine at fixed frequency for two different types of machines.

Typically, the operating region of an induction machine is below $50 \%$ of the peak torque. Thus, the operating slip of an induction machine is low (slip $<2 \%$ ). Although the operating slip is very low, the induction generator used in wind turbines has the advantage of giving more compliance than a synchronous generator.

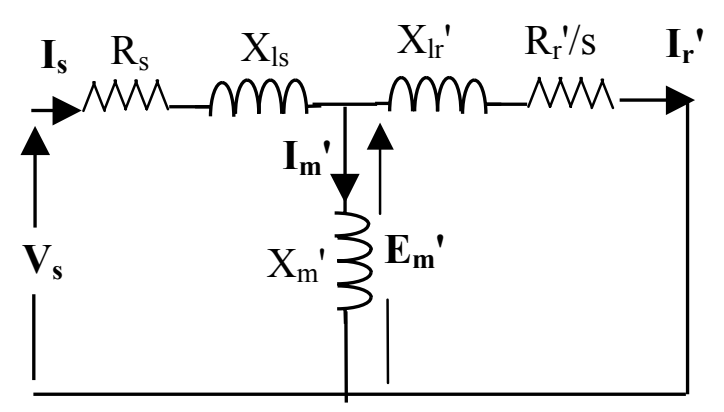

(a) Constant Frequency

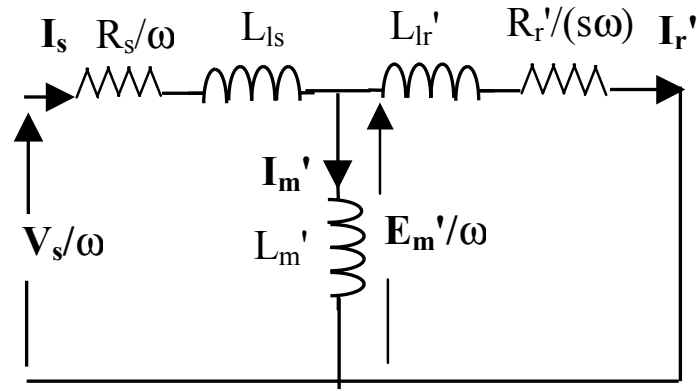

(b) Variable Frequency

Figure IM-3. Equivalent circuit of a squirrel-cage induction generator.

\subsection{Constant-frequency operation}

The equivalent circuit of a squirrel-cage induction generator is shown in Figure IM-3. The parameters of an SCIM consist of stator resistance $\mathrm{R}_{\mathrm{s}}$, stator leakage reactance $\mathrm{X}_{\mathrm{ls}}$, rotor leakage reactance $\mathrm{X}_{\mathrm{lr}}{ }^{\prime}$, rotor resistance $R_{r}^{\prime}$, and magnetizing reactance $X_{m}{ }^{\prime}$. The primed-sign signifies that the equivalent circuit is referenced to the stator side. Thus, the primed-parameter and primed-variable are referenced values and not the actual values. Ideally, the resistances and the leakage reactances are zero and the magnetizing inductance is infinite. In reality, the magnetizing inductance is about 20-50 times the leakage inductance. 
During start-up, the slip is one and the rotor circuit branch presents a much lower impedance (almost short circuit) than the magnetizing branch. The starting current is about 5 to 8 times rated current. Although the rotor current is large, the magnetizing current is small. As the rotor speed increases, the slip decreases. The total impedance of the induction machine increases; thus, the stator current decreases, and the magnetizing current and the torque increases as shown in the torque-speed characteristic. The slip at which the peak torque occurs is approximately:

$$
\text { Slip_peak }=\frac{R_{r}^{\prime}}{\sqrt{R_{s}^{2}+\left(X_{l s}+X_{l r}^{\prime}\right)^{2}}}
$$

From the equation above, the peak-torque slip can be increased by using a higher rotor resistance (design D).

\subsection{Variable-frequency operation with voltage source mode}

The application of variable-frequency operation in motor drives is very common. In variable-frequency operation, the common arrangement is to use one power converter connected to the generator to control its characteristics. Another power converter is used to transfer the power generated by a wind turbine to the utility. Between the two power converters, a DC bus or resonant tank (link) is used. It is preferable that the power converters be bi-directional to enable operation as a motor during start-up of the wind turbine. The induction machine used is the SCIM, although a WRIM can also be used. To analyze an SCIM in variable-speed mode, the equivalent circuit shown in Figure IM-3a is redrawn and is shown in Figure IM-3b. The voltage source and the parameters of the induction generator are divided by the electrical angular frequency $\omega$. The variablefrequency equivalent circuit is very similar to the equivalent circuit at a constant frequency (Figure IM-3a), except the voltage is replaced by the $\mathrm{V}_{\mathrm{s}} / \omega$, the reactance is replaced by the inductance, and the slip is replaced by the slip-frequency $(\mathrm{s} \omega)$. Figure IM-4 shows the torque-speed characteristics of an SCIM connected to a variable-frequency source at constant volt $/ \mathrm{Hz}$. An example of a variable-speed SCIM for a wind turbine is shown in Figure UI-1 (Section 6.3). The characteristics of an induction machine in variable speed are similar to the constant-frequency operation of an induction machine when connected to a constant $\mathrm{V}_{\mathrm{s}} / \omega$ source. At high frequencies, the $\omega$ is large enough that the $R_{s} / \omega$ is negligible. Thus, the torque-speed characteristics can be drawn as a set of curves shifted with frequency. In the lower-frequency region, $R_{s} / \omega$ cannot be neglected because its size increases as $\omega$ decreases. If the $\mathrm{V}_{\mathrm{s}} / \omega$ is constant, the torque-speed characteristics of the induction machine shrink (refer to curve $T_{1}, f_{1}$ in Figure IM-4). Many drives operate with constant $V_{s} / \omega$, which is commonly called constant volt/hertz. However, in the lower-frequency region, $\mathrm{V}_{\mathrm{s}} / \omega$ is boosted a little to compensate for changes in $\mathrm{R}_{s} / \omega$.

From the torque-speed characteristics shown in Figure IM-4, an SCIM can be operated as a generator at any speed by controlling the frequency and keeping $\mathrm{V}_{\mathrm{s}} / \omega$ constant. At higher frequencies, there is a limit when the power converter cannot further increase the voltage $\mathrm{V}_{\mathrm{s}}$. If the operation is to be continued by increasing the frequency at constant voltage, the $\mathrm{V}_{\mathrm{s}} / \omega$ (volt/hertz) must be reduced. This is called the flux-weakening region. As a result, the torque speed characteristics are reduced as the frequency increases. In this region, a constant $\mathrm{kVA}$ operation is generally maintained.

Using an off-the-shelf voltage source inverter with constant volts/hertz ratio, an induction generator can be controlled in a simple way. For example, given the wind turbine torque-speed characteristic $\left(\mathrm{T}_{\text {wind }}\right.$ turbine $)$ the frequency at operating points $T_{1}, T_{2}, T_{3}$, and $T_{4}$ can be pre-computed. A map of frequency versus speed can be pre-programmed and the variable speed can be controlled with this pre-programmed path. 


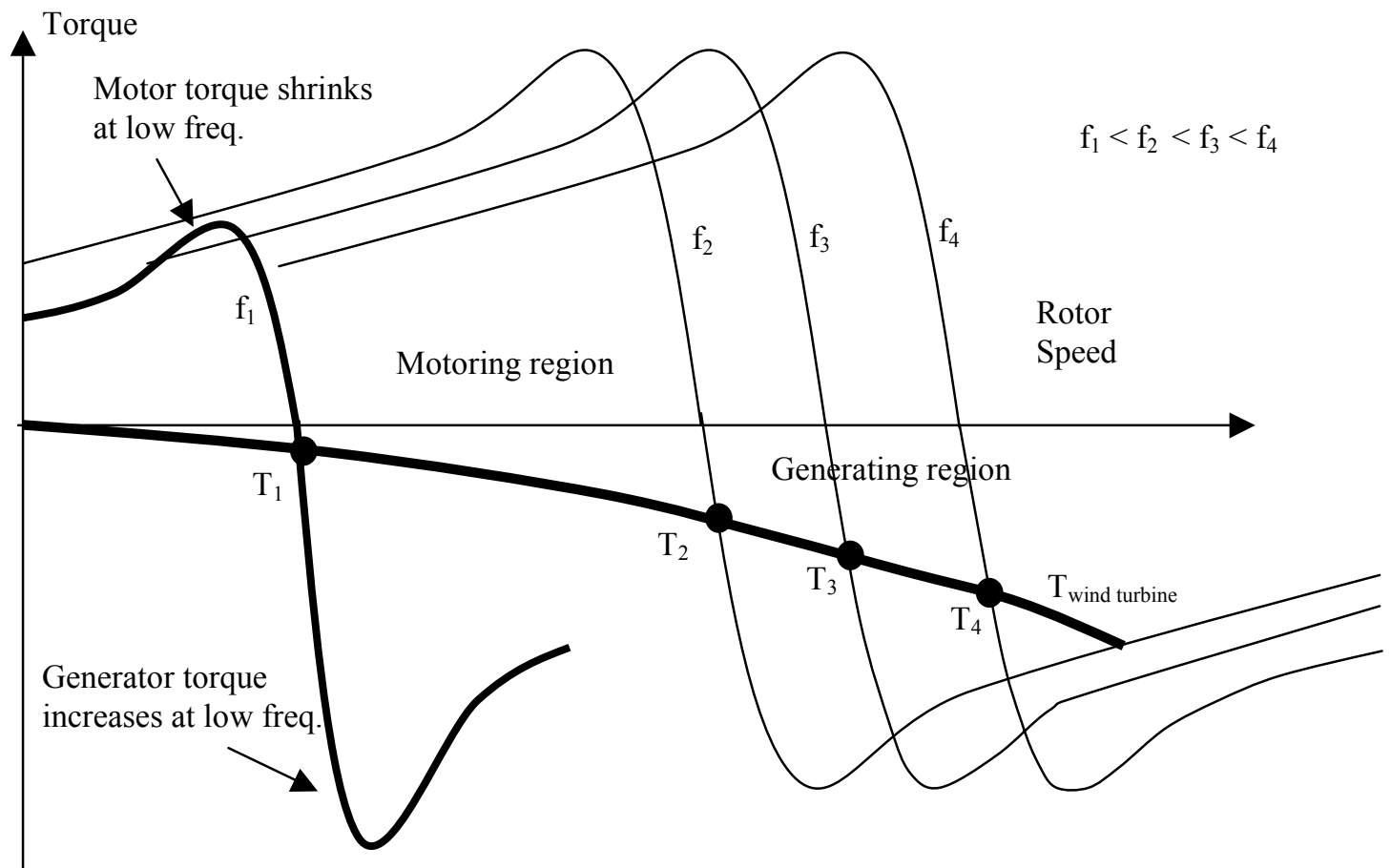

Figure IM-4. Torque-speed characteristic of an induction machine in variable frequency at constant volt/hertz operation.

\subsection{Field-oriented control in variable speed}

A modification of the equivalent circuit of Figure IM-3b is shown in Figure IM-5. It will be helpful to simplify the analysis of the variable-speed SCIM in current source mode operation. Reference [1] provides good information on this subject. With a current source, the phase angle and the amplitude of current $\mathbf{I}_{\mathbf{s}}$ can be controlled independently at any frequency provided that the power converter is within the limit of its capability. The power converter uses current feedback to control the phasor $\mathbf{I}_{\mathbf{s}}$. The power converter is controlled to generate the command current. (Implementation of current sources is presented in section 6.2.3). These currents are controlled at any speed to have a certain torque (controlling $\mathbf{I}_{\mathbf{q s}}$ ) and at a rated flux (controlling $\mathbf{I}_{\mathbf{d s}}$ ). Given the torque and flux component (normally the latter is kept constant at rated value), the slip frequency can be computed. Thus, the torque-speed characteristics can be tailored accordingly. This flux-oriented control or vector control has been used very extensively in the drive industry since the early 1970s. Different control strategies can also be used to control the torque-speed characteristic.

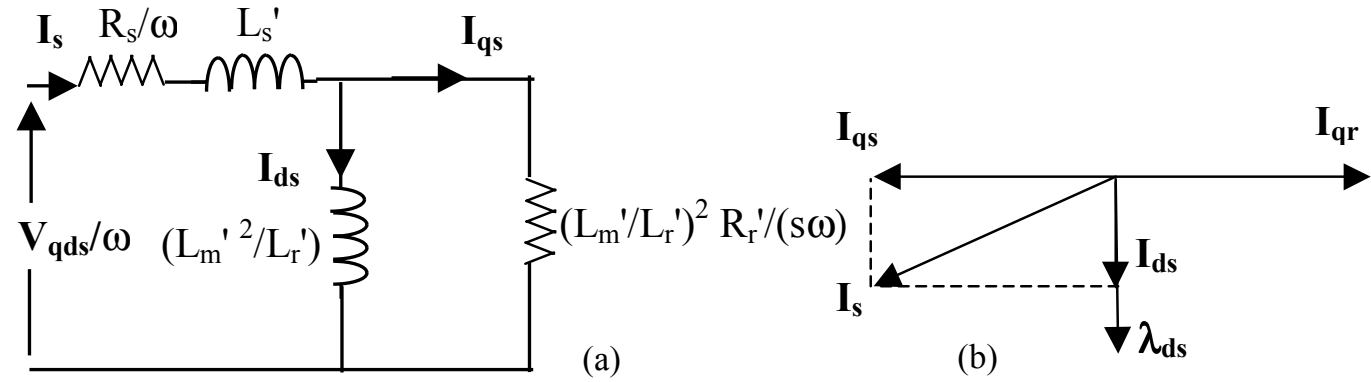

Figure IM-5. Modified equivalent circuit of a squirrel-cage induction generator to illustrate variable-speed implementation with current source 
The following equations can be used:

$\mathrm{s} \omega=\left(\mathrm{R}_{\mathrm{r}}^{\prime} / \mathrm{L}_{\mathrm{r}}^{\prime}\right)\left(\mathrm{I}_{\mathrm{qs}} / \mathrm{I}_{\mathrm{ds}}\right)$

$\mathrm{T}=\mathrm{K}_{\mathrm{T}} \mathrm{I}_{\mathrm{qs}} \mathrm{I}_{\mathrm{ds}}$

where $\mathrm{K}_{\mathrm{T}}$ is constant, $\mathrm{I}_{\mathrm{ds}}$ is generally kept at rated (except in a flux-weakening region), and $\mathrm{I}_{\mathrm{qs}}$ is specified based on torque requirement. The slip frequency is computed.

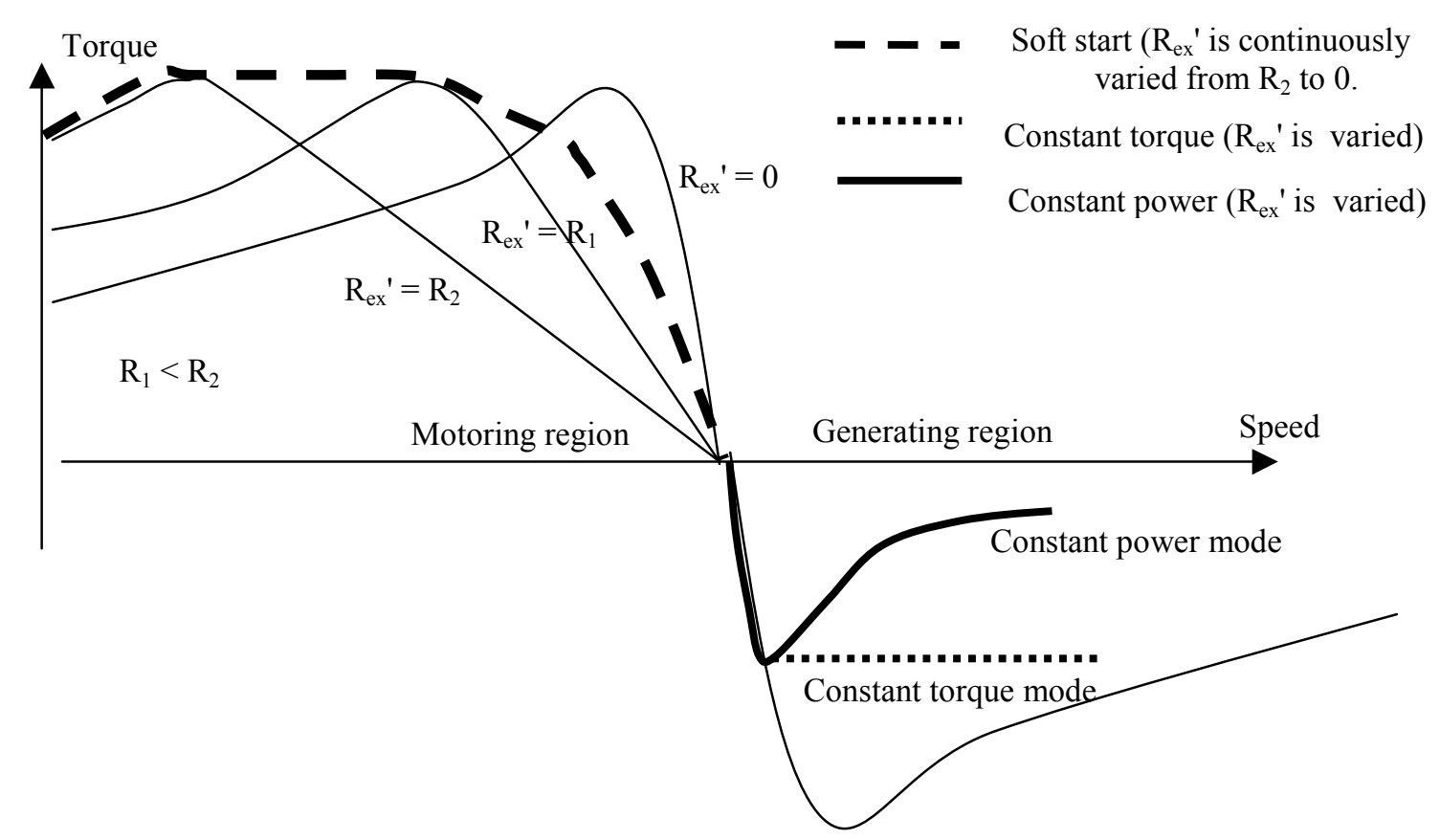

Figure WRIM-1. Torque-speed characteristic of a WRIM with the resistive load is adjusted by power converter to vary the apparent $R_{e x}$.

\subsubsection{Wound rotor induction machine with resistive load control}

The physical diagram of the WRIM can be illustrated in the previous Figure IM- $1 \mathrm{~b}$. The characteristics of the wound rotor induction generator are shown in Figure WRIM-1. In this machine, three-phase slip rings are mounted on the rotor shaft. The slip rings can be connected to a three phase passive adjustable resistance or a three-phase power converter. The stator is connected to a constant-frequency $(60-\mathrm{Hz})$ utility supply. The torque speed characteristic can be changed by inserting different values of external rotor resistances $R_{\mathrm{ex}}$. For example, installing $R_{1}$ will make the slope lower and installing $R_{2}$ will make the slope even lower. In wind turbines, this adjustable rotor resistor control (a Rheostat) was used as early as 1930 in Yalta, USSR. With rheostat control, at start-up (motoring mode) the rheostat can be set to $\mathrm{R}_{2}$. Then, when the generator starts generating, the rheostat is controlled to $\mathrm{R}_{1}$ or it can be shorted completely. Although the torque-speed characteristics can be changed by the operator, there are additional losses associated with external resistors.

The additional losses are proportional to:

P_extra_loss $=3 \mathrm{I}_{\mathrm{r}}{ }^{2} \mathrm{R}_{\mathrm{ex}}{ }^{\prime}$

These extra losses are converted into heat that must be dissipated, preferably outside the generator frame so that the heat loss does not increase the winding temperature. The concept of a rheostat can be extended by using a power converter to adjust the resistive load presented (apparent $R_{e x}$ ) to the rotor winding which can be accomplished by using a three-phase diode bridge and a DC-DC converter with a resistive load connected on the DC bus. Thus, by controlling the duty ratio of the DC-DC converter, the fictitious rheostat can be 
continuously controlled. This power electronics adjustable resistor has been implemented by Vestas with their product called Opti-slip. Again, we can generate a map of duty ratio versus rotor rpm. Thus, with the rotor rpm as the feedback, the duty ratio is controlled continuously to give:

- $\quad$ Soft start-up capability (dashed line in the motoring region)

- Constant power generation (solid line in the generating region)

- Or constant torque generation (dotted line in the generating region).

In some WRIM systems, the resistive power in the rotor is returned to the utility. A combination of three- phase diodes and three-phase line-commutated inverters is used. In this system, the $\mathrm{P}$ _extra loss shown above is returned to the utility (MOD-5B). The torque-speed characteristic can also be mapped and used to control the torque or power.

When the direction of power is coming out of the rotor, the generating region starts only above synchronous speed. The equivalent circuit used to describe the system is shown in Figure WRIM-2a. Normally, the pitch control is used to limit the speed of the wind turbine once the power limit or torque limit is achieved. The phasor diagram related to this system can be illustrated in Figure WRIM-3a. It can be shown that the output power at the stator side will always be inductive (lagging or under-excited), as shown in Figure WRIM-3a, because there is no compensation in the rotor circuit.

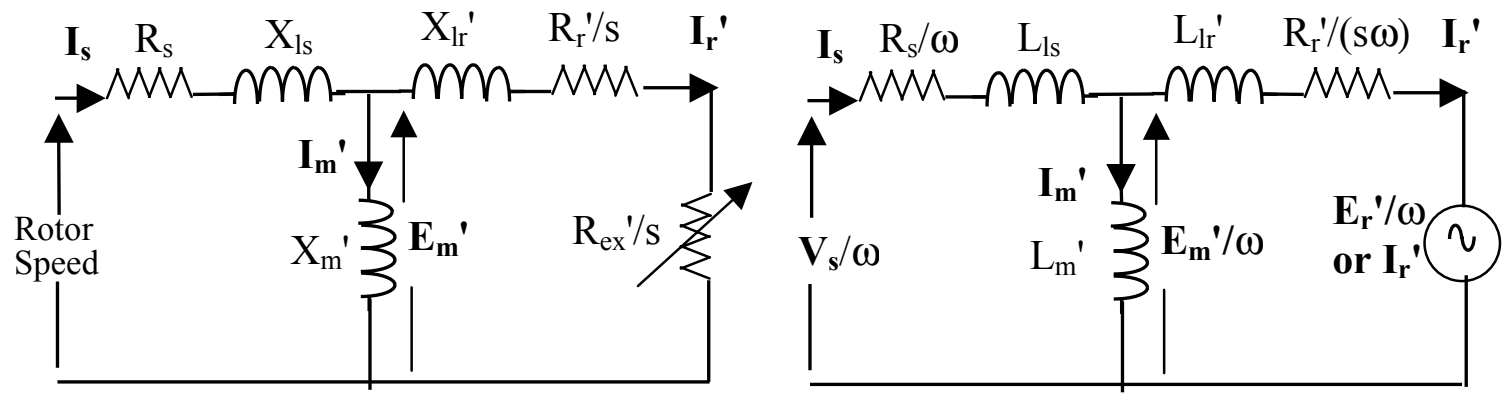

(a)

(b)

Figure WRIM-2. Equivalent circuit of a wound rotor induction machine

$\begin{array}{lll}\text { (a) Resistive load control (b) Doubly fed operation. } & \end{array}$

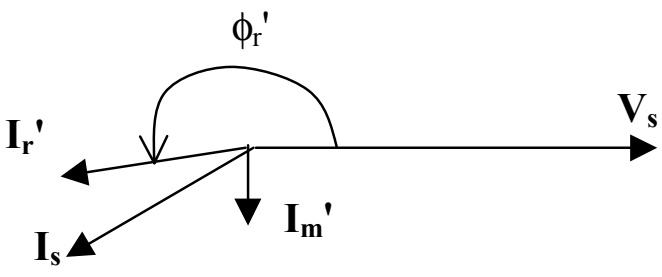

(a)

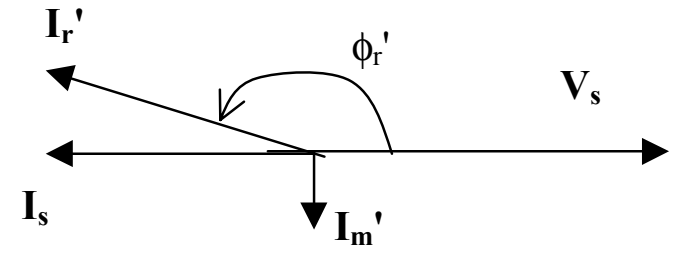

(b)

Figure WRIM-3. Phasor diagram of two different rotor controls (a) Resistive load control (b) Doubly fed operation.

\subsubsection{Doubly fed WRIM with power electronics driven rotor.}

For a doubly fed wound rotor induction machine, the stator is connected to a three-phase, constant- frequency supply and the rotor is connected to a three-phase, variable-frequency power converter. The doubly fed WRIM equivalent circuit is shown in Figure WRIM-2b. Two methods for connecting a variable speed WRIM to a utility are shown in Figure WRIM-5. The frequency fed to the rotor winding is proportional to the slip times the stator frequency, and the voltage across the rotor winding is determined by the stator voltage, the slip, and the turns ratio of the rotor-to- stator winding. In order to lock the phase angle between the voltage of the stator, the stator voltage must be referred to the rotor side. This requires knowledge of the turns ratio, the slip, and the 
stator frequency. By referring the stator voltage to the rotor side, the output voltage of the power converter connected to the rotor winding can be synchronized to the stator voltage. The amplitude and the phase angle can then be controlled to generate the correct torque at any speed.

Without synchronizing the rotor voltage or current to the stator voltage, the rotor speed may be controlled. However, the system behaves more like a synchronous generator than an induction generator. The torque and the power fluctuation will depend on the wind speed input fluctuation. The phasor diagram for the currents with respect to the stator voltage is illustrated in Figure WRIM-3b (above). Again, it is assumed that the voltage drop across the stator resistance and leakage reactance are negligible. The resulting magnetizing current $\mathbf{I}_{\mathbf{m}}{ }^{\prime}$ is practically constant at any condition and it is practically perpendicular to the voltage $\mathbf{V}_{\mathbf{s}}$. Thus, the current $\mathbf{I}_{\mathbf{s}}$ will be directly affected by the current $\mathbf{I}_{\mathbf{r}}{ }^{\prime}$. The stator current can be controlled by controlling the output voltage of the power converter connected to the rotor or by controlling the output current of the power converter. Also, phasor $\mathbf{E}_{\mathbf{r}}$ ' of the voltage source or the phasor of $\mathbf{I}_{\mathbf{r}}$ ' in the case of the current source inverter must be synchronized with respect to the stator reference. With a doubly fed induction generator, the power converter enables the system to generate below synchronous speed (positive slip) because the power converter is able to have a bi-directional power flow.

Figure WRIM-4 shows a utility being fed by a cluster of three generators. Three different modes of operating a wound rotor machine are illustrated. All three shown can generate only above synchronous speed.

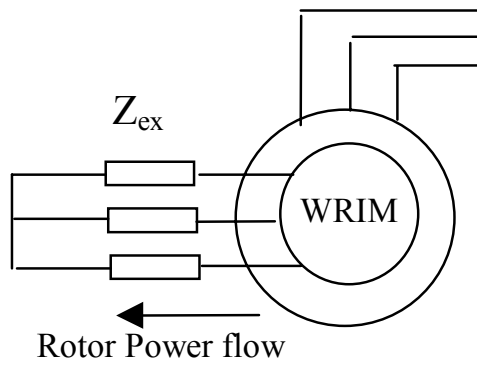

(a)

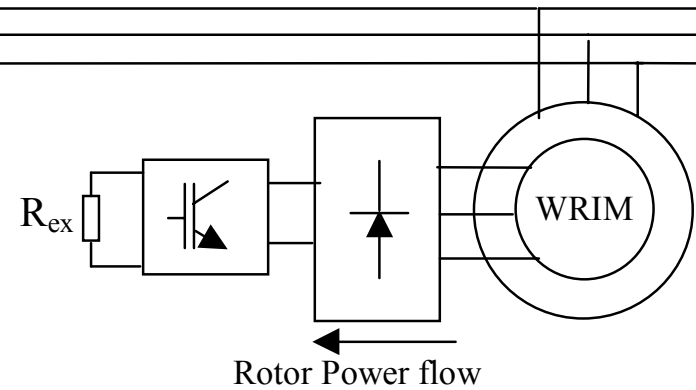

(b)

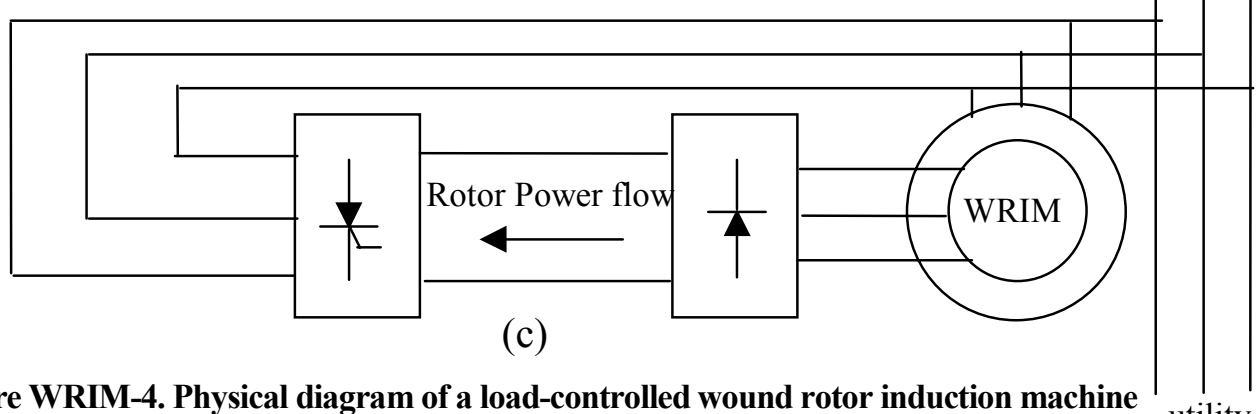
Figure WRIM-4. Physical diagram of a load-controlled wound rotor induction machine utility
(a) Passive (b) Variable resistive load control (c) Regenerative load control.

In Figure WRIM-4a, a passive load control is shown. The load $Z_{\text {ex }}$ can be a resistive three-phase load, which will change the torque-speed characteristic of the WRIM at constant frequency. The heat loss in the external load $\mathbf{Z}_{\mathbf{e x}}$ is not recovered.

In Figure WRIM-4b, a variable resistive load control can be achieved by using a three-phase diode bridge and $\mathrm{DC}-\mathrm{DC}$ converter to control the power entering the external resistive load $\mathrm{R}_{\mathrm{ex}}$. The torque-speed characteristic of the WRIM will be shaped based on command. Thus, a torque-speed characteristic can be programmed such as the characteristic shown in Figure WRIM-1. The heat loss in the resistive load $\mathrm{R}_{\mathrm{ex}}$ is wasted and must be dissipated.

In Figure WRIM-4c, a regenerative system is implemented. Thus, the power generated in the rotor is returned to the utility. 
Compared to the squirrel-cage winding, the wound rotor induction, variable-speed generator has the following advantages:

- SCIM requires a power converter with full power-processing capability, whereas WRIM requires a smaller power converter to process the slip power. Thus the smaller range of operating slip, the smaller the required power converter. The size of the power converter may strongly affect the cost of energy $(\$ / \mathrm{kWh})$.

- WRIM has a simpler control because the magnetizing current is practically constant regardless of the rotor frequency. $\mathbf{I}_{\mathbf{r}}$ ' must be synchronized with respect to stator reference.

- The utility side of the power converter of the WRIM can be sized differently from the generator sides of the power converter. The power factor to the utility can be controlled by either side of the power converter's WRIM (utility side or rotor side of power converter).

(a)

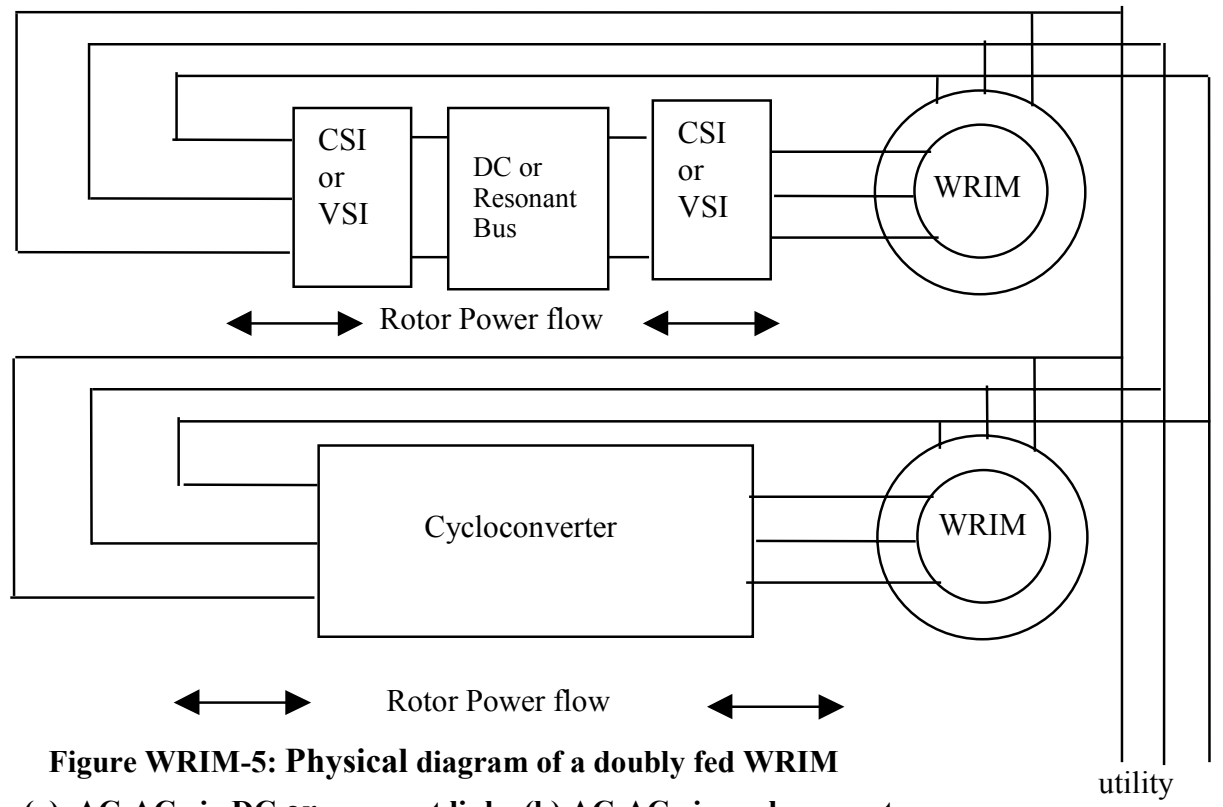

(a) AC-AC via DC or resonant link (b) AC-AC via cycloconverter

\subsection{Voltage-Frequency Converters}

\subsubsection{DC-DC Converter}

There are many types of DC-DC converters. The earliest and most primitive is a simple resistor or rheostat, which simply lowers a voltage to the required value by dropping some of the supply voltage across a resistor. This usually wastes a large portion of the supply energy. Of the remaining efficient converters, only two basic ones will be discussed in this section. (See figure PE-1) A DC-DC power converter can be used to control a DC circuit such as the armature current or the field current of a DC generator, the field current of a synchronous generator, or the DC bus voltage of a battery-charging system. The DC-DC converter can be controlled by modulating the duty ratio $(\mathrm{D}=$ turn-on time/switching period) of the power switches (IGBT, power transistor, etc.). In a continuous conduction mode, where DC inductor current flows continuously, the equation describing the DC-DC converter can be written as:

Step-down converter: $\quad \mathrm{V}_{\text {out }} / \mathrm{V}_{\text {in }}=\mathrm{D}$

Step-up converter: $\quad \mathrm{V}_{\text {out }} / \mathrm{V}_{\text {in }}=1 /(1-\mathrm{D})$ 

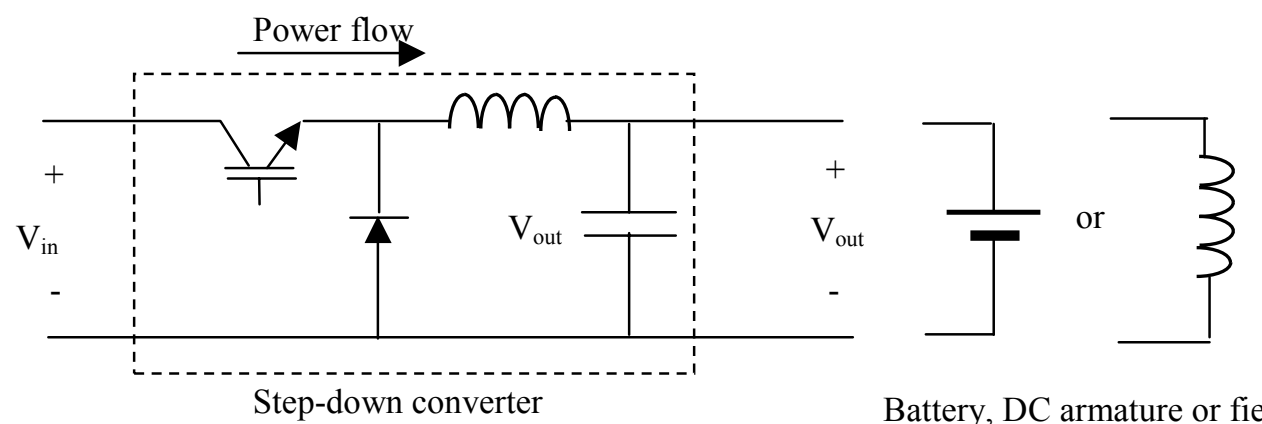

(a)

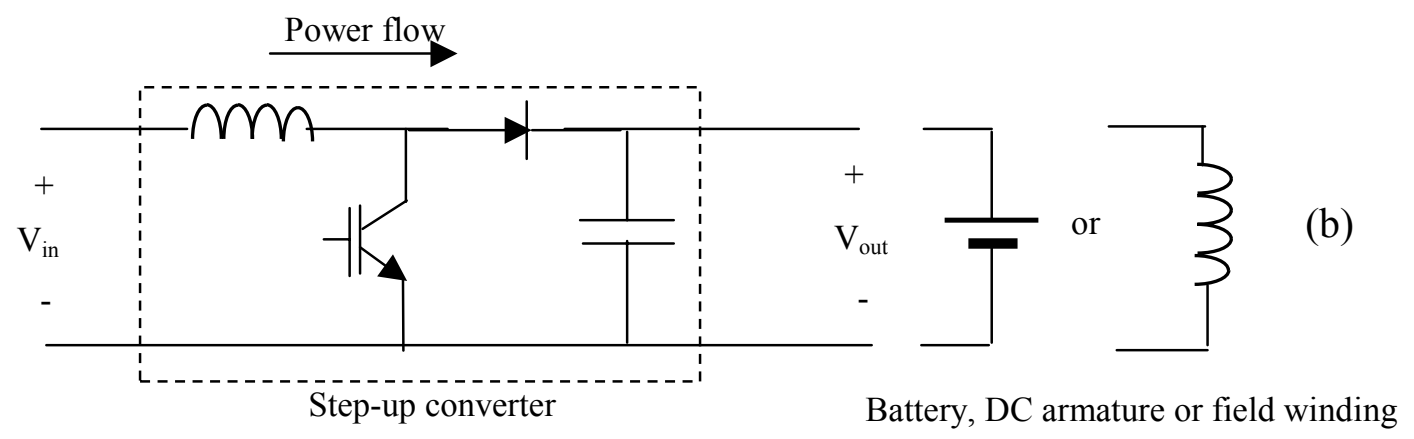

Figure PE-1. DC-DC converter to change one DC level to another

a) Step-down converter

b) Step-up converter

\subsubsection{AC-DC Power Converter}

The device for converting AC to DC is called a rectifier. Figure PE-2 shows two types of rectifiers. The threephase diode bridge and the three-phase, phase-controlled rectifier both convert AC to DC. The output of a diode bridge cannot be controlled; however, the phase-controlled rectifier output can be controlled by adjusting the firing angle $(\alpha)$ of the silicon-controlled rectifier.

The input-output relationship for a continuous conduction mode can be written as follows:

Three-Phase Rectifier:

$$
V_{d c}=3 \frac{\sqrt{2}}{\pi} V_{L L}
$$

Phase-Controlled Rectifier:

$$
V_{d c}=3 \frac{\sqrt{2}}{\pi} V_{L L} \cos \alpha
$$

While the DC load connected to the diode rectifier is presented as a resistive (R) load to the generator, the same load connected to a phase-controlled rectifier is presented as an adjustable inductive (RL) load to the generator. The adjustable firing angle presents a time delay or lagging current with respect to the voltage. Thus, the generator characteristic is affected in different ways when connected to a diode rectifier or phase- controlled rectifier because the output of the diode rectifier is not adjustable, a DC-DC converter is normally placed in series with the diode bridge. Examples of applications include synchronous machine field winding control, charging current control in battery charging, DC bus control, and heater control. 


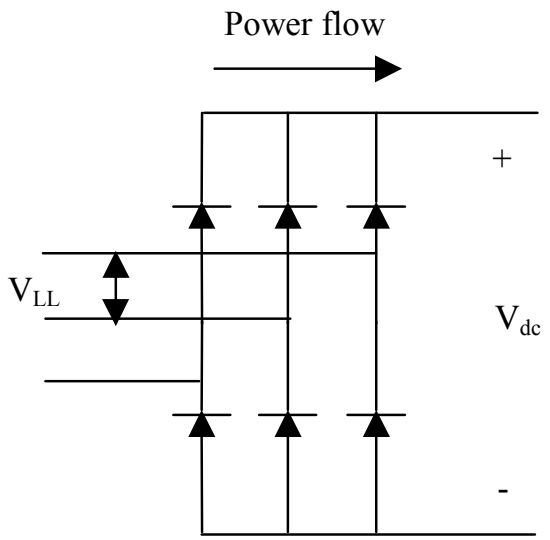

(a)

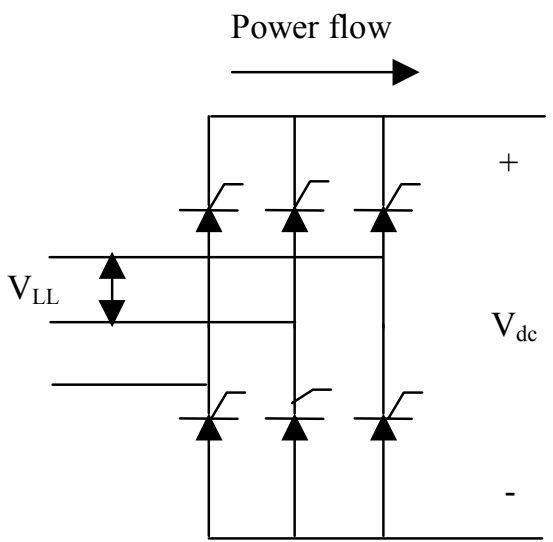

(b)

Figure PE-2. Three-phase rectifier

b) Three-phase diode bridge rectifier c) Three-phase phase-controlled rectifier

The current on the $\mathrm{AC}$ sides for both diode bridge and phase-controlled rectifiers is not sinusoidal. If the AC sides are connected to the utility, the harmonic currents should be corrected to limit the harmonics within defined limits. If the $\mathrm{AC}$ side is connected to the generator, the non-sinusoidal current may generate torque pulsations and increase the heat loss generated by harmonic currents.

\subsubsection{DC-AC Power Converter}

The device for converting $\mathrm{DC}$ to $\mathrm{AC}$ is called an inverter. In the early development of power inverters, SCR switches were used. The SCR is a rugged power switch that can be turned on when the voltage across it is forward biased. However, in order to turn off the SCR, a commutation circuit is needed. With the advent of power electronics, faster switches such as power transistors, IGBT's, and power MOSFETs are used. (See Table 3.0, section 3.5 in this report.) The devices can be turned on and off any time by applying the correct signal on the base drives. In Figure PE-3a, a generic three-phase inverter is shown. IGBTs replace the SCRs from early inverter generations. The diodes parallel to the power switches are called freewheeling diodes because they allow the current to continue to flow in the inductance when the power switches (IGBTs) are turned off. The circuit shown in Figure PE-3a is a typical voltage source inverter converting DC to AC, where the switches are turned on and off to imitate sinusoidal voltage. In the early stages of development, a six-step, square-wave voltage source was used. A typical per-phase voltage across the load is shown in Figure PE-3b. The frequency of the square-wave can be changed to adjust the speed or the power of the electric machine. The amplitude, which depends on the amplitude of the DC bus voltage, can also be adjusted by adjusting DC bus voltage. Thus, a volt/hertz ratio can be created. One drawback of this type of inverter is the resulting current is non-sinusoidal. In a conventional electric machine, only the fundamental component of the stator current generates useful torque. The harmonic components create torque pulsations and additional losses.

In more modern designs, PWM techniques are used to turn the power switches on and off. Many concepts have been developed around PWM techniques to generate output with lower harmonics. The sine-triangular comparison is a classical one that compares the sine wave (at the fundamental frequency requested) to a triangular wave (at the selected switching frequency). With this technique, the magnitude and the frequency 


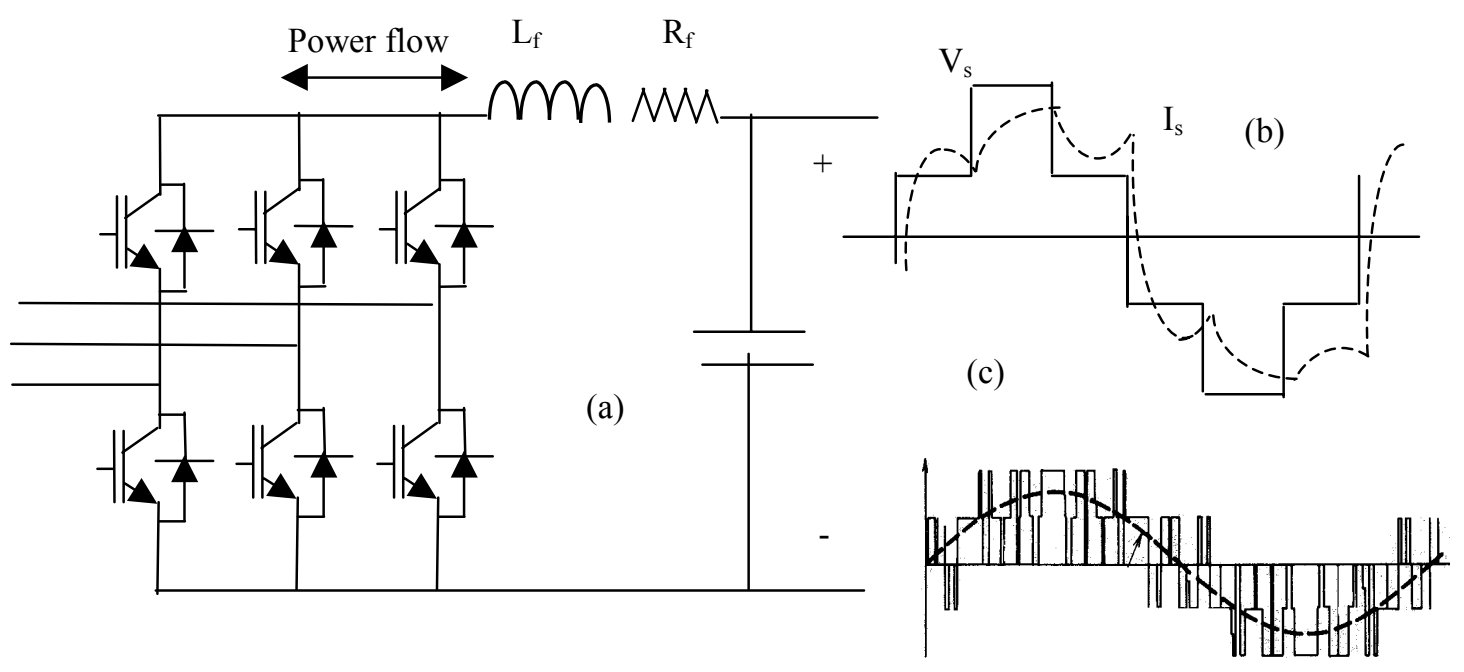

Figure PE-3. Three-phase voltage source inverter

a) Circuit diagram

b) Per phase voltage of a square-wave inverter

c) Per phase voltage of a PWM inverter

can be modulated with a constant DC bus. A higher switching frequency can generate a smoother current wave form but higher switching losses. A balance between efficiency and performance is important in making a final decision. However, with faster switches used in the power converter, the issue of switching losses becomes less significant.

Another way to control a three-phase inverter is to control the output current of the inverter. In early developments, a line-commutated inverter was used to return the power generated by the wind turbine to the line supply. Or a load-commutated inverter was used to control a variable-speed synchronous generator. This type of inverter is shown in Figure PE-4a. With an LCI, the current can be controlled in frequency, magnitude, and phase angle. The power converter uses SCRs for the power switches. SCRs are available in high power ratings. Although these power converters work very well, the resulting current presented to the three-phase side is non-sinusoidal. In an LCI, the non-sinusoidal current generates torque pulsations (especially at lower frequencies) and other harmonic-related losses. At the utility side, the line-commutated inverter is controlled to return the power to the utility at constant frequency. The drawback of using a line-commutated inverter to return the power to the utility is that the power factor is not controlled (non-unity power factor) and the harmonic content is high. Some filtering may need to be included in the utility system to reduce the harmonics generated to the utility. Some systems use zigzag transformers and dual converters to create a twelve-pulse inverter.

With faster switches available, CRPWM are used. The power converter behaves like a highpower amplifier, which shapes the output current based on the commanded current. A current template is needed to shape the output current and this commanded current is compared to the actual current from the current sensor. The current controller turns on and off the correct switch (top or bottom) of the corresponding phase. The circuit diagram of the three-phase current inverter is shown in Figure PE-4(b) below. Only the controller for phase A is shown. The other phases are controlled in the same fashion. Note that in the current controlled inverter, the phasor Ia, Ib, and Ic can be instantaneously controlled in its magnitude, frequency, and its phase angle. In general, speed sensors are also needed at the generator to determine the stator currents, frequency, and phase angle to produce commanded torque. 


\section{Current Source:}
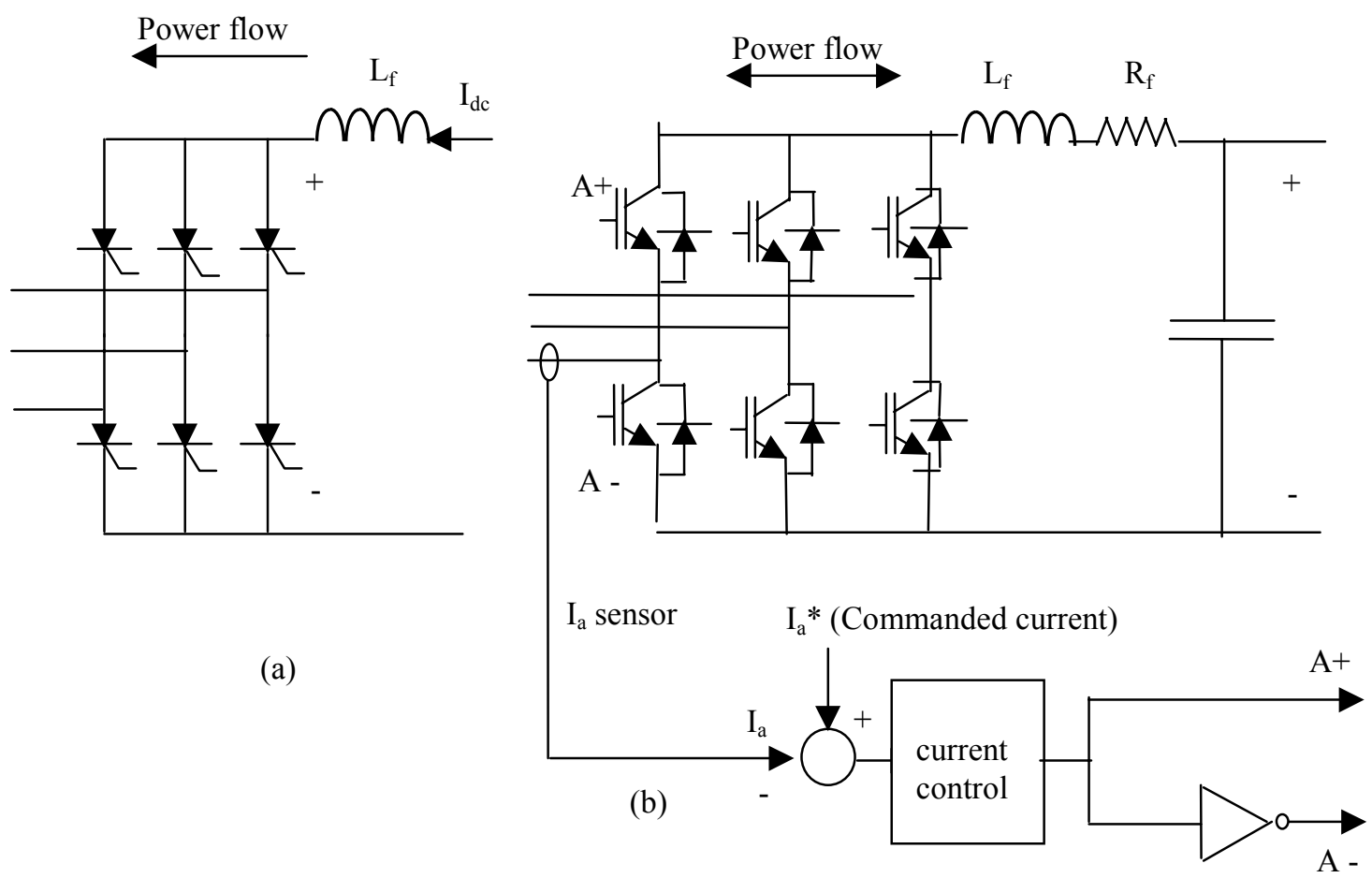

(a)

\subsubsection{Cycloconverter}

Cycloconverters such as the one shown in Figure PE-5 use six SCRs in each phase for positive or negative current conversion. Overall, $36 \mathrm{SCRs}$ are needed to convert three-phase $60-\mathrm{Hz}$ to a three-phase, variablefrequency output. The output is limited to about $20 \mathrm{~Hz}$. The use of a cycloconverter in variable-speed wind turbines can be found in several systems such as the MOD-0A, the MOD-5B, and the Growian. In each system, a wound rotor induction generator is used. The stator is directly connected to the fixed- frequency input line and the rotor is fed by the cycloconverter via slip rings. The advantage of using a cycloconverter for the doubly fed WRIM is the use of SCRs as the power switches, which allows for scaling up the power generation while the input frequency requirement at the rotor side is kept low (slip frequency only). The disadvantages are the number of the SCRs needed and the harmonic current produced on the line side. The introduction of higherspeed switches, such as IGBTs, reduces the impact of harmonics by improving the wave form. However, the number of IGBTs required to implement this scheme is much higher than required for an AC-DC-AC approach of comparable power capacity. The future introduction of two-way switches could help to alleviate this problem and make this approach more attractive. 


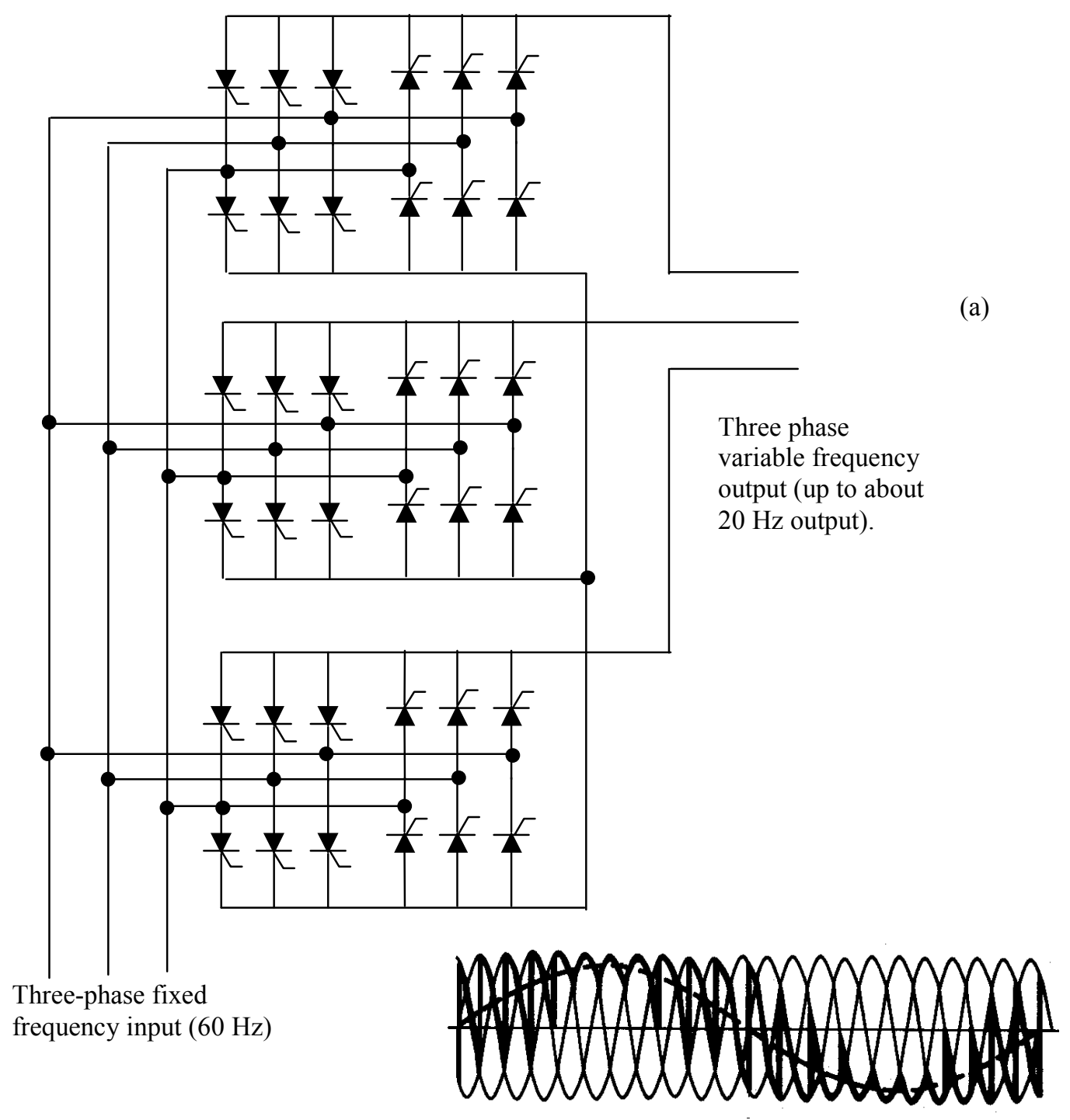

(b)

Figure PE-5. AC-AC conversion through a cycloconverter

a) Circuit diagram

b) Sample of output voltage

\subsection{Utility Interface}

At the utility side, the power generated by the wind turbine must be transferred to the utility at constant frequency. With a line commutated inverter connected to the utility, the current wave form will be nonsinusoidal and some kind of filtering will be required. The process of generating electricity from a wind turbine requires a source of power and a sink for power. One example of a wind turbine system is shown below. CRPWM can be employed at both the source side (wind turbine generator) and the sink side (utility). The power balance must be maintained. 


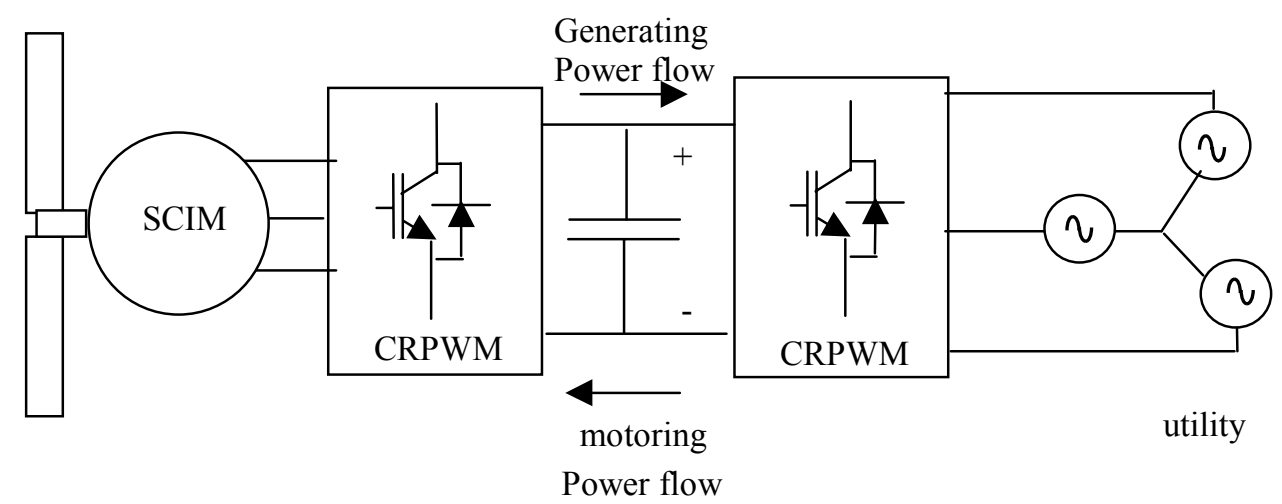

Figure UI-1. Three-phase variable-speed wind turbine generation

Power balance requires that:

Power generated at the source $=$ Power transmitted to the sink + Losses

If the power generated is higher than the power transmitted and losses, the energy will go to energy storage (in this case, the DC capacitor shown). As a result, the DC bus voltage will increase. On the other hand, if the power returned is larger than the generated power, the DC bus voltage will decrease. This power balance concept must be implemented in the controller to keep the system stable. With the power conversion shown above, the torque-speed characteristics of the generator can be controlled at any rotor speed and the power quality at the utility side can be maintained. The power conversion described above uses CRPWM on both sides. Thus, at the generator side, a torque or power control can be commanded at any time and with a good sinusoidal wave form, the generator torque will be smooth. (Refer to Section 6.1.3.1.3) At the utility side, the current wave form can be commanded to have an adjustable power factor at minimum current distortion while maintaining the DC bus voltage constant (power balance).

\subsection{A LOOK AT FUTURE DEVELOPMENT}

A quick review of the preceding history of wind energy technology, shows that wind energy engineers and designers have long been aware of the implicit natural difficulty of matching a wind driven prime mover to a utility connected electric generator. A century of electric technology development has yielded electric machines with outstanding energy conversion efficiency, but are optimized to operate at exactly one speed. On the other hand wind driven machines whose power is based on the lift derived from airfoils have optimal performance when their angle of attack is a relatively constant near a known optimum value. For this to be true for a wind turbine airfoil the optimal rotor speed must be proportional to the impinging wind speed, an entity well known for its variability.

As the preceding material has shown, there has been a remarkable diversity of solutions offered to ameliorate this mismatch. So far, rather than modifying mechanical transmissions or designing novel types of electric generators, system designers have coupled the variable electrical energy from traditional generators to the client utility through a great variety of power electronic networks. The elements chosen to comprise such networks have depended on the state of the electronic art at the time the system was built. Early on when only silicon controlled rectifiers (SCR's) were available, six- and twelve-pulse inverters were employed with their concomitant poor current waveform. As the variety of more efficient and faster switches grew, other circuit topologies were selected to capitalize on the then current state of the art. An important guiding example for wind system designers has been the swift improvement of large adjustable speed motor drives (ASD's), which were developed in response to a rapid rise in demand from industry. 
Would it be foolhardy to forecast the next level of development? At this point global technology is often modeled as two parallel and mutually dependent streams, namely, software and hardware. New hardware options based on novel electronic circuits and rapidly improving components promise an ever widening field of possible approaches, while the state of the art hardware found in the variety of emerging wind turbines opens an opportunity for wind turbine software innovation. The field now seems ripe for an exhaustive search for control schemes with the goal of finding those that can simultaneously maximize both performance and equipment lifetime.

As in all technologies, the future is difficult to predict. Concepts borrowed from other fields or other applications could have profound effects on future designs. Clearly, there are bound to be surprising changes in variable speed architectures in the coming years. 


\section{References}

1. Novotny, D.W., Lipo, T.A.; "Vector Control and Dynamics of AC Drives." Oxford Science Publications, 1997.

2. Hasse, K.; "On the Dynamic of Speed Control of a Static AC Drive with a Squirrel Cage Induction Machine." Ph D. Dissertation, Tech. Hochschule, Darmstadt, Germany, 1969.

3. Blashke, F.; "The Principle of Orientation- the Basis for the Transvector Control of Three-Phase Machines." Siemens Zeitschrift, Vol. 45, No. 10, pp. 757-760, 1971.

4. Krause, P.C.; "Analysis of Electric Machinery," McGraw-Hill Book Company, 1986.

5. Mohan, N., Undeland, T.M., Robbins, W.P.; "Power Electronics, Converters, Applications, and Design," John Wiley \& Sons, 1989.

6. Lipo, T.A.; "Variable Speed Generator Technology Options for Wind Turbine Generators." Wisconsin Electric Machines and Power Electronics Consortium, Research Report, 84-4, June 1984.

7. Caroll, D.P., Krause, P.C., "Security Assessment of Power Systems Including Energy Storage and with the Integration of Wind Energy." Progress Report for Period July 1, 1981-September 30, 1981, The United States Department of Energy, under contract No. DE-AS02-77ET 29100 (formerly EC-77-S02-4206).

8. Meritt, B.T.; "An Asynchronous AC/DC/AC Link for Wind Power Application." Ph.D. Thesis, University of Wisconsin-Madison, 1977.

9. Reitan, D.K.; "A Wind Powered Asynchronous AC/DC/AC Converter System." NASA/NSF Workshop Proceedings NSF/RA/W-73-066, Washington, D.C., June 1973. 


\subsection{ACKNOWLEDGEMENTS}

In assembling such a history no single author or source possesses all the necessary information. The authors would like to acknowledge input and feedback from the following:

The Wind Industry and Academia

Mr. Steve Atkins, The Wind Turbine Co.

Mr. Elliott Bayly, World Power Technologies

Mr. Mike Bergey, Bergey Windpower

Dr. Jamie Chapman, OEM Development Corporation

Mr. Clint (Jito) Coleman, Northern Power Systems

Dr. Edgar DeMeo, Consultant

Dr. Tom Lippo, University of Wisconsin

Dr. Andrew Swift, UTEP

Mr. Claus Weigand, Electronic Power Conditioning, Inc.

The National Laboratories

Ms. Al Berger, NREL

Mr. Sandy Butterfield, NREL

Dr. Henry Dodd, Sandia

Mr. Lee J. Fingersh, NREL

Dr. Robert Thresher, NREL 


\section{APPENDIX A}

\section{Selected References}

The following section includes lists of papers, technical reports, and patents that are believed to be of significance in the area of variable speed.

\section{Publications}

1. Yadavalli, S.R.; Jayadev, T.S. “A New Generation Scheme for Large Wind Energy Conversion Systems.' Proceedings of the Eleventh Intersociety Energy Conversion Engineering Conference, pp 1761-1765, State Line, Nevada, American Institute of Chemical Engineers, New York, September 12-17, 1776.

2. Jayedev, T.S.;"Windmills Stage a Come Back." IEEE Spectrum, v 13 n 11 pp 44-49, November 1976

3. Morash, R.T.; "Exact 60 Cycle Power Generation at Any Speed." Proceedings of the $12^{\text {th }}$ Intersociety Energy Conversion Engineering Conference, Vol I.; American Nuclear Society, Inc., La Grange Park, Illinois, 1977.

4. Jacob, A., Veillette, D., Rajagopalan, V.; “Control Strategy for a Variable-Speed Wind Energy Conversion System"; Proceedings Canadian communication and power conference, IEEE, 1978.

5. Smith, G.A., Nigim, K.A.; "Wind-Energy Recovery by a Static Scherbius Induction Generator"; IEEE Proceedings, Part C (United Kingdom)Vol. 128:6., 1981.

6. Lipo, T.A., Carroll, D.P., Krause, P.C.; "Investigation of Variable Speed for Wind Turbine Power Generation.” Technical Report DOE/ET/29100-18, 1981.

7. Lauw, T.H.; “ac-dc-ac Conversion System for Mains-Connected Windpower Generator." Proceedings $2^{\text {nd }}$ ASME Wind Energy Symposium, ASME, 1983.

8. Velayudhan, C., Bundell, J.H.; "Variable-Speed, Constant-Frequency Wind Power Generation Scheme Using a Slip-Ring Induction Generator.' Proceedings IECEC '84, American Nuclear Society, La Grange Park, Illinois, 1984.

9. Balcerak, J.C., Minges, G.P., "Application of a Variable Speed, Constant Frequency Generator to a Small Wind System." Proceedings $2^{\text {nd }}$ ASME Wind Energy Symposium, ASME, 1984.

10. Lipo, T.A.; "Variable Speed Generator Technology Options for Wind Turbine Generators." Technical Report RR-84-4, Wisconsin Electric Machines and Power Electronics Consortium. Available from AIAA Technical Library, 1984.

11. EPRI; "Final Report: Variable Rotor Speed for Wind Turbines: Objectives and Issues." EPRI AP-4261, Project 1996-9, September 1985.

12. Doman, Glidden S.; "Applications of Broad Range Variable Speed Generators to Large Horizontal Axis Wind Turbines.” Proceedings Windpower'85, AWEA, 1985.

13. Richards, B., Bilgen, E., Hollands, K.G.T.; "The Variable Speed Power Train for Project Eole: 4 MW Vertical Axis Wind Turbine Generator"; Proceedings INTERSOL '85, Elmsford, New York, Pergamon Books, Inc., 1985.

14. Valter, G.P.; "A Comparison Between Constant Speed and Variable Speed Conversion Systems for Wind Turbine Operation.” Proceedings Windpower'85, AWEA, 1985.

15. Schmidt, W.C., Birchenough, A.G.; "Evaluating Variable Speed Generating Systems on the DOE/NASA MOD-0 Wind Turbine"; Proceedings Windpower '85, AWEA, 1985.

16. Ernst, J., Palz, W.; "Control of a Variable Speed Wind Energy Converter with a Synchronous and a d.c. Link Converter." Proceedings EWEC'84, Bedford, (Great Britain), H.S. Stephens and Associates, 1985.

17. Boldin, D., Muehloecker, H., Palz, W.; "Induction Generators Adapted to Variable Speed Operated Wind Turbines.” Proceedings EWEC'84, Bedford, (Great Britain), H.S. Stephens and Associates, 1985.

18. Herrera, J.I., Reddoch, T.W., Lawler, J.S.; "Experimental Investigation of a Variable Speed Constant Frequency Electric Generating System from a Utility Perspective." Technical Report DOE/NASA-4105-1, NASA-CR-174950, 1985.

19. Naganathan, S., Sharaf, A.M.; "Microprocessor Control of Wind Driven Squirrel Cage Induction Generator." Proceedings Power Electronics \& Applications, Koninklijke Vlaamse Ingenieursvereniging, Technologisch Inst, Antwerp, Belgium, 1985.

20. DiValentin, E., "The Application of Broad Range Variable Speed for Wind Turbine Enhancements." Proceedings EWEC'86, October, EWEC, 1986.

21. Steinbuch, M., Meiring, F.; "Analysis and Simulation of a Wind Turbine with Variable Speed." Report PB-87-163150/XAB, Kema Scientific and Technical Reports, Vol. 4, No. 7 71-78, 1986. 
22. Almarsoomi, A.R.; "Laboratory Investigation of Wind Power Generation Using Variable Speed Synchronous Generators.” Report STEV-VIND-86-17, Statens Energiverk, Stockholm, Sweden, 1986.

23. Carlson, O., Hylander, J., Tsiolis, S.; "Variable Speed AC-Generators Applied in WECS." EWEC'86, Report STEV-VIND-86-16, Statens Energiverk, Stockholm, Sweden, 1986.

24. Hughes, P.S.; "Variable-Speed Generator Improves Turbine Efficiency." Modern Power Systems (United Kingdom) Vol. 6:12, 1986.

25. Doman, G., Swift, A.H.P.; "Influence of Broad Range Variable Speed Operation upon the Hamilton Standard WTS-4 Wind Turbine." Proceedings of the $5^{\text {th }}$ ASME Wind Energy Symposium, ASME, 1986.

26. Quareshi, S., Richards, B.; Lodge, M. (ed.); "Design Features of Project Eole Prototype." Proceedings CANWEA'85, CANWEA, 1987.

27. Carlson, O., Tsiolis, S., Johansson, G.; "Variable Speed AC-Drive System with Pitch or Yaw Control"; Proceedings Windpower'87, AWEA, 1987.

28. Smith, G.A.; "Variable Speed Induction Generators". Proceedings of the British Wind Energy Association DEN Workshop on Electrical Generation Aspects of Wind Turbine Operation, May 12, 1987, ETSU-N103, 1987.

29. Steinbuch, M.; "Optimal Multivariable Control of a Wind Turbine with Variable Speed"; EWEC'86, Wind Engineering, United Kingdom, Vol. 11:3, 1987.

30. Herrera, J.I., Reddoch, T.W.; "Analysis of the Electrical Characteristics of a Westinghouse Variable Speed Generating System for Wind Turbine Applications.” Technical Report STR-217-3133, SERI, 1988.

31. Weh, H., Hoffman, H., Landrath, J., Mosebach, H., Poschadel, J.; Palz, W. (ed.); "Directly-driven Permanent-Magnet Excited Synchronous Generator for Variable Speed Operation." Proceedings EWEC'88, Bedford, Great Britain, H.S. Stephens and Associates, 1988.

32. Carlin, P.W., Swift, A.H.P., Thresher, R.W.; "Analysis of Variable Speed Operation of Horizontal Axis Wind Turbines." Proceedings $7^{\text {th }}$ ASME wind energy symposium, ASME, 1988.

33. "Power-Electronic, Variable-Speed Wind Turbine Development: 1988-1993, A Summary of the 33M-VS Wind Turbine Development Program Conducted by Kenetech Windpower, Pacific Gas and Electric Company, Niagara Mohawk Power Corporation, and EPRI.” EPRI Technical Report TR-104738, Projects 1590-16; 3062-02, EPRI, 1995.

34. Carlin, Palmer W.; "The Probable Source of Certain Spurious Frequencies Found in the Output of a Variable Speed Generating System Using Slip Recovery.” Technical Paper TP-217-3515, SERI, 1989.

35. Carlson, O., Hylander, J.; "Variable Speed ac-Generators in Wind Energy Converters." MELECON'89: $5^{\text {th }}$ Mediterranean Electrotechnical Conference, IEEE, 1989.

36. Matsuzaka, T., Tsuchiya, K., Yamada, S., Kitahara, H.; "A Variable Speed Wind Generating System and its Tests Results." Proceedings EWEC'89; Pt. 2, London, Great Britain, Peter Peregrinus, Ltd., 1989.

37. Vachon, W.; "Smart Control Algorithms For Operation of Variable Speed Wind Turbines." Proceedings $9^{\text {th }}$ ASME Wind Energy Symposium, ASME,1990.

38. McNerney, G., Richardson, R.D., Holley, W.; "The Effect of a Power Electronic Converter on Power Fluctuation and Harmonic Distortion in a WECS.” Proceedings $9^{\text {th }}$ ASME Wind Energy Symposium, ASME, 1990.

39. Avolio, S., Calo, C., Foli, U., Rubbi, L., Casale, C., Sesto, E.; "Gamma 601.5 MW Wind Turbine Generator", Proceedings 1990 EWEC Conference, Bedford, Great Britain, H.S. Stephens and Associates, 1990.

40. Djurovic, M., Savelic, R.; "Double Fed Induction Generator for Variable Speed Constant Frequency." Proceedings 1990 World Renewable Energy Congress, Oxford, Great Britain, Pergamon Press, 1990.

41. Lauw, H.K., Krishnan, S.; "Control Aspects of the Brushless Doubly-Fed Machine." Technical Report DOE/BP/24332-1, Bonneville Power Administration, 1990.

42. Vas, P.; "Vector Control of AC Machines." Monographs in Electrical and Electronic Engineering; Vol. 22; Clarendon Press, Oxford University Press, Oxford, England, 1990.

43. "Implementing Agreement for a Programme of Research and Development on Wind Energy Conversion Systems-Annex XI; $21^{\text {st }}$ Meeting of Experts, Electrical Systems for Wind Turbines with Constant and Variable Speed." Goteborg, Sweden, October 7-8, IEA, 1991.

44. Vachon, W. A., "Control of Variable Speed Wind Turbines." Proceedings $10^{\text {th }}$ ASME Wind Energy Symposium, ASME, 1991.

45. Weber, T. L., Wilson, R. E., Walker, Stel N.; “Analysis of a Teetered Variable Speed Rotor." Technical Paper TP-257-4366, SERI, June 1991.

46. Ghandakly, A. A., Sbeiti, Z. H.; "A Digital Optimal Controller for VSCF Wind Generators"; Proceedings 1991 IEEE Industry Application Society Annual Meeting, IEEE, 1991. 
47. Pierek, J.T.G., Van Engelen, T.G., Baltus, C.W.A., Veltman, A.T., Warmenhoven, A., Hoeijmakers, M. J., Vleeshouwers, J.M.; "A Variable Speed System with Integral Control for Wind Turbines (IRFLET): Design of the Test-Rig." ECN-RX-91-040, Petten Netherlands Energy Research Foundation (ECN), 1991.

48. Schluter, L.L., Vachon, W.A.; "Advanced Control Strategies for Wind Turbines." Proceedings Windpower'92, AWEA, 1992.

49. Veltman, A.T., De Haan, S.W.H., Frumea, C.F.A., Wildenbeest, E., Smith, G.A., Infield, D.G., Simmons, D.A., Didcot, Chilton; "Advanced Power Interface and Controller for Variable Speed Wind Turbines." Technical Report ECN-RX-93-040, Netherlands Energy Research Foundation (ECN), Petten, Netherlands, 1993.

50. Vachon, W.A.; "Control Algorithms for Effective Operation of Variable-Speed Wind Turbines." Technical Report SAND-90-7112; Sandia National Laboratories, 1993.

51. Yonah, Z.O., El-Serafi, A.M., Krause, A.E.;"Regulation of Terminal Voltage and Output Frequency of a Variable-Speed Dual-Excited Synchronous Generator by Using a Computer-Based Two-Phase Excitation System." Proceedings 1993 Canadian Conference on Electrical and Computer Engineering; Dept of Electrical and Computer Engineering, University of Victoria, Victoria, BC Canada, 1993.

52. Torrey, D.A., Childs, S.E.; "Development of Variable-Reluctance Wind Generators." Proceedings Windpower'93, AWEA, 1993.

53. Hagg, F., Joosse, P.A., Kuik, G.A.M. van Beurskens, J.H.M.; Dekker, J.W.M.; "The Results of the Dutch Flexhat Programme: The Technology for the Next Generation of Wind Turbines." Winpower'93 Proceedings, American Wind energy Association, 1993.

54. Smith, G.A., Stephens, R.G., Marshall, P., Kansara, M.; "Sinewave Interface for Variable-Speed Wind Turbines." Proceedings of the $5^{\text {th }}$ European Conference on Power Electronics and Applications, IEE, Michael Faraday House, Stevenage, England, 1993.

55. Pierek, J.T.G., Frumau, C.F.A., Veltman, A.T., Wildenbeest, E.J., De Haan, S.W.H.; "Advanced AC-DCAC Converter for Variable Speed Wind Turbines." Technical Report ECN-C-94-017, Netherlands Energy Research Foundation (ECN), Petten, Netherlands, 1994.

56. Ekelund, T.; "Control of Variable Speed Wind Turbines in a Broad Range of Wind Speeds." Technical Report NUTEK-VIND-94-9, Swedish National Board for Industrial and Technical Development (NUTEK), Stockholm, Sweden, 1994.

57. Weigand, C., Marckx, D. A.; "Variable Speed Wind Generation: Electrical Options and Power Systems Issues." Proceedings Windpower '94, AWEA, 1994.

58. Spera, D. A. (Editor); "Wind Turbine Technology; Fundamental Concepts of Wind Turbine Engineering", ASME Press, 1994.

59. Spee, R., Bhowmik, S., Enslin, J.H.; "Novel Control Strategies for Variable-Speed Doubly Fed Wind Power Generation Systems." Renewable Energy Vol. 6:8, 1995.

60. Munz, H., Connor, B., Leithead, W.E.; " Sensitivity of Performance of Stall Regulated Variable Speed HAWTS to Rotor Inertia." Proceedings 1995 British Wind Energy Association Conference on Wind Energy Conversion; London, United Kingdom, Mechanical Engineering Publications, Ltd., 1995.

61. Chen Z., Spooner, E.; "Modular, Permanent-Magnet Generator for Variable Speed Wind Turbines." Proceedings of the $7^{\text {th }}$ International Conference on Electrical Machines and Drives, IEEE Conference Publication no. 412, IEEE, Stevenage, England, 1995.

62. Jones, R., Gilmore, I.; "Benefits of Sinusodial Rectifiers on Variable Speed Wind Turbines-High Quality Mains Power from Variable Speed Wind Turbines." Proceedings 1995 British Wind Energy Association Conference on Wind Energy Conversion; London, United Kingdom, Mechanical Engineering Publications, Ltd., 1995.

63. Muljadi, E., Butterfield, C. P., Migliore, P.; "Variable Speed Operating of Generators with Rotor Speed Feedback in Wind Power Applications." Proceedings Wind Energy, ASME, 1996.

64. "Final Report: Direct-Drive Wind Turbine Feasibility Study." EPRI TR-106794, Project 1590-07, April, EPRI, 1996.

65. Muljadi, E., Gregory, B., Broad, D.; "Self-Excited Induction Generator for Variable-Speed Wind Turbine Generation.” Technical Report NREL/CP-440-21436, NREL, 1996.

66. Weigand, C.H., Lauw, H.K., Marckx, D.A.; "Utility-Scale Variable-Speed Wind Turbines Using a DoublyFed Generator with a Soft-Switching Power Converter." Proceedings Windpower'96, AWEA, 1996.

67. Smith, G.A.; "A Novel Converter for VSCF Wind Turbines.” Renewable Energy Vol. 9:1-4, 1996.

68. Pena, R., Clare, J.C., Asher, G.M.; "A Doubly Fed Induction Generator Using Back-to-Back PWM Converters Supplying an Isolated Load from a Variable Speed Wind Turbine.” IEEE Proceedings, Electric Power Applications Vol. 143:5, 1996. 
69. Lior, D., Idan, M.; "A Novel Variable Speed Wind Turbine Transmission and Control." Proceedings $36^{\text {th }}$ Israel Annual Conference on Aerospace Sciences; AIAA Technical Library, 1996.

70. Carlson, O., Ulen, E.; "Torque Control of Synchronous and Induction Generators for Variable Speed Operation of Wind Turbines." Proceedings EWEC'96, Bedford, Great Britain, H.S. Stephens and Associates, 1996.

71. Carlson, O., Hylander, J., Thorborg, K.; "Survey of Variable Speed Operation of Wind Turbines." Proceedings EWEC'96, Bedford, Great Britain, H.S. Stephens and Associates, 1996.

72. Zinger, Donald S., Muljadi, E., Miller, A.; "Simple Control Scheme for Variable Speed Wind Turbines." Proceedings $31^{\text {st }}$ IEEE Industry Applications Meeting, IEEE, 1996.

73. Lampola, P., Perho, J.; "Electromagnetic Analysis of a Low-Speed Permanent-Magnet Wind Generator." Proceedings of the 1996 International Conference on Opportunities and Advances in International Electric Power Generation, IEEE Conference Publication no. 419, IEE, Stevenage, England, 1996.

74. Kendall, L., Balas, M.J., Yung J. L., Fingersh, L.J.; "Application of Proportional-Integral and Disturbance Accommodating Control to Variable Speed Variable Pitch Horizontal Axis Wind Turbines." Wind Engineering Vol. 21:1, 1997.

75. Simoes, M.G., Bose, B.K., Spiegel, R.J.; "Design and Performance Evaluation of a Fuzzy-Logic-Based Variable Speed Wind Generation System"; IEEE Transactions on Industry Applications, Vol. 33:4, IEEE, 1997.

76. Atkinson, D.J., Lakin, R.A., Jones R.; "Vector-Controlled Doubly-Fed Induction Generator for a VariableSpeed Wind Turbine Application." Transactions of the Institute of Measurement and Control Vol. 19 no.1, 1997.

77. Sutherland, H.J., Carlin, P.W.; "Damage Measurements on the NWTC Direct-Drive, Variable-Speed Test Bed." Proceedings $17^{\text {th }}$ ASME wind energy symposium, ASME, 1998.

78. Fingersh, L.J., Carlin, P.W.; "Results from the NREL Variable-Speed Test bed"; Proceedings $17^{\text {th }}$ ASME Wind Energy Symposium, ASME, 1998.

79. Hand, M.M., Balas, M.J.; "Systematic Approach for PID Controller Design for Pitch-Regulated, VariableSpeed Wind Turbines." Proceedings $17^{\text {th }}$ ASME wind energy symposium, ASME, 1997.

80. Muljadi, E., Pierce, K., Migliore, P.; "Control Strategy for Variable-Speed, Stall-Regulated Wind Turbines.” Technical Report NREL/CP-500-24311, NREL, 1998.

\section{Patents}

1. "Field Control for Wind Driven Generators." Soderholm,, et al, U.S. Patent Office; 4,331,881, May 25, 1982.

2. "Methods and Apparatus for Maximizing and Stabilizing Electric Power Derived from Wind Driven Sources." Barron, et al, U.S. Patent Office; 4,400,659, August 23, 1983.

3. "Wind Turbine Maximum Power Tracking Device", Wertheim, et al, U.S. Patent Office; 4,525,633, June 25, 1985.

4. "Wind Powered System for Generating Electricity." Baskin, et al, U.S. Patent Office; 4,565,929, January 21, 1986.

5. "Wind Energy Conversion System.” Longrigg, U.S. Patent Office; 4,651,017, March 17, 1987.

6. "Variable Speed Wind Turbine." Doman, et al, U.S. Patent Office; 4,695,736, September 22, 1987.

7. "Speed Avoidance Logic for a Variable Speed Wind Turbine." Kos, et al; U.S. Patent Office; 4,700,081, October 13, 1987.

8. "Torque Control for a Variable Speed Wind Turbine." DiValentin, et al, U.S. Patent Office; 4,703,189, October 27, 1987.

9. "Doubly Fed Generator Variable Speed Generation Control System." Lauw, et al, U.S. Patent Office; 4,994,684, February 19, 1991.

10. "Variable Speed Wind Turbine." Richardson, et al, U.S. Patent Office; 5,083,039, Jan 21, 1992.

11. "Speed Control System for a Variable Speed Wind Turbine." Holley, U.S. Patent Office; 5,155,375, October 13, 1992.

12. "Variable Speed Wind Turbine with Reduced Power Fluctuation and a Static VAR Mode of Operation." Erdman, U.S. Patent Office; 5,225,712, July 6, 1993.

13. "Speed Control System for a Variable Speed Wind Turbine." Holley, U.S. Patent Office; 5,289,041, February 22, 1994.

14. "Variable Speed Wind Turbine Generator with Zero-Sequence Filter." Muljadi, U.S. Patent Office; 5,798,632, August 25, 1998. 


\section{REPORT DOCUMENTATION PAGE}

Form Approved OMB NO. 0704-0188

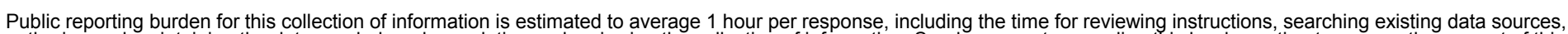

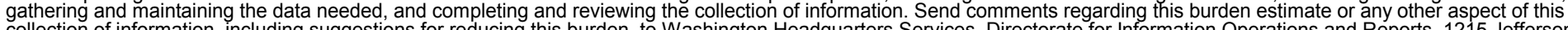

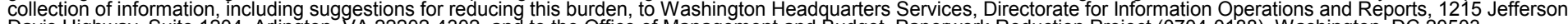
Davis Highway, Suite 1204, Arlington, VA 22202-4302, and to the Office of Management and Budget, Paperwork Reduction Project (0704-0188), Washington, DC 20503.
1. AGENCY USE ONLY (Leave blank)
2. REPORT DATE
February 2001
3. REPORT TYPE AND DATES COVERED
Technical Report

4. TITLE AND SUBTITLE

The History and State of the Art of Variable-Speed Wind Turbine Technology

5. FUNDING NUMBERS

6. $\operatorname{AUTHOR}(\mathrm{S})$

P.W. Carlin, A.S. Laxson, and E.B. Muljadi

7. PERFORMING ORGANIZATION NAME(S) AND ADDRESS(ES)

National Renewable Energy Laboratory

1617 Cole Blvd.

Golden, CO 80401-3393

9. SPONSORING/MONITORING AGENCY NAME(S) AND ADDRESS(ES)

8. PERFORMING ORGANIZATION

REPORT NUMBER

NREL/TP-500-28607

10. SPONSORING/MONITORING AGENCY REPORT NUMBER

11. SUPPLEMENTARY NOTES

12a. DISTRIBUTION/AVAILABILITY STATEMENT

National Technical Information Service

12b. DISTRIBUTION CODE

U.S. Department of Commerce

5285 Port Royal Road

Springfield, VA 22161

13. ABSTRACT (Maximum 200 words)

The National Renewable Energy Laboratory's (NREL's) National Wind Technology Center (NWTC), directed by the Department of Energy (DOE) is pursuing several research projects in variable speed. In the near future the laboratory will be reevaluating its ongoing experiments and plans. The starting point for this reevaluation will be a sound understanding of the current state of the art in design and application of variable-speed technology. This report, which outlines current technologies and historical applications of variable-speed, will provide a baseline in deciding the course of research in the upcoming years.

14. SUBJECT TERMS

15. NUMBER OF PAGES

variable-speed wind turbine, wind energy

16. PRICE CODE

17. SECURITY CLASSIFICATION OF REPORT

Unclassified
18. SECURITY CLASSIFICATION OF THIS PAGE Unclassified
19. SECURITY CLASSIFICATION OF ABSTRACT Unclassified
20. LIMITATION OF ABSTRACT

UL 